\title{
IV. NATION UND POLITISCHE DEUTUNGSMUSTER
}

Den öffentlichen Symboldiskurs hat, nicht anders als den nationalen Diskurs überhaupt, keine der großen politischen Bewegungen und Kräfte des 19. Jahrhunderts in einem der drei Länder vollständig monopolisieren können. Politische Deutungshoheiten waren gleichwohl evident. In Paris blieben sie eher auf der Seite des republikanischen Liberalismus und kaprizierten sich besonders auf die memoriale Aufbereitung der großen Exklusionsdiskurse des ausgehenden Jahrhunderts. In Berlin hatte sich der Konservativismus in den Monarchen- und Militärdenkmälern bereits so sehr wiederfinden können, daß zusätzliche Zeichensetzungen obsolet erschienen, während der politische Liberalismus mühsame Anläufe zur symbolischen Selbstbehauptung unternahm. In London schließlich gerieten die liberalen gegenüber den konservativen Denkmalunternehmungen rituell wie programmatisch seit Mitte der 1870er Jahre rasch ins Hintertreffen, so daß sich hier am ehesten eine Art symbolpolitischer Machtwechsel mit programmatischen Folgen für die Konnotierung des Nationsbegriffs vollzogen hat.

\section{Paris: Toleranzfanale und rechte Randbereiche}

Politischer Liberalismus und republikanischer Opportunismus waren in Paris längst im Rahmen der Denkmäler für die Staatselite im Bezirk um die Tuilerien an zentraler Stelle in der Kapitale öffentlich gewürdigt worden, ebenso entstammten die großen "Intellectuels engagés«, die zu Denkmalehre gekommen sind, in der überwiegenden Zahl der Fälle aus dem liberalen Lager. Verhandelt wurde, wie gesehen, vor allem im Rahmen der ersten Personenkategorie, nicht nur die liberal-republikanische Vision der partizipatorischen Nation, sondern immer auch zugleich ihre Gefährung durch rechte wie linke Überformungsversuche.

Jenseits der Statuen für die Ministerpräsidenten ist dieses Thema noch zweimal nach der Jahrhundertwende mit den Denkmälern für Ludovic Trarieux und Auguste Scheurer-Kestner bedeutsam geworden. In beiden Fällen stand die Dreyfus-Affäre als große Exklusionskrise des Jahrhunderts gleichsam zur mentalen Nachbereitung an, in deren Zuge man zunächst den jüdischen Hauptmann Dreyfus 1894/95 landesverräterischer Spionage bezichtigt, degradiert und zu lebenslanger Haft verurteilt hatte, bevor Verschwörungsindizien aus den Reihen der französischen Armee zutage gefördert werden konn- 
ten, die nach zäher Intervention der Verteidiger und Sympathisanten Dreyfus' die Revision des gesamten Prozesses unumgänglich gemacht hatten, an dessen Ende 1906 seine vorbehaltlose Rehabilitierung stand ${ }^{1}$.

Im Mai 1907 wurde zunächst das Denkmal des ehemaligen Senators für die Gironde, Justizministers und Gründers der liberal-republikanischen Ligue pour la défense des droits de l'homme et du citoyen, Ludovic Trarieux, im Jardin Denfert-Rochereau im Beisein des Staatspräsidenten Armand Fallières, daneben des Ministerpräsidenten Clemenceau und des Generals Georges Picquard gefeiert, der als Chef des Nachrichtendienstes Mitte der 1890er Jahre die Entlastungsindizien zugunsten Dreyfus' beigebracht hatte ${ }^{2}$. Die Reden identifizierten Trarieux in der Tat vor allem als engagierten Dreyfusard und spielten darauf an, da $\mathrm{B}$ er im Februar 1898 begonnen hatte, die Befürworter einer Revision des Dreyfus-Prozesses zu einen und die maßgeblich aus den Reihen von Juristen, Intellektuellen, und bürgerlichen Berufen rekrutierte und zum Linksrepublikanismus tendierende Ligue pour la défense des droits de l'homme zu gründen ${ }^{3}$. Senatspräsident Dubost zufolge verlangte die Demokratie mehr als jede andere Staatsform nach einem ausgeprägten »culte civique« zugunsten der "grands citoyens" und ihrer politischen Tugenden, denn nur so war die Nation als "société véritablement émancipée« anvisierbar ${ }^{4}$. Er bescheinigte Trarieux' politischem Engagement aus dieser Perspektive eine hohe Orientierungsfunktion für das von der Dreyfus-Krise zerrissene Frankeich, stilisierte ihn zum Seismographen für den fieberhaften inneren Aufruhr, in den die antisemitische Kampagne die französische Öffentlichkeit versetzt hatte, und zum Kompaß, der Wege zur Distanzierung der wahren, nicht-rassistischen Nation von einer extremistischen Minderheit wies ${ }^{5}$. Mit der moralischen Bewältigung der Affäre und dem Appell an die unterschiedslose Gültigkeit der »loi émanée de la souveraineté nationale« blieb die moderne Nation Dubost zufolge dauerhaft beauftragt.

Um den nach wie vor gefährdeten Status der Gesellschaft im Zuge der Dreyfus-Krise zu illustrieren, zog Dubost schließlich Krankheitsmetaphern heran: Die Affäre mochte die Widerstandskräfte der Nation gestärkt haben, sie ge-

I Vgl. u.a. GeORge, MOLLIER, La plus longue des Républiques, S. 207-224; Michel WINOCK, Le mythe fondateur: l'affaire Dreyfus, in: Serge BERSTEIN, Odile RUDELLE (Hg.), Le modèle républicain, Paris 1992, S. 131-146.

2 An der Feier nahmen neben den Präsidenten der Kammern Antonin Dubost und Brisson u.a. auch Polizeipräfekt Lépine, der Trarieux-Nachfolger und Vorsitzende der Ligue und des Denkmalkomitees Francis de Pressensé, Conseillers, Anwälte sowie der ehemalige Kolonialminister Leygues, der vehemente Dreyfusard Joseph und sein Bruder Salomon Reinach teil. Vgl. Le Temps, 13. Mai 1907, S. 2; Le Siècle, 13. Mai 1907, S. 2.

3 Vgl. ibid. Zur Ligue vgl. kurz REBÉRIOUX, La République radicale, S. 44-45.

Vgl. Le Temps, 13. Mai 1907, S. 2; Le Siècle, 13. Mai 1907, S. 2.

Vgl. ibid. 
fährdete aber weiter die "santé générale d'une nation « ${ }^{6}$. Die gesunde war dann nicht etwa die rassisch selektierende, sondern im Gegenteil die ethnisch, politisch und religiös plurale Nation. Das Denkmal für Trarieux gewann so die Qualität eines Bekenntniszeichens für die französische Gesellschaft. Übergangen wurde dabei freilich, daß die Denkmalerrichtung etwa im konservativen Lager des Conseil municipal durchaus auf heftigen Widerstand gestoßen war, der sich offen gegen Trarieux' Rolle im Dreyfus-Prozeß richtete'.

Auf solche Akzeptanzlücken machte der republikanische Siècle aufmerksam, indem er darauf hinwies, daß die Affäre vorerst irreparable Risse in der nationalen Gesellschaft erzeugt hatte ${ }^{8}$. Die These von der erst noch abschließend zu leistenden Bewältigung der Exklusionskrise hatte schwerwiegende Folgen für die Deutungskompetenz der republikanisch-toleranten Nation: Trarieux' Erbe wurde demzufolge ausschließlich vom »bloc républicain« weiter verwaltet, der das Rechtsbewußtsein der Dreyfusards zum authentischen Nationalgefühl stilisierte, während er die nicht-republikanischen Kräfte von einem legitimen Vertretungsanspruch nationaler Interessen auszugrenzen suchte. Die Affaire wurde so unversehens zum Kristallisationspunkt einer gemeinsamen politischen Identität der »fractions républicaines«, die sich in der nach wie vor andauernden "bataille« zu bewähren hatten?.

Ähnliche programmatische Vorgaben lagen dem Denkmal zugrunde, das am 11. Februar 1908 für den langjährigen Vizepräsidenten des Senats Auguste Scheurer-Kestner im Jardin du Luxembourg eingeweiht werden konnte. Neben der Dreyfus-Affäre wurde hier nun mit der elsässischen Abkunft des Geehrten auch der Gedanke der territorial versehrten und revancheberechtigten Nation akut. Dabei verlieh erneut die Anwesenheit des Staatspräsidenten Fallières, der neben den Senats- und Kammerpräsidenten Dubost und Brisson sowie Ministerpräsident Clemenceau erschienen war, der Feier besonderes Gewicht ${ }^{10}$. In den Festreden standen Verortungen der Rolle des republikanischen Liberalismus fuir die politische Konturierung der Nation an. Brisson ordnete ScheurerKestner unvermittelt der Affäre zu, sofern dieser erstmals die zuvor nur vage kolportierte Unschuldsvermutung zugunsten Dreyfus' formell und öffentlich ausgesprochen hatte, dafür lange Zeit Schmähungen hinnehmen mußte und doch weiter unermüdlich Belege für Dreyfus' Unbescholtenheit gesammelt hatte $^{\text {Il }}$. Brisson zufolge war mit dem Rechtsurteil der Cour suprême vom

Vgl. ibid.

Vgl. Observations sur l'érection du monument Trarieux, séance du 19 juillet 1906, in: CMPV, Année 1906, $2^{\mathrm{c}}$ sem., S. 481; Renvoi (...), séance du 11 avril 1906, in: CMPV,

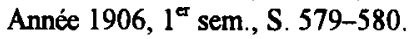

Vgl. auch ibid. 12. Mai 1907, S. 1.

${ }^{10}$ Vgl. Le Petit Journal, 12. Februar 1908, S. 3; Le Gaulois, 12. Februar 1908, S. 1

1 Vgl. [An.,] Scheurer-Kestner. La cérémonie du 11 février 1908. La statue du Luxembourg. Hommage du Journal d'Alsace-Lorraine à la mémoire de l'illustre compatriote, Strasbourg 
12. Juli 1906, das Dreyfus vollständig rehabilitierte, letztlich ScheurerKestners Beharrlichkeit zum Ziel gekommen. Daß Scheurer-Kestner als Deputierter für das Elsaß nach 1871 in der Nationalversammlung saß, machte ihn zugleich zum Inbegriff der "patrie«, die ungeachtet der Gebietsabtrennung auch dort weiter bestand und von ihm vertreten wurde ${ }^{12}$. Der hochdekorierte Militär Jean Lalance setzte unterdessen neue Akzente: er ehrte Scheurer-Kestner zuerst als "Alsacien-Lorrain « und schrieb sein Demokratiebewußtsein und seinen »patriotisme« eben dieser Abkunft zu. Die »tenacité alsacienne« hatte ihn nicht anders als den ebenfalls aus dem Elsaß stammenden Oberst Picquard zur Verteidigung des wiederum elsässischen Dreyfus motiviert. Lalance stilisierte damit der Gebietsabtretung zum Trotz in einem subtilen Revanchismus das Elsaß zum Hort eines für Rechtsgleichheit mobilisierbaren Nationalismus ${ }^{13}$.

Auch in den noch folgenden Reden bot das antisemitische Votum der Dreyfus-Gegner, das mit der Krise je neu wieder angesprochen wurde, nicht Anlaß zur Problematisierung eines erklärungsbedürftig massenwirksamen populistischen Rechtsnationalismus. Vielmehr erschien dieser als temporäres Minderheitenphänomen, als Resultat von Spionagekampagnen gegen den jüdischen Hauptmann, die die französische Öffentlichkeit aus Sorge um die »défense nationale ${ }^{14}$ gegen Dreyfus aufgebracht hätten. Während eine kritische Analyse der Konjunkturbedingungen eines religiös-ethnisch exklusiven Nationsbewußtseins im Frankreich um die Jahrhundertwende fehlte, dominierte der Triumph über die Rehabilitierung Dreyfus' und mit ihm des "principe même de la justice (...), vérité [et] liberté « ${ }^{15}$ als Quintessenz der Werte, denen die krisengestärkte republikanische Nation nun einmal mehr verpflichtet war.

In seiner Eigenschaft als amtierender Ministerpräsident, nicht zuletzt aber aufgrund seiner zentralen Rolle in der Affäre, in deren Verlauf er aus dem Lager der Kritiker in das der Dreyfusards übergewechselt war und Zolas großer Anklage gegen eine befangene Justiz im von ihm herausgegebenen Aurore ein öffentliches Forum bot, sprach schließlich auch der Radical Georges Clemenceau. Er setzte zu demokratiekritischen Überlegungen Tocquevillescher Prägung an: Die Demokratie müsse immer mehr sein als »le gouvernement du nombre«, denn daß die »opinion publique« zu drastischen Fehlurteilen gelangen, zum »brutal déchaînement du nombre« führen könne, habe die Affäre

1908, S. 7-8. Vgl. auch André RoUMIEUX, Auguste Scheurer-Kestner (1833-1898), in: DROUIN (Hg.), L'affaire, S. 277-281.

12 Vgl. [An.,] Scheurer-Kestner, S. 9.

13 Vgl. ibid. S. $12 f$.

14 Vgl. ibid. S. 15; Louis LEBLOIS, Discours prononcé à l'inauguration du monument de Scheurer-Kestner (11 février 1908), Paris 1908, S. 4.

15 [An.,] Scheurer-Kestner, S. $21 f$. 
erwiesen $^{16}$. Anders als seine Vorredner wertete Clemenceau die DreyfusAffäre damit als problematisches Mehrheitsphänomen, als Krise der Humanität, aus der letztlich nur der »acte d'un héros" herausgeführt habe. Umgekehrt traute er mit ihnen gerade der französischen Nation als Hort der »vertu civilisatrice« die Fähigkeit zur moralischen Regeneration $\mathrm{zu}^{17}$. Daß diese Potentiale der Nation vor allem aus dem Elsaß erwuchsen, illustrierte dann auch Clemenceau, indem er Scheurer-Kestner in eine Kontinuitätslinie mit den ebenfalls von dort stammenden Revolutionsgeneralen wie Kléber und Ney stellte. Damit avancierte aber nicht nur neuerlich das an Deutschland verlorene Grenzgebiet zum Herzstück der Nation, Scheurer-Kestner erschien darüber hinaus auch als Bestandteil einer »légitime filiation de ces héros français d'Alsace et de Lorraine ${ }^{18}$, als Nachfahre der Exponenten einer revolutionären "gloire militaire«, die im zivilen und demokratischen Republikanismus mühelos aufzugehen schien. Über dem Filiationsgedanken und der spezifischen Heldenanalogie implizierte Clemenceau eine Nationsidee, aus der nun nicht etwa die in die antisemitischen Umtriebe an erster Stelle involierte Armee ausgegrenzt wurde. Vielmehr blieb das Militär in die nationale Tradition über die Assoziation der Französischen Revolution wieder versöhnlich integriert und mit dem Gedanken der Rechtsgleichheit und Demokratie positiv verbunden ${ }^{19}$.

Nur der Gaulois berichtete von Zwischenfällen am Rande der Zeremonie, die weder in der Festschrift noch von der republikanischen Presse erwähnt wurden. Demnach hatten die verstärkten Anstrengungen der Denkmalstifter, die Veranstaltung als »huis-clos« zu organisieren, es nicht vermocht, eine Studentengruppe der rechtsnationalen Action française aus dem Quartier Latin von einer Demonstration abzuhalten und Clemenceau beim Verlassen des Festplatzes mit Hochrufen auf den antidreyfusardischen General und Kriegsminister Mercier zu brüskieren ${ }^{20}$. Zwar blieb die Episode marginal, daß aber die Nation anders als es das selbstbewußte Räsonieren der Redner nahelegte, die politische und moralische Bewältigung der Affäre nicht etwa bereits hinter sich, sondern immer noch zu leisten hatte, veranschaulichte die Szene dennoch deutlich. Daß es Vertretern eines dezidiert royalistischen, antiparlamentarischen und tendenziell antisemitischen Rechtsnationalismus ${ }^{21}$ gelang, ihren Unmut über die Ehrung des Demokraten zu äußern, offenbarte eher die Kontinuität der dissoziierten »deux France« als der über ihre politische Ausrichtung

16 Vgl. ibid. S. 26.

${ }^{17}$ Vgl. ibid. S. 31.

18 Ibid. S. 33.

19 Die Inaugurationsschrift, die anläßlich der Feier 1908 erschien, enthielt in einem umfangreichen Anhang Auszüge aus der Korrespondenz Scheurer-Kestners und den Urteilstext des Kassationsgerichtshofes vom 12. Juli 1906, mit dem Dreyfus rechtskräftig rehabilitiert worden war. Vgl. ibid.

20 Vgl. Le Gaulois, 12. Februar 1908, S. 2.

21 Vgl. zur Action française u.a. BECKER, AUDON-ROUZEAU, La France, S. 207-213. 
und ihren Traditionsvorrat einigen Gesellschaft. In seiner unverhohlenen Anerkennung für die souveräne Reaktion Clemenceaus auf die Provokation ließ der Gaulois erkennen, daß er mit den Demonstranten nicht konform ging, veranschaulichte aber zugleich warnend, daß umgekehrt die Harmoniefiktionen der exklusiven Festgesellschaft anläßlich der Denkmaleinweihung der politischen Realität zutiefst widersprachen ${ }^{22}$.

Die übrige Presse ${ }^{23}$ bemühte sich ähnlich wie die Denkmalstifter, die erfolgreiche Prozeßrevision zum Nachweis einer Art neuerlichen Revindikation des angeblich nur vorübergehend von rechts besetzten und inzwischen wieder geläuterten, feindbildfreien, liberalen Nationalismus zu stilisieren. Seine rassistische Variante, die ihn qualitativ kaum mehr von entsprechenden rechten Formen des deutschen Nationalismus unterschied ${ }^{24}$, wurde demonstrativ zur überwundenen Episode erklärt. Die Elsaß-Thematik sollte zugleich wieder zum festen Bestandteil des nationalen Diskurses aufgewertet werden. Der Balanceakt, sich von der rechtsautoritären Nationsidee, wie sie die Dreyfus-Krise nach oben geschwemmt hatte, zu distanzieren, andererseits aber außenpolitisch revanchistische Postulate - zu denen sich freilich die republikanische Linke seit 1871 bekannte ${ }^{25}$ - jetzt explizit zu verhandeln, blieb am Ende prekär. Dies vor allem, weil nun nicht mehr eigens erwähnt wurde, daß sich der radikalrepublikanische Liberalismus in der Tradition Gambettas bei allen Revisionswünschen im Blick auf die Annexion durch ein klares Bekenntnis zum Pazifismus und durch den Willen zum Arrangement mit dem Deutschen Reich ausgezeichnet hatte.

Formell bestätigten damit zwar das Trarieux- wie das Scheurer-KestnerDenkmal eine ungebrochene Symbolmacht des politischen Liberalismus. Die zeremonielle Interruption, vor allem aber die angestrengte Rhetorik, mit der sich die Denkmalstifter um die Revindikation eines Nationsbegriffs bemühten, der spätestens mit der Dreyfus-Krise massiven Überformungen von rechts unterzogen worden war, entlarvte die vermeintliche Symboldominanz als rhetorisch-semantisches Rückzugsgefecht. Damit wurde erneut erkennbar, was sich bereits im Rahmen der letzten République-Feier 1899 mit den republikanischen Verwahrungen gegen den rechten "césarisme« und nach der Jahrhundertwende vor allem im Zuge der Waldeck-Rousseau- und Ferry-Feiern angekündigt hatte: Mit den Inklusionstopoi sollte die rechte Vereinnahmung des Nationsbegriffs abgewehrt und die republikanische Deutungshoheit gewahrt werden, während sich in der nun offen benutzten Revancherhetorik darüber hinaus programmatische Schnittstellen zwischen linkem und rechtem Nationalismus ankündigten.

22 Vgl. Le Gaulois, 12. Februar 1908, S. 2.

${ }^{23}$ Vgl. u.a. Le Petit Journal, 12. Februar 1908, S. 3; Le Temps, 12. Februar 1908, S. 1.

24 Vgl. STERNHELL, The political culture, S. 30, 36.

25 Vgl. BECKER, AUDON-ROUZEAU, La France, S. 155. 
Zwar sind nicht anders als in Berlin auch in Paris keine öffentlichen Denkmäler für Exponenten eines politischen Konservativismus oder der Reaktion zustandegekommen. Grundsätzlich anders als in Berlin zeichnete dafür aber nicht die Okkupation eines konservativen Nationsbilds durch andere Denkmalkategorien verantwortlich, sondern eher eine spezifische Flexibilität republikanischer Symbolstifter, auch die konservativen Randbereiche in das Credo zugunsten der republikanischen Nation zu integrieren.

Davon zeugte vor allem die Einweihung eines Denkmals für den Poeten Jean Béranger 1885 auf dem Square du Temple mitten im 3. Arrondissement, in dem er lange gelebt hatte ${ }^{26}$. Initiative und Fest blieben durchaus republikanisch geprägt; die programmatische Absorption des Napoleon-Kults, für den Béranger stand, bereitete den Interpreten aber durchaus Mühe. Die Attraktivität des konservativen Deutungsmusters von der militärisch ruhmreichen Nation bewog aber zum Versuch, sich die Kultfigur anzueignen ${ }^{27}$. Der Gehalt der knappen Reden griff auf, was bereits die Zeitung La Chanson als Verfechterin der Denkmalidee seit 1879 betont hatte, wenn sie das Monument zum Zeichen des "triomphe définitif de la République« für opportun erachtete ${ }^{28}$. In der Tat wurde der Versuch unternommen, den populären Dichter für die republikanisch-liberale Nation zu vereinnahmen, obschon Bérangers führende Rolle bei der Propagierung der Napoleon-Legende während der Julimonarchie insbesondere in liberalen Kreisen massiver Kritik ausgesetzt gewesen war $^{29}$.

Die republikanische Presse unterstützte das Vorhaben. So war etwa der Petit Journal bemüht, Béranger vom Vorwurf des Napoleon-Kultes zu rehabilitieren, indem es behauptete, dieser habe sich hier nur zum sinterprète de l'opinion publique« gemacht, von der Napoleon in der Tat unter dem Eindruck der bourbonischen Restauration zum nationalen Heroen aufgewertet worden $\mathrm{sei}^{30}$. Nicht alle konservativen Kommentatoren hingegen machten Anstalten, Béranger als Repräsentant eines napoleonischen Nationalgedächtnisses überhaupt in Anspruch zu nehmen ${ }^{31}$. In Le Monde identifizierte Oscard Havard Béranger zwar nach wie vor als authentischen Napoleon-Verehrer und spottete über die von den Denkmalstiftern konstruierte Konversion zum Liberalismus ${ }^{32}$. Das

26

28

29 nument à la mémoire de Béranger. Zu Béranger vgl. KORNER, Das Lied von einer anderen

31

32

La Croix, 17. Juli 1885 , 2

Vgl. Le Monde, 17. Juli 1885, S. 1. 
republikanische Interesse an der Figur leitete Havard nun aber besonders von Bérangers dezidiertem Antiklerikalismus her, der ihn umgekehrt für die Konservativen gänzlich unattraktiv erscheinen lie $B^{33}$.

Trotzdem veranschaulichte die Aufnahme des Napoleon-Apologeten in das Arsenal nationaler Kultfiguren am Ende das flexible Vermögen republikanisch-liberaler Sinnstifter, auch Traditionen nicht-republikanischer Provenienz in das propagierte Nationsbild aufzunehmen. Dieselbe Flexibilität trat darüber hinaus erstens auch zutage, wenn - wie gesehen - seit Mitte der 1880er Jahre in Paris öffentliche Denkmalstiftungen stattfinden konnten, die sich vordergründig als Literaten- und Künstlerehrungen ausnahmen, faktisch aber weniger an einer geistig-kulturellen als an einer dezidiert militärischen, auf Napoleon und das Erste Empire abhebenden Traditionsbildung arbeiteten. So zielte die Denkmalserie für die Künstler de Neuville, Raffet und Meissonier auf ein von der Republik weitgehend entkoppeltes militärisch-konservatives, um den autoritären Empereur zentriertes Nationsbild, und doch wurde ihr Versuch, eine nationale gloire militaire zunächst noch mit, dann aber zunehmend ohne Rekurs auf die Niederlagenerfahrung von $1871 \mathrm{zu}$ illustrieren, als eine Art memoriale Kompensation des Niederlagengedenkens toleriert ${ }^{34}$. Memoriale Flexibilität trat schließlich zweitens zutage, wo sich im Zuge der erhitzten Debatte um die Zuordnung von Nation und Religion konservative Nationsideen Bahn brachen, indem sich mit dem Plädoyer für die Inklusion des Katholizismus nicht immer, aber eben durchaus auch monarchische oder sonst reaktionäre Aspirationen verbanden. Dies galt insbesondere für die katholischen Interpreten der Jeanne d'Arc-Denkmäler, von denen noch zu reden ist.

Gelegentlich eignete sich - auch dies Indiz für die memoriale Flexibilität der Liberalismus das national konnotierte Personal nicht an, sondern tolerierte abweichende Deutungen. Unter diesen Umständen traten schließlich im Juni 1909 Sinnstifter um das Denkmal für François Coppée auf der Place AndréTardieu im westlichen 7. Arrondissement an. Hier gelang nun die Monumentalisierung eines Schriftstellers, in dessen Tradition sich weniger der laizistische Liberalismus als ein bonapartistischer Katholizismus zu stellen wünschte.

Die Huldigungen der Redner bezogen sich auf Coppées literarisches Werk wie sein politisches Engagement zugunsten eines zwar nicht antisemitischen, aber dezidiert antiparlamentarisch-rechtskonservativen Nationalismus. Bot schon das Profil der Denkmalinitiatoren, denen Journalisten und Herausgeber konservativer und katholischer Presseorgane wie des Figaro, der Croix, aber auch des Petit Journal angehörten ${ }^{35}$, bereits ein einschläges Bild, war ein

33 Vgl. ibid.: "Les Loges ont voulu honorer dans Béranger (...) l'adversaire sournois du christianisme. « Vgl. ähnlich das Votum im L'Univers, 19. Juli 1885, S. 1.

34 Vgl. bereits Teil 2, Kapitel III.1.2.

35 Vgl. [An.,] Inauguration du monument François Coppée à Paris, le 5 juin 1910 sur la place de Saint-François Xavier, Paris 1910 [up] 
letztes deutliches Indiz für die politische Orientierung der Veranstaltung in dem Umstand zu sehen, daß der Chef der 1898 revitalisierten rechten Ligue des Patriotes Déroulède zu den Festrednern zählte, dem die von Coppée 1899 mitbegründete und phasenweise präsidierte, vor allem aus akademischintellektuellen Kreisen rekrutierte und vehement anti-dreyfusianische Ligue de la Patrie française nahestand ${ }^{36}$. In der Tat war es vor allen anderen Déroulède, der die Anfänge von Coppées politischem Engagement mit dem Erstarken des Linksradikalismus Ende der 1890er Jahre in Verbindung brachte, dessen fatale Folgen für die Nation sich daran bemerkbar machten, daß er die Konturen Frankreichs im Rahmen eines diffusen winternationalisme $z \mathfrak{z u}$ nivellieren drohte $^{37}$. Auf diesem Negativhintergrund erschien Coppée als nationaler Held, der als "bon Français« und »bon catholique« antrat, die Obstruktion der "vieille religion« und die Preisgabe des »ancien territoire " Elsaß-Lothringen zu verhindern. "Patrie« und »défense religieuse« kristallisierten sich zu den Sinnträgern der Nationsidee, um die Déroulèdes Ausführungen kreisten.

Mit der Denkmaleinweihung der Coppée-Figur fand damit eine explizite und selbstbewußte, wenngleich in eher bescheidenem Rahmen inszenierte Zuerkennung katholischer und revanchistischer Wertorientierungen zum Nationsbegriff statt. Damit meldete sich hier nun erstmals im öffentlichen Denkmalterrain der Kapitale auch die rechte Opposition nicht länger nur mit öffentlichen Störmanövern im Rahmen anderweitiger Denkmalfeiern, sondern mit einem eigenen Anspruch auf Teilhabe an der Stiftung von Deutungsmustern für die Nation in der Hauptstadt zurück.

So wenig die weithin im Dunkeln gebliebenen Konturen der einzelnen Stiftergruppen Anlaß gaben, eine konzertierte Symbolaktion hinter dieser heterogenen Gruppe von Denkmälern zu vermuten, so deutlich reflektierten sie doch eine Trendwende im öffentlichen Sinnstiftungsdiskurs, indem sich der Wunsch Symbolmacht verschaffte, auf das Erbe vor allem des Ersten Empire zur Konstruktion einer autoritären Tradition der Nation oder auf den religiösen Horizont des Katholizismus im öffentlichen Nationsbild nicht zu verzichten. Insofern schlugen sich hier zugleich die Folgen einer Rechtswendung des nationalen Diskurses nieder, denn anders als bei der Programmatik, die zu den zahllosen republikanisch und liberal intendierten Monumenten verlautbart wurde, fehlte hier nun jeder Rekurs auf konstitutionelle Rahmenbedingungen und das freiheitlich-revolutionäre Erbe, während ausschließlich Napoleon als Inbegriff einer imposanten Eigentradition oder eine von 1871 unbelastete gloire militai$r e$ im Zentrum nationaler Sinnbildung stand. Ein dezidiert antidemokratischer

37 Vgl. ibid. S. 43-47. 
oder antirepublikanischer Ton, wie er den entwickelten Rechtsnationalismus charakterisieren sollte, kam dabei allerdings nicht zum Vorschein ${ }^{38}$.

Während die erwähnten Denkmalprojekte klar dokumentieren, daß in und nach der Dreyfus-Affäre lediglich die Dreyfusards, nicht aber die Rechtsstaatsgegner und Antisemiten öffentliche Symbolmacht erhielten, zeichnete sich im sogenannten »Monument Henry « Ende der 1890er Jahre der verbal und polemisch gebliebene Versuch des radikalen Rechtsnationalismus ab, eben doch Deutungskompetenz an sich zu ziehen. Das »Monument«, das den antisemitischen Diskurs der französischen Gesellschaft seit Mitte der 1890er Jahre reflektierte, blieb imaginär, nahm nie materielle Gestalt an und erschien trotz seiner rein publizistischen Erscheinungsform symptomatisch zumindest für einen Ausschnitt öffentlich propagierter Nationsentwürfe am rechtsextremen Rand des politischen Spektrums.

Im Dezember 1898 veröffentlichte die rechtsorientierte Libre Parole einen Aufruf, der Witwe des Oberst Henry mit einer Subskription zu Hilfe zu kommen $^{39}$. Die Aktion erwies sich als propagandistischer Paukenschlag inmitten eines bereits seit Jahren aufbrandenden Antisemitismus: Henry, selbst Mitglied des französischen Nachrichtendienstes, hatte Ende August 1898 Selbstmord begangen, nachdem sich die Nachweise dafür zu verdichten begannen, daß er das Dokument, aufgrund dessen man Dreyfus 1894/95 des Landesverrats überführt zu haben glaubte, unter Anstiftung Major Esterhazys gefälscht hatte ${ }^{40}$. Anfang Dezember 1898 nun beschuldigte mit Joseph Reinach einer der profiliertesten Dreyfusards Oberst Henry der antisemitischen Verschwönung im Namen des Generalstabs. Die Libre Parole bot sich daraufhin Henrys Witwe als öffentliche Plattform zur Dementierung der Vorwürfe an. Das Organ veröffentlichte eine larmoyante Stellungnahme der "Veuve Henry « gegen Reinach ${ }^{41}$ und nahm mit einem programmatischen Artikel zugunsten des Obersten Stellung ${ }^{42}$.

Während der gesamten zweiten Dezemberhälfte des Jahres veröffentlichte die Libre Parole regelmäBig Subskriptionslisten, die der antisemitischen Offentlichkeit Gelegenheit zur offensiven Parteinahme boten und nicht selten von den Subskribenten mit entsprechenden Motti versehen wurden. Ein Jahr später publizierte Pierre Quillard die gesamten Subskriptionslisten der Libre Parole in einer Monographie unter dem Titel »Monument Henry«. Quillard gab sich als vehementer Revisionist und Dreyfusard zu erkennen und beabsichtigte mit

38 Vgl. DROZ, Der Nationalismus, S. $6 f$.

39 Vgl. La Libre Parole, 11. Dezember 1898, S. 1.

40 Vgl. Eric CAHM, The Dreyfus Affair in french society and politics, London 1996, S. 1-4, 117-122.

41 Vgl. La Libre Parole, ibid. Auch die katholisch-assomptionistische Zeitung La Croix veröffentlichte den Brief der Witwe am 13. Dezember 1898, S. 1.

42 Vgl. La Libre Parole, 13. Dezember 1898, S. 1 [Marie Anne DE BoVET] 
seiner Publikation ein öffentliches Fanal gegen die antijüdische Agitationspresse, der die Libre Parole nur als eines unter zahlreichen Organen angehör$\mathrm{te}^{43}$.

Nicht die Subskribenten oder die rechte Presse, sondern erst Quillard hatte den »monument«-Begriff in diesem Zusammenhang geprägt, um die Propagandaaktion als ideelle und gleichwohl politisch äußerst handgreifliche Manifestation zu entlarven, als eine Art Schandmal des Antisemitismus ${ }^{44}$. Die Subskribenten rekrutierten sich zu einem überproportional großen Teil aus Militärs, Berufen mit höherer akademischer Bildung, aber auch Arbeitern und Handwerkern, während kaum kleine Angestellte und Angehörige landwirtschaftlicher Berufe vertreten waren ${ }^{45}$. Symptomhafter als das Subskribentenprofil nahm sich indessen auch in Quillards Augen die Sprache des Antisemitismus aus, auf die hin die Listen mit den zahlreichen Injurien, die wie Abbreviaturen oder Codes den Namen folgten, auch gelesen werden konnten. Quillard selbst trug einige der wüstesten Verwünschungen aus den Listen im Vorwort zusammen, die von Deportationsforderungen bis zur Gewaltphantasien kollektiver körperlicher Folterstrafen reichten ${ }^{46}$, und ging davon aus, daß aus solchen Voten auch der Wille zur Tat sprach.

Selbst wenn einer aggressiven und polarisierenden Diskurspraxis Rechnung zu tragen war, die auch außerhalb eines dezidierten Antisemitismus auftrat, blieben die bereits in den knappen Motti entfalteten Vernichtungsszenarien gegenüber einem gleichsam animalisierten ethnischen Feind, dem unter anderem auch das Komplott gegen die nichtjüdische Nation und die von Henry verkörperte "patrie« zur Last gelegt wurde, frappant ${ }^{47}$. Quillards Dokumentation geriet an dieser Stelle in der Tat zum virtuellen Monument, bei dem nun nicht die Ikonographie einer öffentlichen Bronzefigur, sondern die namentliche und parolenhafte Eintragung auf einer Liste zur zutiefst negativen Projektionsfolie für eine wirre, verbal gewalttätige, exklusiv-antiliberale und antijüdische Nationsidee geriet. Der immensen innenpolitischen Sprengkraft der Dreyfus-Krise geschuldet, blieb das nie errichtete »Monument« das Fanal für einen deformierten und enthumanisierten Nationsbegriff; seine Signalwirkung

Vgl. Pierre QUILLARD, Le monument Henry. Liste des souscripteurs classés méthodiquement et selon l'ordre alphabétique, Paris 1899, S. IV-LX.

44 Vgl. ibid. S. VI: „C'est tout un parti, hétérogène seulement d'apparence, qui s'est dénombré lui-même dans ces feuilles; c'est le parti de l'autorité religieuse et militaire qui réclame, avec des clameurs discordantes, l'écrasement de toute pensée libre."

$45 \mathrm{Vgl}$. Georges BENSOUSSAN, L'Idéologie du rejet. Enquête sur "Le Monument Henry« ou archéologie du fantasme antisémite dans la France de la fin du XIX ${ }^{e}$ siècle, Paris 1993, S. 65; GEORGE, MOLLIER, La plus longue des Républiques, S. 215-216.

46 Vgl. QUILLARD, Le monument Henry, S. LX-XI. Unter den Parolen, die die Subskribenten hinter ihre Namen setzten, waren u.a. die Floskeln: »les bouter hors de France«, »les jeter à l'égout«, »les revêtir d'une robe jaune«, »leur crever les yeux «, »leur tanner la peau« etc.

$47 \mathrm{Vgl}$. BENSOUSSAN, L'idéologie du rejet, passim. 
aber schien ungeachtet der luziden zeitgenössischen Analyse Quillards auch im linksrepublikanischen Lager nicht kritisch aufgegriffen worden zu sein.

2. Berlin: Denkmäler der Opposition oder symbolische Grabenkämpfe

Die bisweilen martialische Dominanz Berliner Monarchen- und Triumphdenkmäler drohte zu verdecken, daß im Laufe der Jahre eine erhebliche Zahl von Liberalen unterschiedlicher Observanz durchaus auf offentlichem Terrain zu Denkmalehren gelangte. So wurden Anläufe unternommen, das monarchischmachtstaatliche Deutungsmonopol mit eigenen Zeichensetzungen zu ergänzen und gelegentlich $\mathrm{zu}$ konterkarieren. Mangelndes Inszenierungsvermögen und unzureichende publizistische Reflexion haben manche der Initiativen zwar unscheinbar aussehen lassen; in ihrer Summe allerdings machten sie kenntlich, daß der politische Liberalismus in der Kapitale durchaus auch symbolisch präsent war.

Mit der Nationalstaatsgründung war die Verbindung zur nationalen Bewegung der Vorkriegsjahre nicht einfach abgeschnitten, ihre Leitwerte blieben virulent, unterlagen aber unter dem Eindruck der militärisch und machtstaatlich imponierenden Reichsgründung spezifischen Modifikationen. Von ihnen zeugten zunächst Genese, Feier und Kommentierung des Berliner Jahn-Denkmals 1872 . Obschon zeitlich weit voneinander entfernt, animierten später die Denkmäler für den Freiherrn vom Stein 1875 und Hardenberg 1907, im ersten Falle die öffentlichen Kommentatoren, im zweiten die Denkmalstifter selbst dazu, den Traditionswert der preußischen Reformen für die Binnenausstattung der Nation zu bestimmen und Partizipationsverheißungen zu erinnern, die sich mit beiden Staatsmännern verbunden hatten. Seit den 1890er Jahren schließlich entstanden mit den Denkmälern für Waldeck, Schulze-Delitzsch und Virchow neue Versuche, liberale Symbolmacht in der Kapitale zu erringen und im öffentlichen Diskurs liberale Traditionsanteile an der Reichsnation geltend zu machen.

\subsection{Relikte und Transformationen einer partizipatorischen Nationsidee}

Die Einweihung des Denkmals für Friedrich Ludwig Jahn auf der Hasenheide im südöstlichen Berlin am 10. August 1872 trug über die Zäsur von 1871 hinweg alle Anzeichen eines weder monarchisch noch militärisch überformten Nationalfestes. Nur der notorisch antiliberale preußische Innenminister Friedrich Graf zu Eulenburg nahm als offizielles Regierungsmitglied an der Feier 
teil, die sonst ganz die Tradition der bürgerlichen Tumerfeste wiederaufleben ließ: dies zum einen mit einer Teilnehmerschar, die nicht nur aus Preußen, sondern aus allen deutschen Staaten sowie Österreich, Ungarn und Nordamerika stammte, und zum anderen mit einem immensen, in mehrere Sektionen aufgeteilten Festzug, an dem sich auch Deputationen volkstümlicher Vereine wie des Handwerker- und des Berliner Arbeitervereins beteiligten ${ }^{48}$.

Schon die topographische Logik des Festzugs, der über die Friedrichstraße im Nordwesten zum Belle-Alliance-Platz und über das Hallesche Tor zur südwestlich gelegenen Hasenheide führte, lag quer zum im Osten konzentrierten monarchischen und militärischen Symbolarrangement in der Kapitale. Er orientierte sich nämlich im rechten Winkel zur monarchischen Repräsentationsachse der Linden und in beträchtlicher westlicher Entfernung vom Repräsentationszentrum um das StadtschloB, indem er sich entlang einer NordSüdachse bewegte.

Schlug sich in der Festregie eine selbstgewählte Distanz der Zelebranten zum monarchischen Machtstaat nieder, drückte sich in der Abwesenheit der höchsten staatlichen Würdenträger einschließlich des ursprünglich geladenen Kaisers und des Kronprinzen das demonstrative Desinteresse der Monarchie am zumindest zeremoniell partizipatorischen »Volks«-Fest und die Distanzierung von dem aus, was die Reden in Bezug auf die Nation thematisieren wür$\operatorname{den}^{49}$. Ohnedies hatte die Monarchie ein Jahr zuvor im elitären Kreis die militärischen und autoritären Leitwerte der von ihr imaginierten Nation bereits im Umfeld der Siegessäule gefeiert ${ }^{50}$. Trotzdem übermittelte man, als sich im Anschluß an die Einweihung die Turnerschaft mit etwa 1.300 Personen nachmit-

Unter den Ehrengästen befanden sich vor allem Vertreter der Stadt und Turnlehrer. Während der Festzug mit etwa 120 Fahnen und Bannern einschließlich des Banners Berlins, durch die Straßen zog, hatten die Zuschauer die Chance zur symbolischen Beteiligung, indem sie den Teilnehmern Kränze und Blumen zuwarfen. Vgl. NZ, 11. August 1872 (M.), S. 2-4. Von 4.000 Teilnehmern am Zug sprach die VZ, 11. August 1872, 4. B., S. 1; NAZ, 11. August 1872, S. 3, von 3.000; NZ, ibid. S. 4 und Germania, 11. August 1872, S. 3. Vgl. zum Jahn-Denkmal Dieter LANGEWIESCHE, "... für Volk und Vaterland kräftig zu würken ...«. Zur politischen und gesellschaftlichen Rolle der Turner zwischen 1811 und 1871, in: Ommo GRUPE (Hg.), Kulturgut oder Körperkult? Sport und Sportwissenschaft im Wandel, Tübingen 1990 (Studium Generale), S. 22-61, hier S. 58 (wieder in: DERS., Nation, Nationalismus, Nationalstaat in Deutschland und Europa, München 2000, S. 103131).

49 Vgl. NAZ, 13. August 1872, S. 1. Unter den Ehrengästen waren Bismarck, Unterrichtsminister Falk, Kriegsminister von Roon, Finanzminister Camphausen, u. a.; vgl. Carl EULER, Das Jahndenkmal in der Hasenhaide bei Berlin. Eine ausführliche Darstellung seiner Geschichte und Beschreibung der bei seiner Enthüllung am 10. und 11. August 1872 veranstalteten Festlichkeiten. Beilage zur deutschen Turnzeitung 1873-1874, Leipzig 1874, S. 34 .

so Vgl. zum "Symbolkampf« erstmals Dieter LANGEWESCHE, Kulturelle Nationsbildung im Deutschland des 19. Jahrhunderts, in: DERS., Nation, Nationalismus, Nationalstaat in Deutschland und Europa, München 2000, S. 82-102, hier S. 96-99. 
tags zum Festbankett im Konzerthaus einfand, dem Kaiser ein Grußtelegramm und überging damit beschwichtigend dessen demonstrative Abwesenheit ${ }^{51}$.

Im Rahmen der Festivitäten der Folgetage blieb das eher bunte Bild von Teilnehmern erhalten und präsentierte sich die feiernde Nation hier gleichsam transnational und sozial inklusiv. Zugleich knüpfte man so unmittelbar an die in ähnlicher Weise vollzogene Grundsteinlegungsfeier vom August 1861 wie überhaupt an die Tradition der frühen Turnbewegung ${ }^{52}$ an. Zwar hatten auch 1861 bereits die preußischen Fahnen im Festumzug zur Hasenheide dominiert $^{53}$; sofern aber anders als später die Vertreter der Denkmalbewegung aus dem Ausland fehlten, nahm sich die Feier von 1872 im Vergleich noch inklusiver aus. Mit Ausnahme des Polizeipräsidenten von Winter waren hingegen 1861 staatliche Vertreter zum Zeremoniell nicht geladen ${ }^{54}$, während die Initiatoren der Einweihungsfeier 1872 auf deren Präsenz immerhin Wert legten und sich auch damit bereits am existenten Machtstaat orientierten. Die Brüskierung der Denkmalstifter 1872 durch den Boykott des gesamten Herrscherhauses ließ indessen darauf schließen, daß die in dieser Form ${ }^{55}$ gefeierte Nation von den Repräsentanten des neu gegründeten Machtstaates mißbilligt wurde.

In seiner zentralen Festrede bekannte sich der Vorsitzende des Denkmalausschusses Kerst einerseits zu emanzipatorischen Idealen der frühen Turnerbewegung, legte sich andererseits aber durchaus auf den Machtstaat von 1871 fest $^{56}$. Jahn hatte Kerst zufolge im frühen 19. Jahrhundert für inakzeptabel erachtet, daß »die ungeheure Mehrheit des Volkes (...) geknechtet« werde, »aller Erinnerungen an die einst vielgepriesene Freiheit verlustig ${ }^{57}$. Partizipationsverweigerung und der Verlust von zukunftorientierter Visionsfähigkeit, zu der »Freiheits«-Werte hätten zählen müssen - so bündelte Kerst die historische Kritik Jahns am Zustand der Gesellschaft zu Jahrhundertbeginn. "Politische[s] Verständnis«, »Freiheit« und "Selbstverwaltung« bildeten demgegenüber die positiven Orientierungsgrößen der Jahnschen Nationsidee ${ }^{58}$. Trotzdem wurde Jahn nicht für eine barrierelos egalitäre Nationsidee in die Pflicht genommen, sondern maximal für eine »angemessene Volksfreiheit«, die nach den vorheri-

51 Vgl. NAZ, 13. August 1872, S. 1.

52 Vgl. LANGEWIESCHE, Zur politischen und gesellschaftlichen Rolle der Tumer, S. 36-38.

53 Vgl. EULER, Das Jahndenkmal, S. 8.

54 Vgl. ibid.

55 Den exklusiven Charakter von Denkmalfesten behielt man trotz inklusiver Programmatik durchaus bei, indem die Zuschauer auch hier hinter eine Umzäunung des Festplatzes zurückgedrängt blieben, zu dem nur Besitzer von Tickets Zugang erhielten. Vgl. EULER, Das Jahndenkmal, S. 38-39.

56 Vgl. zum Folgenden VZ, 11. August 1872, 4. B., S. 1-2, hier S. 1; NZ, 11. August 1872 (M.), S. 3-4; NAZ, 11. August 1872, S. 3.

57 Ibid.

58 Vgl. ibid. 
gen Konnotationen des Begriffs vor allem für das «Bürgerthum« gelten soll$\mathrm{te}^{59}$. Gegen Ende seiner Ausführungen legte Kerst sich ohnedies auf das preuBisch dominierte Machtstaatsmodell als Ordnungsrahmen für die Jahnsche Nationsidee fest. Demgegenüber blieben die anfangs identifizierten emanzipatorischen Orientierungsmarken nachrangig. Schließlich folgte eine klare Exklusionsdrohung gegenüber den wsich im Innern regende[n] (...) antinationale[n], (...) Elemente[n] ${ }^{60}$. Wer genau dieses Verdikt auf sich zog, blieb offen. Es deutete sich aber an, daß jede Form der Gegnerschaft gegen das 1871 gegründete Reich dieses Etikett verdiente ${ }^{61}$.

Gegenüber der Rhetorik, die die Grundsteinlegung zum Denkmal im August 1861 begleitete, hatte sich damit die Sinnzuschreibung deutlich gewandelt. Zwar hatte auch bereits der erste Subskriptionsaufruf des Denkmalausschusses vom Juni 1861 Jahn als den Überwinder deutscher »Zerrissenheit und Schwäche« tituliert, das »Einigungs«-Postulat bezog sich indessen auf »Deutschland «, "Volk « und "Volksthum ${ }^{62}$ als (verfassungs)politisch noch keinswegs eindeutig spezifizierte Ordnungsbegriffe und ließ offen, ob die Zielvision im unitarischen Einheitsstaat oder aber einem föderalen Zusammenschluß der Einzelstaaten liegen sollte. Der Jahn-Kult, den die Initiatoren und Festredner vor der Reichsgründung initiiert hatten, hatte weniger auf die konkrete Umsetzung der Einheitsutopie als auf den - 1872 demgegenüber nachrangigen - Erhebungsmythos der Freiheitskriege abgehoben und daher am Standort des künftigen Monuments vor allem die Nähe der Hasenheide zum Kreuzbergdenkmal betont ${ }^{63}$. Kristallisationskern der Nationsidee war damit 1861 zunächst ein vage über die kulturellen Kriterien von gemeinsamer historischer (Kriegs)Erfahrung und Sprache definiertes deutsches »Vaterland « und »Volksthum « und zugleich eine ebenso unspezifische Partizipationserwartung geblieben, die dem »Volk« das «unveräußerliche Recht« zur Selbstkonstituierung und Außenverteidigung zugebilligt hatte. So sehr hier bereits Preußen als "Hort Deutschlands" gegolten hatte, war eine preußische Führungsrolle beim Zustandekommen der imaginierten nationalen Einheit so nicht thematisiert worden ${ }^{64}$.

1872 wurden allerdings die Deutungsmuster, die Kerst offiziell entwickelt hatte, während des Festbanketts im Konzerthaus im Anschluß an die Einweihung partiell unterlaufen. Hier meldete sich nun als Mitglied des »Central-

59 Vgl. ibid.

$60 \mathrm{Vgl}$. ibid.

61 Vgl. Reinhard K. SPRENGER, Die Jahnrezeption in Deutschland 1871-1933. Nationale Identität und Modernisierung, Schorndorf 1985, S. 97f.

$62 \mathrm{Vgl}$. Aufruf zu Sammlungen für ein Denkmal des Turnvaters Friedrich Ludwig Jahn in Berlin, 18. Juni 1861, GStA PK I. HA Rep. 89 Nr. 20835, Bl. 107-108, hier Bl. 107.

${ }^{63}$ Vgl, ibid. Bl. 108.

${ }^{64}$ Vgl. v.a. die Rede Kersts anläßlich der Grundsteinlegung am 10. August 1861, in: EULER, Das Jahndenkmal, S. 8-9. 
Fest-Comités« der Lehrer Hermann mit einer unorthodoxen Interpretation der Jahn-Legende zu Wort. Mit der Reichsgründung sah er weniger den glorreichen Abschluß, als eine Zwischenetappe nationaler Geschichte erreicht und die Binnenkonstituierung der Nation als künftig erst noch zu leistende Aufgabe:

Sollen wir die Wünsche, Hoffnungen und Bestrebungen dieser Zeit [i.e. die Zeit der Grundsteinlegung 1861, H.R.] (...) damit als abgeschlossen betrachten? (...) Nein! Das Denkmal (..) kann uns nicht von unserem alten Streben abbringen! (...) Und war denn die Einheit unser einziges Ziel? Soll nicht auch die Freiheit errungen sein? (...) unerschütterlich bleiben wir treu der Arbeit (...) an der Verwirklichung des Ganzen unserer Hoffnungen, der Einheit wie der Freiheit $^{65}$.

Anders als Kerst drang Hermann nicht nur auf die Einheits-, sondern auch auf die Reform- und Freiheitspostulate, mit denen die Turner- wie die gesamte bürgerliche Nationalbewegung vor 1871 angetreten waren. Er bekannte sich zum inzwischen erreichten Einheitsprimat, um die Einlösung der Idee von der zwar nicht konsequent egalitären und sicherlich zuallererst monarchisch orientierten, zugleich aber dezidiert partizipatorischen Gesellschaft neuerlich einzufordern. Der Versuch, den freiheitlich-demokratischen Motivationsanteil der frühen bürgerlichen Nationalbewegung als Traditions- und Kontinuitätselement mit in den neuen Reichsnationalismus hineinzunehmen, erschien damit wie bereits in der offiziellen Einweihungsfeier sekundär gegenüber der Nationalstaatseuphorie. Er wurde aber immerhin öffentlich unternommen und blieb damit zumindest als Deutungsmuster präsent.

Die öffentliche Rezeption der Denkmalfeier vom August 1872 blieb ungeachtet der mehrere Tage währenden Feierlichkeiten begrenzt ${ }^{66}$. Die Zustimmung besonders der liberalen Presse drückte sich dezent im ästhetischen Lob der Festszene und der gelungenen Inszenierung aus ${ }^{67}$. Das stillschweigende Plazet der publizierenden öffentlichen Meinung kam der euphorisch mit der Nationalstaatsgründung verquickten Jahn-Rezeption zugute, für die nicht zuletzt der Verfasser der Festschrift Carl Euler stand ${ }^{68}$.

65 Ibid. S. 46.

${ }^{66} \mathrm{Vgl}$. die bis hierher genannten Artikel und NPKZ, 13. August 1872, S. 2-3.

${ }^{67}$ Vgl. u.a. VZ, 11. August 1872, S. 1; NZ, 11. August 1872 (M.), S. 2: "Eine reiche Fülle bunter, stattlicher Fahnen, Banner und Wappenschilde überwehte das Ganze und bot ein ungemein malerisches und fröhliches Bild (...). Gerade diese Mischung (...) hatte etwas unbeschreiblich Ansprechendes, Munteres und Fesselndes. «

${ }^{68}$ Vgl. u.a. EULER, Das Jahndenkmal, S. 30: "Ist es nicht ein wunderbares Zusammentreffen, daß, während das Standbild des Mannes, den man während seines Lebens die verkörperte Idee des unter einem mächtigen Kaiser wieder geeinten deutschen Vaterlandes nennen konnte, seiner Vollendung entgegengieng, Kaiser und Reich neu und mächtiger denn je erstehen sollten?« 


\subsection{Die preußischen Reformen als Bezugspunkt liberaler Traditionsbildungsversuche}

Bevor Ende Oktober 1875 auf dem Dönhoffplatz gegenüber dem preußischen Abgeordnetenhaus ein Denkmal für den preußischen Reformer Freiherrn vom Stein errichtet werden konnte, ging dem Projekt ein langwieriger Entstehungsprozeß voraus. Die frühe liberale Prägung des Projekts wurde bald monarchisch überformt und mit Deutungsmustern konnotiert, die Stein mit einer konservativen Nationsidee kompatibel machen sollten.

Die Denkmalerrichtung war keineswegs von Beginn an auf einhellige $\mathrm{Zu}$ stimmung seitens des preußischen Staates, vielmehr vor dem Anbruch der Neuen Ära 1858 äußerst kritisch aufgenommen worden. Im Rahmen interner Korrespondenz mit dem preußischen König Friedrich Wilhelm IV. wenige Monate vor seiner Ablösung durch den Kronprinzen im Oktober des Jahres war das Projekt echauffiert erörtert worden. Innenminister Otto von Manteuffel riet dazu, das Anliegen des initiierenden Zentralvereins zurückzuweisen. Stein sei zwar zweifelsfrei denkmalwürdig angesichts seiner »Bestrebungen für die energische Fortführung der Befreiungskriege im Jahre 1813«, der König solle aber besser die Initiative an sich ziehen, da sie eine »der Staatsregierung durchaus würdige Aufgabe« darstelle ${ }^{69}$. Manteuffel folgte hier dem Votum seines reaktionären Amtsvorgängers Ferdinand von Westphalen, dessen Einschätzung zufolge es sich bei der bisherigen Initiative aus dem westfälischen Wetter »lediglich (...) [um ein] Unternehmen einseitiger politischer Parteien und Fractionen « handle, das den "Gedanken allgemeiner nationaler Anerkennung « nur vortäusche ${ }^{70}$. Westphalen war sich sicher, daß der Aufruf des Komitees auf die "parlamentarische Linke» und "Opposition« zurückging $^{71}$. »Männern der conservativen Partei« jedenfalls sei die Aufnahme in das Komitee verweigert worden ${ }^{72}$.

Sein Bericht kulminierte in der Gegenüberstellung zweier Deutungsmuster zur historischen Person Steins, von der nur eine gleichsam national verträglich, die andere hingegen unauthentisch-tendenziös erschien: Stein war demnach als "Reformer auf dem Gebiete staatlicher Organisationen und Vorkämpfer preuBischen Patriotismus'" von »zutiefst conservativem Geist. " Nicht hingegen zu vereinnahmen war er für die wihm verhassten flachen Nivellierungstheorien eines rationalen Liberalismus und einer revolutionairen Demokratie ${ }^{73}$. Demnach zielten die Stein'schen Reformen auf die Restituierung eines nach außen

Vgl. Von Manteuffel an den König am 14. Juli 1858, GStA I. HA Rep. 89 Nr. 20916, Bl. 10.

Vgl. von Westphalen an von Manteuffel, 3. Juli 1858, ibid. Bl. 12-15, hier Bl. 12-12 Rs.

71 Vgl. ibid. Bl. 13.

72 Vgl. ibid. Bl. 13 Rs.

73 Ibid. Bl. 14. 
wehrhaften, nach innen effizienten und produktiven Staates Preußen als starker Nation, nicht aber auf die Egalisierung der Gesellschaft über die Grenzen einer berufsständischen und vor allem nach unten tendenziell exklusiven Bürgergesellschaft hinaus. Westphalens Aufgeregtheit war der Sorge geschuldet, Steins sozialkonservative Nationsidee könne gleichsam progressiv und sozialrevolutionär umgedeutet werden, so daß sein öffentliches Denkmal politische Postulate zu verewigen drohte, denen gegenüber der restaurative Preußenstaat wenige Monate vor dem Thronwechsel und unter dem Eindruck eines im Aufschwung begriffenen politischen Liberalismus 1858 einmal mehr auf Distanz zu bleiben wünschte.

Westphalens Argumentation lebte zugleich von einer klaren Differenzierung zwischen dominanten, politisch konservativen Sinnstiftern zum einen und zur Sinnstiftung nicht befugten, liberalen und demokratischen Kräften zum anderen. Sein Plädoyer galt unverhohlen der Aufrechterhaltung des staatlich-konservativen Deutungsmonopols über die nationale Geschichte und ihre Protagonisten. Unter diesen Umständen riet er nun nicht zur Abblockung, sondern zur taktischen Absorption und unmittelbaren organisatorischen Übernahme des Projekts in die Hand des Staates und des Monarchen ${ }^{74}$ und nahm damit in der Tat das Verfahren monarchischer Überformung vorweg, das sich in den folgenden Monaten und Jahren abspielen sollte ${ }^{75}$. Die skeptischen Stimmen im Gefolge von Westphalens Mahnungen verstummten dennoch rasch ${ }^{76}$.

Das Einweihungsfest im Oktober 1875 war dann ebenso von preußischer wie deutscher Staatssymbolik bestimmt, obschon aus den außerpreußischen Staaten keine Ehrengäste erschienen waren, mit dem Reichstagspräsidenten und Repräsentanten der Stadt wie der Universität und Geistlichen nach dem Urteil der Vossischen Zeitung aber eine durchaus bunte militärische und zivile Versammlung in »Talaren und bürgerlichen Fracks ${ }^{77}$ die Festszene bestimm$\mathrm{te}^{78}$. Vom Abgeordnetenhaus in der Leipziger Straße zogen die Ehrengäste

74 Vgl. ibid. Bl. 14 Rs.

75 Vgl. bereits Einleitung, Kapitel II.1.2.

76 Vgl. Bericht der Denkmalkommission an den König, 14. Januar 1860, GStA PK I. HA Rep. 89 Nr. 20916, Bl. 19-21, hier Bl. 21. Vgl. auch [An.,] Die Stellung der deutschen Nation zum Freiherm vom Stein, oder: Jetzt ist es doch wohl Zeit, daß Deutschland auch dem Freiherrn vom Stein ein Monument errichtet. Ein Anruf an die deutsche Nation. Der Ertrag zum Besten des Stein-Denkmals, Weimar 1860.

77 VZ, 27. Oktober 1875,1 . B., S. 1; NZ, 28. Oktober 1875,1 . B., S. 1.

78 Vgl. zum Folgenden VZ, 27. Oktober 1875, 1. B., S. I; NZ, 26. Oktober 1875, S. 1-2; NAZ, 27. Oktober 1875, S. 1; ibid. 29. Oktober 1875, S. 1; Germania, 27. Oktober 1875, S. 2-3; Deutscher Staats-Anzeiger, 26. Oktober 1875, LAB A Rep. 000-02-01 Nr. 1633, Bl. 77. $\mathrm{Zu}$ den geladenen Gästen zählten sämtliche Minister, weiter Generalfeldmarschall von Wrangel, der Chef der neugebildeten Admiralität Albrecht von Stosch, der ehemalige Reichstagspräsident und Nationalliberale Eduard Simson, die Präsidenten des Herrenhauses und des Reichstages Otto Graf zu Stolberg-Wernigerode von der Deutschen Reichspartei und der ostpreußische Liberale, Mitbegründer der Deutschen Fortschrittspar- 
unter der Führung von Moltkes zum Festplatz ${ }^{79}$. Dort sollten nach Gebet und Hymne Hochrufe nicht nur auf den Kaiser, sondern auch auf »Deutschland« und das abschließende »Mailied « von Claudius noch einmal einen reichsnationalen Horizont des Festes herstellen ${ }^{80}$.

In sein Weihegebet schloß der Hofprediger, der bereits bei der Einweihung des Denkmals für Friedrich Wilhelm III. 1871 mitgewirkt hatte, eine autorisierte Lesart des Denkmals ein. Er apostrophierte Stein als »Bahnbereiter für die (...) unserem geliebten Deutschland wunderbar geschenkte Einheit« und nahm ihn für die »christlich sittlichen Grundlagen des Staates« zum einen wie für eine opferfreudige Loyalität zu »Kaiser und Reich« und somit für eine verbindliche monarchisch-reichsstaatliche Ordnungsstruktur der Nation in Beschlag ${ }^{81}$. Eine knappe »Freiheits«-Reminiszenz blieb in diese Grundkonfiguration von Werthaltungen so eng eingebunden, daß sie sich kaum entfalten konnte $^{82}$. Als Vertreter des Denkmalkomitees illustrierte Gneist Steins historisches Verdienst um die Nation zu Jahrhundertbeginn. Das von Frankreich zerschlagene Preußen von 1807, zu dessen Beschreibung der Redner anthropomorphisierende Metaphern des Siechtums aufbot, war "frühzeitig gealtert, ermattet, verstümmelt« und lag vor dem »stolzen Eroberer« erniedrigt. Umso mehr erschien Stein in der Rolle des politischen Retters, indem er »dem unterdrückten Theile [des Volks] Freiheit, Selbständigkeit und Eigenthum [gab] und ihm den Schutz der Gesetze angedeihen $\left[\right.$ ließ $\aleph^{83}$. Daß Steins Reformprogramm sich auf die Gewährleistung von »freier Arbeit« für »Arbeiter«, »Bauern«, »Bürger« und »Adel« und also auf die vor allem gewerbliche Freisetzung einer rigide ständisch gegliederten und nur nach äußerst elitären Besitzqualifikationen politisch beteiligten Gesellschaft kapriziert hatte, gab Gneist keinerlei Anlaß zu Kritik. Ganz außer Betracht blieb, daß sich der Reformimpetus Steins wie weiter Teile der preußischen Reformer überhaupt schlicht aus dem

tei 1861 und der Nationaliberalen Partei 1866 Max von Forckenbeck, der Oberbürgermeister von Breslau und Nationalliberale Arthur Hobrecht, der Vorstand der Stadtverordneten, Polizeipräsident von Madai, Rektor und Dekane der Universität sowie mehrere Geistliche. Ein Pavillon auf dem Festplatz war mit "preußischen und deutschen Fahnen« beflaggt und mit dem Preußenadler geschmückt.

79 Vgl. NZ, 26. Oktober 1875, S. 1-2; ibid. 27. Oktober 1875, S. 1; NPKZ, 28. Oktober 1875, S. 1.

${ }^{80}$ Die Auswahl des Schlußliedes war erst wenige Tage zuvor auf Vorschlag des liberalen Kultusministers Adalbert Falk erfolgt, der das urspünglich vorgesehene Lied »Was ist das deutsche Vaterland « ersetzt sehen wollte, weil es das ’preußische` Symbolübergewicht der Feier zu besiegeln drohte, während das Mailied seine gewisse allgemeine Beziehung (...) auf Deutschland« habe. Vgl. Entwurf des Programms, GStA PK I. HA Rep. 89 Nr. 20917, Bl. 18 und Schreiben Falks an den König vom 15. Oktober 1875, ibid. Bl. 34.

81 Vgl. zum Folgenden NZ, 26. Oktober 1875, S. 2; VZ, 27. Oktober 1875, 1. B., S. 1-2, hier S. 1; NAZ, 27. Oktober 1875, S. 1; NPKZ, 27. Oktober 1875, S. 1.

82 Vgl. ibid.

${ }^{83}$ Ibid. 
Willen zur Revolutionsprophylaxe gespeist hatte ${ }^{84}$. Vielmehr schien in Steins "Bildung (...) der Nation (...) von innen «, zu »Staat und Volk« als etatistisch orientierter modernisierter Gesellschaft weit über Preußen hinaus die Reichsgründung von 1871 schon zu Jahrhundertbeginn vorweggenommen ${ }^{85}$. Die Revolution von 1848 und die ganz unterschiedliche Entwicklung der nichtpreußischen Staaten kam in dieser Kontinuitätsfiktion nicht vor. Auch in dieser Hinsicht arbeitete Gneists historischer Exkurs allenthalben mit Verkürzungen und Umwertungen.

Für Gneists Deutung war vor allem die liberale Presse zu gewinnen. Die National-Zeitung überschlug sich nahezu im Stein-Kult und wünschte das Reich regelrecht mit Stein-Statuen zu überfluten ${ }^{86}$. Seine Nationsidee spitzte das Blatt darüber hinaus »bürgerlich« zu: Stein selbst firmierte, obschon adliger Abkunft, als »Symbol und (...) reinste[r] Ausdruck des deutschen Bürgerthums ${ }^{87}$. "Ordnung und Freiheit» waren damit Zusagen an die Nation als freie Bürgergesellschaft, nicht hingegen an unterbürgerliche Sozialformationen. Andererseits wurde nun anders als in der Gneist-Rede die konstitutionelle Verankerung parlamentarischer Gremien, des »preußische[n] Landtag[s]《 und »deutsche[n] Parlament[s] $\aleph^{88}$ nicht hingegen die an keiner Stelle ausdrücklich erwähnte monarchische Staatsspitze zum Signum der Bürgernation. Daß die lange und hartnäckige Obstruktion der Monarchie gegen die Konstitutionalisierung in Preußen für dieses mehr als für alle anderen deutschen Staaten eine Hypothek darstellte, die die Parlamentarisierung und Demokratisierung belastete, reflektierte die National-Zeitung in ihrer Bilanz nicht mit. Die konservative Neue Preußische Kreuz-Zeitung verwahrte sich demgegenüber gegen die Deutung des Stein-Denkmals durch die liberale Presse, sofern hier versucht worden sei, Stein auf das wfortschrittliche Postament« des Liberalismus zu stellen und

mit energischem Stillschweigen (..) über die (..) lästige geschichtliche Thatsache [hinwegzugehen], daß Steins mationale Ideen (...) tief in seinem christlich-deutschen Wesen wurzelten, so daß (...) die staatliche Emeuerung sich auf dem ewigen Grunde einer religiössittlichen Wiedergeburt des Volkes vorbereiten und geistig rüsten sollte ${ }^{89}$.

Steins religiöse Identität sollte nicht historisiert werden, sondern als verbindlicher Teil der Kultfigur wie der von ihr repräsentierten Nation gelten, nationale und christlich-religiöse Identität verbindlich amalgamiert bleiben ${ }^{90}$.

Vgl. NOLTE, Staatsbildung, passim; Reinhart KOSELLECK, Preußen zwischen Reform und Revolution. Allgemeines Landrecht, Verwaltung und soziale Bewegung von 1791 bis 1848 , ND Stuttgart 1989, u.a. S. 163-177.

${ }^{85}$ Subskriptionsaufruf, 12. März 1860, BLHA Rep. 2A I P Nr. 719 [up].

${ }^{86}$ Vgl. dazu und zum Folgenden NZ, 26. Oktober 1875 (M.), S. 1.

${ }^{87}$ Ibid.

88 Ibid.

${ }^{89}$ NPKZ, 28. Oktober 1875, S. 1.

$90 \mathrm{Vgl}$. ibid. 
Unter anderen konfessionellen Vorzeichen folgte auch die katholische Germania diesem Deutungsmuster ${ }^{91}$. Als Motiv eines gleichwohl mühsam entwikkelten Konsens mit der Figur Steins ${ }^{92}$ wirkten hier nicht nur Steins christliche Werthaltung und die Authentizität seines Willens zur Einheit der Nation; zum Konsens bewog erneut die explizite Gegnerschaft gegen die ")/Liberalen( unserer Tage«, die Stein säkular und damit unauthentisch umdeuteten ${ }^{93}$. Der Artikel ließ erkennen, daß die Germania die Marginalisierung oder gar Ausgrenzung des Katholizismus aus der Reichsnation nicht nur nicht hinnahm, sondern aktive Anwartschaft auf nationales Kultpersonal bekundete, mit dem sie Anschluß weniger an ein (gesellschafts)politisch präzisiertes als an ein prinzipiell christlich assoziierbares Nationskonzept suchte.

Jenseits der konservativen und liberalen Voten lag indessen der Kommentar des Neuen Social-Demokraten. Die Reform, für die Stein stand, ersetzte dem Blatt zufolge als evolutionäres Pendant zur französischen Revolution das ,feudale Staatswesen< durch den "von der Bourgeoisie beherrschte[n] Staat ${ }^{94}$. Während der Social-Demokrat zu konzedieren bereit war, daß dieser gesellschaftspolitische Einflußtransfer eine historische Modernisierungsfunktion hatte, erachtete er den Status der Bourgeoisie inzwischen als »überlebt« und formulierte die revolutionäre Erwartung, daß die »Bourgeoisie-Herrschaft (...) fallen [müsse]«, um durch den »triumphierenden Socialismus« ersetzt zu werden, den er als einzig legitime sthatsächliche und rechtliche Herrschaft des gesammten Volkes« anerkannte ${ }^{95}$. Daher verbreitete der Social-Demokrat nicht den gängigen »Weihrauchqualm« um die Person Steins, sondern taxierte den Reformer als späten symbolischen Abglanz einer überlebten Ordnung. Der unverhohlenen Revolutionsvision folgte eine gewagte Traditionsstiftung zwischen Stein und Napoleon: Nicht ersterem und nicht dem selbsternannten "Bürgerthum" sei nämlich das große Reformwerk als "sociale Umgestaltung" und Entfeudalisierung der modernen Gesellschaft zuzurechnen:

Die eisemen Würfel, die bei Jena und Auerstädt rollten, brachten die Entscheidung, Napoleon zerschmetterte dort die Kraft des preußischen Adels, er zwang ihn Platz zu machen dem bürgerlichen Stande, und die Stein'sche Reform war nur das Testament, durch welches der sterbende Adel die Bourgeoisie als Erben einsetzte ${ }^{96}$.

Napoleon identifizierte der Neue Social-Demokrat hier mokant als die eigentliche nationale Gründerfigur des preußischen Reformstaates:

91 Germania, 26. Oktober 1875, S. 1.

92 Vgl. ibid.: »Als Protestant, als Kind seines Jahrhunderts (...) hat Stein über katholische Dinge vielfach nicht richtig gesehen; aber er hat uns stets gerecht sein wollen, und ist es fast immer auch thatsächlich gewesen, und meist hat er uns auch richtig beurtheilt.«

93 Vgl. ibid.

94 Neuer Social-Demokrat, 27. Oktober 1875, S. 1.

95 Vgl. ibid.

96 Ibid. 
Wer also die Steinfeier begeht, indem er Stein als Urheber der liberalen Zeit darstellt, der täuscht sich selbst und feiert in Wahrheit ein Napoleonfest, denn dieser war der sociale Revolutionär, welcher (...) die Bourgeois-Gesellschaft begründet hat. Für einen Franzosenfresser, für einen Nationalliberalen mag das eine recht bittere Wahrheit sein ${ }^{97}$.

Die Erkenntnis, daß ungeachtet vielfacher spätabsolutistischer Vorreformen in der Tat das Kriegsdesaster von 1806 zur eigentlichen Initialzündung für eine umfassende Reformstrategie in Preußen geworden war, vereinseitigte der Social-Demokrat polemisch geschickt zur Stilisierung einer konkurrierenden Gründerfigur. In diesem Sinne gratulierte der Social-Demokrat am Ende der deutschen »Bourgeoisie« zu dem »Schöpfer des deutschen Liberalismus Napoleon Bonaparte $\varkappa^{98}$ und führte damit den monumentalisierten Gründermythos und das allenthalben offiziell propagierte Deutungsmuster vollends ad absurdum.

Die Quintessenz seiner Polemik aber blieb die Klage gegen eine Nation, die sich auf eine Reform als historisches Gründungsereignis berief, welche schon im Preußen des frühen Jahrhunderts deutlich mehr auf die besitzende und gebildete Mittelschicht als auf das breite "Volk« abhob. Auch nach der Reichsgründung hatte man sich nicht erkennbar um soziale und politische Öffnung bemüht. Damit resultierte der sozialdemokratische Widerspruch nicht aus dem Unwillen zur Beteiligung am nationalen Kult, sondern aus der Defizienz an sozialer Inklusion.

War also die gesamte Genese des Berliner Stein-Denkmals ein Indiz dafür, daß man in der Tat vor 1871 der liberalen Opposition keine Symbolmacht hatte geben wollen, ließ sich im Zusammenhang mit der Einweihung nicht verhindern, daß weniger die authentische Bewertung der preußischen Reformen als historischer Prozeß denn die Verortung von Partizipations- und Inklusionswerten im nationalen Diskurs nach 1871 zum zentralen Thema von offiziösen Deutern und Sinnstiftern gleichermaßen wurde. Spuren liberaler Nationsbestimmungen konnten damit über die Zäsur von 1871 hinweg wenige Jahre später durchaus noch einmal symbolisch und programmatisch bedeutsam werden.

Noch bis nach der Jahrhundertwende ließen sich entsprechende Assoziationen - diesmal sogar mehr auf Seiten der Stifter als auf der der Rezipienten abrufen. Im November 1907 nämlich folgte ein Denkmal für den Reformer und Staatskanzler Hardenberg auf der Südseite des Dönhoffplatzes ${ }^{99}$. Vor allem städtische, weniger staatliche Vertreter nahmen am Denkmalfest teil, während sich der eigentlich geladene Kaiser vom uniformiert erschienenen Kronprinzen vertreten ließ ${ }^{100}$.

97 Vgl. ibid.

98 Ibid.

99 Vgl. zum Folgenden VZ, 12. November 1907, S. 2-3

${ }^{100} \mathrm{Vgl}$. ibid. Anwesend waren u.a. Innenminister von Moltke und der ehemalige Vizepräsident des Herrenhauses und Justizminister Georg von Beseler, der als Reichstagsmitglied vom 
In seiner Ansprache kam der Professor der Staatswissenschaften der Universität Breslau Wenckstern nicht umhin, Hardenberg erst einmal vom Odium zeitgenössischer Kritik freizusprechen. Er suchte nach Wegen einer einvernehmlichen Interpretation in der Nähe des einhellig anerkannten Stein, indem er die Modernisierungsleistungen beider Reformer in den verschiedenen Bereichen von Staat, Ökonomie, Bildung, Militär und Finanzen unterstrich und die Reformen ganz in der Tradition borussianischer Historiographie als glorreiches Auftaktkapitel in der Geschichte der Nationswerdung wertete ${ }^{101}$. Regenerationseffekte und überhaupt die Stärkung des monarchisch-bürokratischen Staates wurden stark gewichtet. Unerwähnt blieb, daß ausgerechnet die etatistische Verfassungspolitik gescheitert war, für die Hardenberg, je neu vertröstet mit monarchischen Verfassungsversprechen, eingestanden hatte und die nicht einfach durch eine Konstitutionalisierung auf administrativem Wege kompensiert werden konnte ${ }^{102}$. Auch unterblieb nicht anders als im Kreise der Stein-Zelebranten der Blick auf die gerade in konstitutioneller Hinsicht deutlich bessere Bilanz der Rheinbundreformen, die sich angesichts der Rede vom inzwischen etablierten Reich zur Weitung des preußischen Horizontes hätte anbieten können.

Dennoch gelangte Wenckstern über die reine Perpetuierung des borussianischen Mythos weit hinaus, indem er die reformerischen Postulate politisch reaktiviert sehen wollte und damit das Erfordernis insbesondere sozialer Reform auf die Agenda des Reichs von 1907 zu setzen versuchte:

Mit der Weltstellung des Reiches, mit der Masse der Bevölkerung, mit dem (...) täglich steigenden Niveau der sozialen Pflichten und Rechte, mit diesem (...) günstigen Ergebnis des Wachsens Preußens und des Deutschen Reiches auf dem Fundamente der Stein-Hardenbergschen Politik und Gesetzgebung (...) ist gewachsen auch die Mannigfaltigkeit und Größe der weltpolitischen, der weltwirtschaftlichen und der sozialen Probleme. Die deutsche Welt von 1907 zeigt nirgens etwas, was aussähe wie Ruhen auf Lorbeeren. Hardenbergs Denkmal kann uns einiges in Erinnerung bringen, was uns heute nottut. (...) Hardenbergs Thätigkeit läßt sich um die beiden Pole konzentriert vorstellen: daß er die Grundlage mitschuf eines politisch mächtigen und eines nach sozialer Gerechtigkeit ringenden Preußens und Deutschlands ${ }^{103}$.

Damit hatte der Festredner ausgetretene Pfade der borussianischen Legende verlassen, indem er die Frage sozialer und rechtlicher Egalität zum zweiten, mit der Staatskonsolidierung gleichberechtigten großen Ziel des Reformers erklärte und damit neben dem Staat die reorganisationsbedürftige Gesellschaftsordnung thematisierte. Auch in der Hinsicht erklärte er die preußischen Reformen zum Erbe des Nationalstaates nach 1870/71, daß sie unerfüllte Ega-

rechten Zentrum maßgeblich an der verfassungsrechtlichen Ausarbeitung der Grundrechte beteiligt gewesen war, der Vizepräsident des Herrenhauses und Oberbürgermeister Kirschner, daneben zahlreiche Stadtverordnete und Stadträte.

${ }^{101} \mathrm{Vgl}$. VZ, 12. November 1907, S. 3.

${ }^{102}$ Vgl. NOLTE, Staatsbildung, S. 93-107.

${ }^{103}$ VZ, 12. November 1907, S. 3. 
lisierungserwartungen an ihn weitergaben, so daß die Konsolidierung der Nation, mit der die Reformen in Vorleistung gegangen waren, nicht nur am Aus$\mathrm{maß}$ staatlicher Autoritätssicherung, sondern auch am Zustand sozialer Binnenstrukturen gemessen werden mußte. Das Monument geriet so nicht nur in gängiger Manier zur Reflexionsfläche eines Einigungspostulats, sondern zum Appell an die "Versöhnung" der »entfesselten Volkskräfte" und zur "gerechte[n] Gestaltung aller sozialen Verhältnisse ${ }^{104}$.

Über die Tendenz der Rede, nicht nur die Egalisierungserfolge der preußischen Reform infrage zu stellen, sondern sie erneut zum Thema aktueller Reichspolitik zu machen, setzte sich die Kreuz-Zeitung hinweg ${ }^{105}$. Die National-Zeitung hingegen bekannte sich durchaus zu den »politischen und sozialen Reformgedanken « Hardenbergs, die sie im Sinne Wencksterns zum "Zukunftsprogramm« auch für das Reich aufwertete, deutete indessen mit dem Hinweis auf die überschaubar kleine Festgemeinde einen geminderten offiziellen $\mathrm{Zu}$ spruch zur Sinnstiftung an ${ }^{106}$. Der Vorwärts schließlich zog sich, des Denkmalkults längst überdrüssig ${ }^{107}$, auf das Stilmittel gezielter Sinnpervertierung zurück, indem er die Aufschrift »Rechtsgleichheit« auf einem Aktenbündel zu Füßen des Standbilds als Indiz für den in der Reichsnation damiederliegenden Egalitätsgrundsatz wertete, und gab damit indirekt dem Tenor der Festrede Recht $^{108}$. Selbst deutlich nach der Jahrhundertwende provozierte das Thema der preußischen Reformen erneut einen Reflex auf die Binnenausstattung der Nation, für die insbesondere Monarchen- und Militärdenkmäler wenig programmatische Verheißungen bereitgehalten hatten.

\subsection{Das Ringen um liberale Symbolmacht}

$\mathrm{Ab}$ den 1890 er Jahren ergänzten Statuen für renommierte Linksliberale ${ }^{109}$ das Berliner Denkmalterrain, die gegenüber den großen Krieger- und Militärmonumenten zwar formell bescheiden blieben, jedoch zunächst mühevoll, dann selbstbewußter, durchaus eigene nationale Sinnakzente zu setzen wußten.

Ende Juni 1890 wurde ein Denkmal für den Linken und Führer der Deutschen Fortschrittspartei Franz Waldeck auf dem Jakobikirchhof an der Orani-

${ }^{104}$ Ibid.

${ }^{105}$ Vgl. NPKZ, 12. November 1907 (A.), S. 2.

${ }^{106} \mathrm{Vgl}$. NZ, 12. November 1897 (A.), S. 5.

${ }^{107}$ Vgl. Vorwärts, 13. November 1907 (2. B.), S. 1: "Irgendwelche ordenslüsternen Leute haben es gestiftet, irgend ein Bildhauer hat es angefertigt, irgend ein Professor hat es (...) befestredet, und nun steht es da, steif, langweilig, in Theaterpose."

${ }^{108}$ Vgl. ibid.

${ }^{109}$ Zur Definition des "Linksliberalismus" vgl. Christian JANSEN, Einheit, Macht und Freiheit. Die Paulskirchenlinke und die deutsche Politik in der nachrevolutionären Epoche 1849-1867, Düsseldorf 2000, S. 14-16. 
enstraße eingeweiht, das hier zwar in der Nähe einer öffentlichen Straße stand, durch seine Aufstellung auf dem Friedhof aber zugleich nur halb-öffentlich innerhalb des Kirchhofgitters blieb. Die Feier vollzog sich im engen, überschaubaren Kreis frühmorgens, als sich einige Stadtverordnete, mehrere Reichstagsmitglieder und Angehörige der Deutschen Freisinnigen Partei sowie Vertreter politischer Vereine einfanden ${ }^{110}$. Tags darauf hielt der deutschfreisinnige Arbeiterverein Berlins eine eigene Festveranstaltung "zu Ehren der Enthüllung« des Waldeck-Denkmals ab, an der etwa 800 Personen teilnahmen $^{111}$. Die explizit parteipolitische Sinnzuschreibung an das neue Monument fand damit aber nicht mehr unmittelbar im öffentlichen Raum statt.

In seiner Festrede auf dem Jacobikirchhof bezog etwa der Liberale und Mitbegründer der Deutschen Fortschrittspartei Rudolf Virchow eindeutig Stellung. Indem er die lange Verzögerung der Denkmalaufstellung mit der politischen Verfolgung und Inhaftierung Waldecks unter dem Vorwurf des Hochverrats und der Konspiration 1849 parallelisierte, erhob Virchow gegenüber den Denkmalverhinderern wenig kaschiert die Anschuldigung illegitimer und unkonstitutioneller Reaktion $^{112}$. Im Rahmen einer vom Berliner Arbeiterverein initiierten und damit nicht mehr unmittelbar öffentlichen, sondern eher exklusiven Feier am folgenden Tag hielt auch der Stadtverordnete und Rechtsanwalt H. Sachs eine Festansprache, in der er auf den maßgeblichen Anteil des Arbeitervereins an der Denkmalinitiative verwies und damit umfassende Deutungsmacht von seiten der Linken geltend machte.

Sachs erwähnte, daß in der Tat erst eine kompensatorisch entpolitisierte Sprachregelung die städtischen Behörden zur Genehmigung der Denkmalerrichtung nicht für den Vertreter der Freisinnigen Partei, sondern für den "Ober-Tribunal-Rath Waldeck" ermöglichte. So erhalte die Monumentalsymbolik ihre genuin politische Sinndeutung erst durch die Rede Virchows zurück $^{113}$. Zugleich erinnerte Sachs an Waldecks Arbeit an der Spitze der preußischen Verfassungskommission 1848, seine Mitgliedschaft in der unter dem Druck des preußischen Verfassungskonfliktes 1861 gegründeten Deutschen Fortschrittspartei und schließlich seine Festlegung auf den Freiheitsprimat in der Phase der Zielkollision innerhalb des Liberalismus $1866^{114}$. Auf den freiheitlich-demokratischen (allerdings nicht gegen das Klassenwahlrecht gerichteten) Wertekanon, für den Waldecks Politik stand, wies Sachs hier knapp hin,

${ }^{110}$ Vgl. Berliner Tageblatt, 30. Juni 1890, LAB A Rep. 000-02-01 Nr. 1634, Bl. 230. Berliner Vereine und der Verein der Fortschrittspartei aus Leipzig legten Kränze am Standbild nieder. Vgl. auch Manfred HETTLING, Politische Bürgerlichkeit. Der Bürger zwischen Individualität und Vergesellschaftung in Deutschland und der Schweiz von 1860-1918, Göttingen 1999 (Bürgertum, 13), S. 282-283.

${ }^{11}$ Vgl. Berliner Tageblatt, 2. Juli 1890, LAB A Rep. 000-02-01 Nr. 1634, Bl. 230.

112 Vgl. ibid. 30. Juni 1890, ibid.

${ }^{113}$ Vgl. ibid. 2. Juli 1890, ibid. Bl. 230

${ }^{114}$ Vgl. auch Die Gartenlaube Jg. 1876, S. 88-91. 
ohne den Anteil des gesamten Linksliberalismus an der Nationsbildung vor 1871 exakt zu bestimmen.

Der Reichstagsabgeordnete und Jenaer Jurist Ernst Harmening würdigte Waldeck als aufrechten Verfechter parlamentarischer und freiheitlicher Politikziele win der Zeit der Erbärmlichkeit « ${ }^{115}$. Erneut war es Virchow, der die verdeckten Angriffe seines Vorredners auf die zaghafte Vorgehensweise des Denkmalausschusses energisch abwehrte, die symbolisch wenig beeindrukkende Feier gleichsam als rituelle Maximallösung bezeichnete und den Obstruktionsvorwurf dezent an die Staatsspitze weiterleitete ${ }^{116}$.

Die Reden vor dem Denkmal und im Rahmen der Feier des deutschfreisinnigen Arbeitervereins ließen erkennen, da $\beta$ die Verhinderungsstrategie des Kaisers die Initiatoren in der Tat derart okkupierte, daß die positive Traditionsstiftung und Zuordnung der Waldeck-Figur auf einen politischen Nationsbegriff höchstens andeutungsweise gelang. $\mathrm{Da}$ Virchow damit beschäftigt blieb, das innerparteiliche Aufbegehren gegen eine zu zaghafte Symbolpolitik zu beschwichtigen, erwies sich insofern als symptomatisch nicht nur für die über lange Jahre geübte Intransigenz seitens des Monarchen gegenüber der ungewollten Monumentalisierung eines Protagonisten der linken Opposition, sondern auch für das vorherrschende Unvermögen, weiter dimensionierte Deutungsmuster hinsichtlich der liberalen, bis dahin kaum in einem dezidierten Kult gewürdigten Figur Waldecks zu entwerfen.

Erst fast neun Jahre später folgte der nächste Monumentalisierungsversuch für einen Liberalen, als am späten Vormittag des 4. August 1899 ein Denkmal für Hermann Schulze-Delitzsch an der Kreuzung von Köpenicker- und Inselstraße eingeweiht wurde. Dazu waren neben zahlreichen Genossenschaftsmitgliedern und städtischen Vertretern zwar keine Minister, wohl aber Repräsentanten der wichtigsten Ministerien entsandt worden ${ }^{117}$; dazu trat als einer der profiliertesten Gäste und Vertreter der Universität wie der Berliner Akademie und ebenso kaiser- wie kanzlerkritischer liberaler Reichstagsabgeordneter Theodor Mommsen auf ${ }^{18}$. Daß noch am gleichen Abend die meisten Kranz-

${ }^{115}$ Vgl. Berliner Tageblatt, 30. Juni 1890, LAB A Rep. 000-02-01 Nr. 1634, B1. 230.

${ }^{116}$ Die Inauguration hatte in der Tat nur stattfinden können, weil der Friedhof inzwischen in städtischen Besitz übergegangen war und kein monarchisches Plazet mehr erforderlich war, vgl. HETTLING, Politische Bürgerlichkeit, S. 282.

117 Vgl. zum Folgenden VZ, 4. August 1899 (B. der A.), S. 5; Berliner Tageblatt, 4. August 1899, LAB A Rep. 000-02-01 Nr. 1635, Bl. 119; NZ, 4. August 1899 (A.), S. 1; Freisinnige Zeitung, 5. August 1899 (Nachtausgabe), S. 1. Anwesend waren Bürgermeister Kirchner, Stadträte und Stadtverordnete und ein Vertreter des Ältestenkollegiums der Berliner Kaufmannschaft. Reden hielten auch Vertreter der Genossenschaftsverbände einschließlich der Repräsentanten eines österreichischen, englischen und französischen Verbandes. Vgl. auch HETTLING, Politische Bürgerlichkeit, S. 278-279.

${ }^{118} \mathrm{Vgl}$. Alexander DEMANDT, Mommsen in Berlin, in: TREUE, GRUNDER (Hg.), Berlinische Lebensbilder, Bd. 3, S. 157-173. 
schleifen zu Füßen des neuen Denkmals abgeschnitten und in ein Genossenschafts-Archiv verbracht wurden, erklärte zumindest die Vossische Zeitung mit der Kostbarkeit dieser Schleifen ${ }^{119}$. Ob womöglich auch eine Provokation des Staates im Rahmen der nicht zitierten Aufschriften durch ihre rasche Beseitigung vermieden werden sollte, blieb dabei offen. Wenige Stunden nach dem Ende der Einweihung jedenfalls baten die städtischen Behörden die Teilnehmer des Genossenschaftstages zu einem Empfang in das Rathaus und verbanden die Denkmalfeier insofern mit einem zusätzlichen Loyalitätsakt gegenüber den Anhängern Schulze-Delitzschs ${ }^{120}$.

Da sie mit politischer Obstruktion ihres Denkmalplans offensichtlich rechneten, hatten die Initiatoren bereits im Vorfeld der Denkmalerrichtung zu erkennen gegeben, mit ihrer öffentlichen Ehrung mehr auf die "volkswirthschaftliche Bedeutung« des Genossenschaftsgründers als auf die "politische Thätigkeit« des demokratisch gesinnten Liberalen zielen zu wollen ${ }^{121}$. In dieser Motivienung kündigte sich der Versuch an, durch eine Separierung verschiedener öffentlicher Rollen und eine eklektische Festlegung auf die möglichst konsensfähig-unpolitische Bedeutungsseite der Figur Konflikte mit den zustimmungspflichtigen Behörden zu umgehen. Der Kaiser indessen war dem strategischen Argument nicht gefolgt und hatte die Differenzierung der beiden öffentlichen Funktionen Schulze-Delitzschs zunächst als vordergründig eingestuft, eine ausdrückliche Diskreditierung des Liberalismus, für den SchulzeDelitzsch stand, aber gemieden, indem er das öffentliche Votum vorschob: so sei mit Protesten aus verschiedenen »Kreise[n] des Volkes« dagegen zu rechnen,

daß einem Manne von seiner politischen Vergangenheit durch die Errichtung eines Standbildes an einem der bedeutendsten und verkehrsreichsten Plätze in mitten der Hauptstadt eine Ehre erwiesen werde, welche vielen um das Vaterland verdienten Männern überhaupt nicht, oder doch nur in gleich hervorragender Weise $z u$ theil geworden sei ${ }^{122}$.

Erst die Einwilligung des Denkmalkomitees in die Änderung des Standorts hatte überhaupt Bewegung in das Verfahren bringen können. In seiner Rede anläßlich der Einweihung 1899 ließ Virchow nun deutlich erkennen, daß die Monumentalisierung Schulze-Delitzschs mit massiven "Schwierigkeiten« verbunden gewesen sei, die er aber nicht näher benannte. Statt dessen feierte er den Gründer des Genossenschaftswesens, der im Sinne eines antiinterventionistischen Linksliberalismus für eine Sozialpolitik eingetreten sei, die den Erfordernissen der modernen Industrie- und Marktgesellschaft und den sich daraus

${ }^{119}$ Vgl. VZ, 5. August 1899 (B. zur A.), S. 5.

${ }^{120}$ Vgl. Berliner Tageblatt, 4. August 1899, LAB A Rep. 000-02-01 Nr. 1635, Bl. 119.

${ }^{121} \mathrm{Vgl}$. Schreiben des Innenministers Ludwig Herrfurth an den Kaiser am 23. November 1891, GStA PK I. HA Rep. 89 Nr. 20837, Bl. 7.

${ }^{122} \mathrm{Vgl}$. Bericht an den Innenminister und den Minister für öffentliche Arbeiten von 1891, ibid. Bl. 16. 
ergebenden Interessen der Arbeiter an Schutz und Versicherung Rechnung zu tragen versuchte ${ }^{123}$. Insofern machte sich Virchow im Sinne Schulze-Delitzschs zum Advokaten einer behutsam staatsfernen Sozialpolitik, die dabei nicht sozialreformerisch oder revolutionär ambitioniert war.

Auch Nachweise für Schulze-Delitzschs nationale Loyalität mühte sich Virchow beizubringen, indem er die von ihm unterstützte Gründung des Deutschen Nationalvereins 1859 und zwei Jahre später der Deutschen Fortschrittspartei mit dem Kontext einer »Zeit tiefer Erniedrigung des nationalen Bewußtseins" motivierte, der eine Schubphase des deutschen Nationalismus unter dem Eindruck der italienischen Einheitsstaatsbildung folgte und die auch Schulze-Delitzsch veranlaßt hatte, die Forderung nach einem deutschen Nationalstaat unter preußischer Führung zum vordringlichen Programm des politischen Vereins zu machen ${ }^{124}$. Die $) E i n h e i t$ des Vaterlandes unter Grundlegung freiheitlicher Entwickelung« identifizierte er als politisches Primat SchulzeDelitzschs und erinnerte so zugleich den liberalen Grundkonsens, demzufolge in der Tat die Nationalstaatsbildung zeitlich vor der Liberalisierung des politischen Systems stand, ohne das Bekenntnis zur Freiheit obsolet zu machen. Die Eigengewichtigkeit dieses zweiten, lediglich chronologisch nachgeordneten Ziels wollte Virchow indessen nicht eigens betonen ${ }^{125}$.

Indem Virchow als Apologet einer von konservativer Seite inkriminierten Figur auftrat, erschien der linke Liberalismus, für den Schulze-Delitzsch stand, nach wie vor in der Defensive, schien akribische Beweisführung vonnöten, um die Inklusionsberechtigung des Geehrten und seiner politischen Anhänger in die Nation zu dokumentieren. Schulze-Delitzschs sozialpolitisches Engagement verstand Virchow kaum als produktiven Beitrag zur Gestaltung der nationalen Binnenordnung zu würdigen, sondern blieb damit beschäftigt, es je neu gegen den Vorwurf der »ungesetzliche[n] Agitation « zu verteidigen ${ }^{126}$.

Ähnlich wie im Rahmen der Waldeck-Feiern dokumentierte Virchows Rede, daß ein gewichtiger Teil des liberalen Erbes, die Idee der freiheitlich-liberalen Durchformung des einmal gegründeten, preußisch geleiteten Einheitsstaates, nach 1870/71 nicht nur nicht eingelöst worden war, sondern auch die Erinnerung daran nicht offensiv wachgehalten wurde. Sie zeigte umgekehrt aber auch, daß der Anspruch auf nationale Ehrung ungeachtet solcher Defensivpositionen öffentlich erfolgreich angemeldet worden war, mithin der Liberalismus mit dem Standbild für Schulze-Delitzsch Symbolmacht in der Kapitale errungen hatte. Selbstbewußter als Virchow machte sich der Berliner Oberbürgermeister Martin Kirschner zum vehementen Interpreten eines eigenen libe-

${ }^{123}$ VZ, 4. August 1899 (B. der A.), S. 5; Freisinnige Zeitung, 5. August 1899, S. 1.

${ }^{124}$ Vgl. ibid. Vgl, zum Kontext Andreas BIEFANG, Die Deutsche Fortschrittspartei in Preußen 1861-1867. National-preußisch oder deutsch-national?, in: GG 27 (1997) S. 361-384.

${ }^{125}$ VZ, 4. August 1899 (B. der A.), S. 5; Freisinnige Zeitung, 5. August 1899, S. 1.

${ }^{126} \mathrm{Vgl}$. ibid. 
ralen Traditionsanteils an der Nation, indem er Schulze-Delitzsch als Protagonisten des auf die nationale Einheit setzenden Nationalvereins wie der Fortschrittspartei und nachgerade als "Mitbegründer des Deutschen Reiches ${ }^{127}$ apostrophierte. Anders als sein Vorredner behauptete Kirschner damit die historisch konstitutive Rolle des politischen Liberalismus bei der Nationalstaatswie der Nationswerdung, ohne diesen Anspruch durch Rechtfertigungstopoi wieder zu verwässern.

Die Vossische Zeitung thematisierte noch einmal den politischen Widerstand gegen das Denkmal, weil »der treue Volksmann als Gegner der Monarchie verdächtigt wurde ${ }^{128}$. Ebensowenig verschwieg der Artikel, daß das obrigkeitliche Plazet zur Errichtung nur unter der Bedingung zu haben war, daß von der ursprünglich vorgesehenen Exponierung auf dem Alexanderplatz zugunsten der Aufstellung an weniger öffentlicher Stelle abgerückt wurde ${ }^{129}$. Daß die »alten Gegner von der Rechten « selbst dann noch die Errichtung nur widerwillig zur Kenntnis nahmen, wurde nicht ganz ohne Häme unterstellt und zum Zeichen verhaltenen Triumphes die erzwungene Standortverlegung zur durchaus willkommenen topographischen Zusatzsymbolik umgedeutet, indem im Köpenicker Stadtviertel mit seinem hohen Anteil an Handwerkern und Arbeitern eben genau diejenigen Menschen in der Nähe des Denkmals lebten, deren Daseinsbedingungen im Zentrum von Schulze-Delitzschs Politik gestanden hätten. Der Abgrenzung gegen den Konservativismus, die der Artikel bis dahin vollzogen hatte, folgte die gegenüber der politischen Linken, denn Schulze-Delitzsch stand der Vossischen zufolge auch für den Kampf der Fortschrittspartei "gegen Sozialdemokratie und Staatssozialismus«, gegen »Lohngesetz[e]《 und »Staatskredit[e]« als Symptome eines abgelehnten Interventionismus, demgegenüber Schulze-Delitzsch auf eine ökonomisch selbständige, am bürgerlichen Ideal orientierte und als verbürgerlichte auch politisch partizipationsberechtigte Arbeiterschaft zählte. Zum »Allheilmittel« des »allgemeinen Wahlrecht[s] « und also barrierefreier Massendemokratisierung ging die Vossische im Namen Schulze-Delitzschs auf Abstand ${ }^{130}$. Auf dem Hintergrund dieser politischen Abgrenzungen nach rechts und links erhielt die These vom Status Schulze-Delitzschs als Repräsentant der Nation eine exklusive Dimension, mündete nämlich in die unmittelbare Verknüpfung von Nation und Liberalismus, während "sozialdemokratische Demagogie« und »gewaltthätige Reaktion« gleichermaßen ausfielen.

Am Tag nach der Denkmaleinweihung setzte die Vossische ihre triumphierende Bilanz fort:

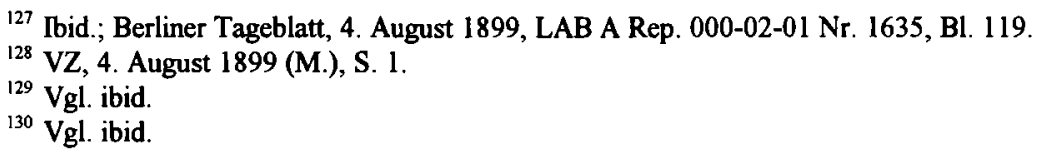


Wo sind die Standbilder konservativer Staatsvertreter? Wer wollte heute behaupten, auch nur einer von den Parlamentariern, die einst im Vordertreffen gegen den Liberalismus gestanden haben, habe solche Verdienste um das Vaterland, und um das Volk, daß ihm ein Denkmal gebühre? Die meisten der konservativen Abgeordneten seit einem halben Jahrhundert, die einst in der Verfolgungswuth gegen den Liberalismus einander überboten, sind vergessen. (...) Dagegen gehören nicht wenige der Männer, die auf der Linken gestanden, der Geschichte an ${ }^{131}$.

Die Errichtung des Schulze-Delitzsch-Denkmals erwies sich somit als Initialmoment für eine Art von (symbol)politischer Generalabrechnung mit dem Konservativismus. Zur freilich verfrühten Ankündigung symbolischer Übertrumpfung kamen massive Anschuldigungen gegen eine konservative Politik, die seit langem von "Widersacher[n] des Liberalismus« betrieben worden sei und das "freiheitliche Bürgerthum (...) schnöden Verfolgungen« ausgesetzt habe $^{132}$. Demgegenüber sah das Blatt mit dem Schulze-Delitzsch-Denkmal nun immerhin eine nachholende "Gleichberechtigung des liberalen Bürgerthums mit den regierenden Parteien « vollzogen ${ }^{133}$. Die Denkmalerrichtung diente hier dazu, die memoriale und tagespolitische Inklusion des Liberalismus in die ungebrochen machtstaatlich-monarchisch, zugleich aber im Blick auf inneren »Frieden« und das »Volkswohl« hin definierte Nation verbindlich einzukla$\operatorname{gen}^{134}$.

Der sozialdemokratische Vorwärts schließlich war anders als die Vossische nicht bereit, die mehrfache Vereitelung der Denkmalaufstellung durch staatliche und städtische Behörden zum am Ende doch noch erreichten Symbolvorteil umzudeuten. Statt dessen entlarvte er das langatmige Entscheidungsverfahren als Symptom für die unveränderte Intransigenz einer zutiefst antiliberalen Regierung, die die unliebsamen Sinnstifter auf »einen der bescheidensten und unscheinbarsten Plätze, die in Berlin zu finden waren«, abzudrängen verstanden hatte ${ }^{135}$. Seit der weitgehenden Verdrängung des Denkmals für Waldeck, das auf Betreiben des Staates nurmehr auf »einer jener umgitterten Todteninseln im flutenden Großstadt-Verkehr ${ }^{136}$ auf dem Jacobifriedhof untergekommen war, hatte sich der düsteren Einschätzung des Vorwärts zufolge die Symbolmacht des Linksliberalismus mit dem Schulze-Delitzsch-Denkmal nur geringfuigig verbessert. Der Kritik an den »regierenden Schichten« entsprach nach der linken Seite hin Versöhnungswille. Hier demonstrierte der Vorwärts nun souveräne Distanz zu den alten Überwerfungen zwischen Linksliberalen und Sozialdemokraten, die er unaufgeregt revidierte:

Nachdem einmal der trennende Schnitt zwischen dem oppositionellen Bürgertum und den klassen-zielbewußten Arbeitem vollzogen war, nachdem ein Rückfall der politisch thätigen Ar-

${ }^{131}$ VZ, 5. August 1899 (M.), S. 1.

${ }^{132} \mathrm{Vgl}$. ibid.

${ }^{133}$ Vgl. ibid.

${ }^{134}$ Vgl. ähnlich NZ, 4. August 1899 (A.), S. 1; Freisinnige Zeitung, 4. August 1899, S. 1.

${ }^{135}$ Vgl. Vorwärts, 5. August 1899 (B.), S. I; ibid. 4. August 1899, S. 1 [Max SCHIPPEL].

${ }^{136} \mathrm{Ibid}$. 
beiterschichten in einlullende manchesterliche Einbildungen niemals mehr zu befürchten war, konnte man auch die Bedeutung der liberalen Opposition und der liberalen Wirtschaftsbestrebungen für das politische und wirtschaftliche Leben Deutschlands zutreffender einschätzen ${ }^{137}$.

Gerade die Verankerung der Sozialdemokratie als Interessenvertretung der »Arbeiter" und Hort sozialrevolutionärer Reformvisionen bildete demnach die Voraussetzung für einen anerkennenden Blick auf den genuinen historischen Beitrag des liberalen Bürgertums zur Konstituierung der Nation, den der Vorwärts nun hinsichtlich Schulze-Delitzschs mindestens ebensosehr schärfte, wie dies die Vossische Zeitung getan hatte. Schulze-Delitzschs Agitation für das freie Koalitionsrecht in Preußen, sein Eintreten »gegen jede Minderung der Volksrechte im Parlament und die Festschreibung von "Grundrechten« in der Verfassung ${ }^{138}$ galten dem Vorwärts als untrügliche Bekundungen freiheitlichdemokratischer Grundüberzeugungen, die er bereit war, auf große Teile der oppositionellen liberalen Nationalbewegung mindestens vor der Reichsgründung gleichsam hochzurechnen und ihr ein entsprechendes Verdienst um eine eigenständige Tradition des Liberalismus in der Geschichte der Nation zu bezeugen ${ }^{139}$.

Sozialpolitische Impulse versuchten schließlich auch Ende Juni 1910 die Errichter und Zelebranten des Denkmals für Rudolf Virchow zu transportieren. Den Pathologen und Politiker hatten schon zu Lebzeiten die Berliner Stadtverordnetenversammlung ${ }^{140}$ wie die unter seiner Mitwirkung gegründete Deutschen Fortschrittspartei als Vertreter der »Volksrechte« und »Volksfreiheiten« gefeiert $^{141}$ und noch ein Jahr vor seinem Tod war ihm bereits eine Büste im Pathologischen Institut von Berlin gewidmet worden ${ }^{142}$. Nun komplettierte den Virchow-Kult ein öffentliches Denkmal auf dem Karlsplatz an der Kreuzung von Luisen- und Charité-Straße nördlich des Brandenburger Tors und der Spree $^{143}$.

${ }^{137}$ Ibid. Vgl, auch Die Hilfe, 13. August 1899, S. 3.

${ }^{138} \mathrm{Vgl}$. Vorwärts, 5. August 1899 (B.), S. 1; ibid. 4. August 1899, S. 1.

${ }^{139} \mathrm{Vgl}$. auch Eugen RICHTER, Schulze-Delitzsch. Ein Lebensbild, zur Denkmals-Enthüllung verfasst, Berlin 1899, passim, hier S. 5-6, 9-10. Zurückhaltend NPKZ, 4. August 1899, S. 2; ibid. 23. Januar 1891, LAB A Rep. 000-02-01 Nr. 2365, Bl. 65-65 Rs.

${ }^{140}$ Vgl. Vorwärts, 21. Oktober 1899 (1. B.), S. 1.

${ }^{14 l} \mathrm{Vgl}$. VZ, 7. November 1892 (1. B.), S. 1.

${ }^{142}$ Vgl. Freisinnige Zeitung, 13. Oktober 1901 (1. Bbl.), S. 2; ibid. 15. Oktober 1901 (Bbl.), S. 1 .

${ }^{143}$ Vgl. NPKZ, 29. Juni 1910, S. 2; VZ, 29. Juni 1910 (A.), S. 3-4. Unter den Festgästen vertreten waren der konservative Kultusminister August von Trott zu Solz, fast die gesamte medizinische Fakultät der Universität, der Generalstabsarzt der Armee und Mitglieder der Kaiser-Wilhelm-Akademie sowie Repräsentanten zahlreicher ärztlicher Gesellschaften und Krankenhäuser, der Berliner Oberbürgermeister Kirschner, mehrere Stadtverordnete und einige studentische Korporationen, während der Reichskanzler sich durch einen Unterstaatssekretär vertreten ließ. 
Vereinzelt versuchten Komiteemitglieder im Rahmen ihrer Redebeiträge zum Einweihungsfest, eine eindeutige Politisierung zu meiden, und zogen sich dann auf die Würdigung des Militärarztes und Mediziners an der Charité zurück $^{144}$. Der Stadtverordnete Paul Michelet hob demgegenüber auf das politische Profil Virchows ab, erwähnte seine Teilnahme an den revolutionären Ereignissen in Berlin 1848 und an der Agitation für eine gleichsam sozialpolitisierte Medizin, die ihm berufliche Benachteiligung eintrug, sowie sein Engagement in der Stadtverordnetenversammlung seit $1859^{145}$. Nationalpolitisches Profil gewann die Figur Michelet zufolge aber vor allem im Zusammenhang mit seiner Involvierung in den preußischen Verfassungskonflikt, die Virchow nicht anders als Schultze-Delitzsch gegen die kompromißbereiten Altliberalen aufbegehren, Parlamentsrechte einfordern und schließlich zur Parteigründung voranschreiten ließ, nach der Virchow wiederholt als Bismarck-Kritiker auftrat. Mitgliedschaft im Abgeordnetenhaus und im Reichstag komplettierten das Bild des Protagonisten der nicht für eine barrierefreie Demokratisierung, wohl aber für eine sozialreformerische Daseinsvorsorge-Politik eingetreten war ${ }^{146}$.

Michelet schien gleichwohl in seiner Rede nicht auf Polarisierung bedacht, denn er umging den Hinweis darauf, daß zu Virchows liberalem Profil auch seine ureigene Prägung des »Kulturkampf «-Begriffs und mithin jene politische Strategie zählte, derzufolge der Katholizismus theokratisch-irrationaler Rückwärtsorientierung geziehen und aus der dezidiert protestantischen Nation herausdefiniert werden sollte. Virchow stand statt dessen infolge glättender Auslassung nicht nur für einen fortschrittlich-reformatorischen Wissenschafts- und Medizinbegriff; das Zitat seines Plädoyers für medizinische Prophylaxe und öffentliche Gesundheitsfürsorge wurde zur Metapher für Inklusion und Partizipation und für die Übertragung von Mitverantwortung und Kompetenz an eine erst noch zu integrierende Bevölkerung.

Im Projektstadium verharrte zumindest bis vor dem Krieg demgegenüber der Plan, der langjährigen Leitfigur der Deutschen Fortschrittspartei bzw. seit 1893 der Freisinnigen Volkspartei Eugen Richer ein Denkmal zu setzen ${ }^{147}$. Mit der Stadt konnte immerhin bereits eine Einigung dahingehend erzielt werden, $\mathrm{da} ß$ der Askanische Platz weit südlich von Tiergarten und Brandenburger Tor als Standort anvisiert werden sollte. Auch lagen bereits 1909 Zustimmungen des Polizeipräsidenten und des Monarchen vor ${ }^{148}$.

${ }^{144}$ Vgl. Christian ANDREE, Rudolf Virchow, in: Wilhelm TREUE, Ralf WINAU (Hg.) Berlinische Lebensbilder, Bd. 2: Mediziner, Berlin 1987, S. 175-190.

${ }^{145}$ Vgl. VZ, 29. Juni 1910 (A.), S. 3-4.

${ }^{146} \mathrm{Vgl}$. dazu auch DAUM, Wissenschaftspopularisierung im 19. Jahrhundert, S. 446.

${ }^{147}$ Vgl. Notiz aus der Reichskanzlei vom 20. November 1908, BArch R 43/2389, Bl. 208.

${ }^{148} \mathrm{Vgl}$. Schreiben des Magistrats an den geschäftsführenden Denkmalausschuß, 18. September 1908, GStA PK I. HA Rep. 77 Tit. 151 Nr. 15 Fasz. 49, BI. 3. An der Spitze des Ausschusses hatte sich der Vorsitzende des Geschäftsführenden Ausschusses der Freisinnigen Volkspartei und Redakteur der Freisinnigen Zeitung Herrmann Müller-Sagan für den 
Danach stagnierte das Vorhaben komplett, so daß es erst 1914 wieder im preußischen Abgeordnetenhaus thematisiert wurde. Für die Sozialdemokraten äußerte hier Karl Liebknecht den Verdacht, daß es inzwischen nun doch Bestrebungen von offizieller Seite gebe, die Denkmalfigur aufgrund politischer Ressentiments zu marginalisieren und nicht länger die Mitte des Askanischen Platzes für die Aufstellung vorzusehen, sondern einen unscheinbaren "Winkel« des Platzes ${ }^{149}$. Liebknecht legte Wert auf den Umstand, daß die Sozialdemokratie als unmittelbarer politischer Konkurrent der Freisinnigen am Rand des linken Parteienspektrums keine Ambition hege, sich zu Richters Fürsprecherin zu machen, während sie sich umgekehrt offenkundig veranlaßt sah, lauten Widerspruch gegen den Versuch der symbolischen Abdrängung des "Oppositionsmann[es]« einzulegen und den reaktionären »Polizeigeist« anzuprangern, der hinter den neuen Obstruktionsversuchen zu stecken schien. Mit Liebknechts Klage verloren sich die Spuren der Initiative, die jedenfalls bis zum Krieg nicht mehr erfolgreich abgeschlossen werden konnte. Daß Richter während seiner langen politischen Karriere nicht nur als profilierter Linksliberaler, sondern auch als dezidierter Kaiserkritiker aufgetreten war, indem er der Monarchie eine krypto-absolutistische Tendenz unterstellte, hatte den Kaiser zwar von einem ersten Plazet nicht abgehalten, minderte indessen langfristig nicht den Argwohn gegen eine Figur, die auch namens der Partei provokant offen für Parlamentarismus und Anti-Militarismus eingetreten war $^{150}$. Einer Manifestation liberaler Symbolmacht in der Berliner Denkmallandschaft standen insofern bis 1914 je neu staatlich-autoritäre Verhinderungstaktiken entgegen, ohne daß sie deshalb ganz hätte unterbunden werden können.

Plan eingesetzt. Vgl. zur Zustimmung von 1909 Mitteilung des Ministers für öffentliche Arbeiten von Breitenbach und des Innenministers von Moltke an den Geheimen Kabinettsrat von Valentini, 16. Februar 1909, ibid. Bl. 8 und Bescheid Wilhelms II. vom 12. März 1909, ibid. Bl. 9.

${ }^{149} \mathrm{Vgl}$. Ausschnitt aus der Sitzung des Hauses der Abgeordneten am 19. Februar 1914 (2. Session), GStA PK I. HA Rep. 93 B Nr. 2366, Bl. 138.

${ }^{150}$ Vgl. Bernd SOSEMANN, Der Verfall des Kaisergedankens im Ersten Weltkrieg, in: RÖHL, Der Ort Kaiser Wilhelms II, S. 145-170, hier S. 149; HETTLING, Politische Bürgerlichkeit, S. 286-287. 


\section{London: Zwischen liberaler Konsensformel und konservativen Übergriffen}

\subsection{Monumentale Voten des politischen Liberalismus}

Die Verankerung des politischen Liberalismus im parlamentarischen System Englands schlug sich nicht automatisch in einer sympolpolitischen Dominanz auf dem Londoner Denkmalterrain nieder. Im Falle eines ersten PalmerstonMonuments jedenfalls mißlangen sowohl die Kultgeste als auch jeder Popularisierungseffekt, während erst deutlich später, nach der Jahrhundertwende, ein weiteres Denkmal für Gladstone mit spezifischen Nationsentwürfen aufwarten konnte.

Im Februar 1878 wurde nun zunächst die Statue für Viscount Palmerston auf dem Parliament Square aufgestellt, mithin für einen ausgewiesenen Exponenten des politischen Liberalismus, der sich über zehn Jahre hinweg bis 1865 fast ununterbrochen als liberaler Premier, zuvor als langjähriger Secretary at War bis Ende der 1820er Jahre und schließlich - mit Ausnahme der konservativen Peel-Administration zwischen 1841 und 1846 - seit 1830 und bis zu seiner Entlassung 1851 als Außenminister profiliert hatte. Weil eine öffentliche Inszenierung unterblieb, nahm die Presse indessen kaum Notiz vom neuen Denkmal $^{151}$. Der Frage, warum eine rituell aufwendigere Übergabe an die Öffentlichkeit vermieden wurde, entzog man sich gemeinhin. Ansonsten sah der Evening Standard in Palmerston die whonour of England" und den "pride in the greatness of the empire « verkörpert und assoziierte mit dem neuen "national monument« die Nation als weltweit dominantes Kolonialreich und interventionistische Macht zugunsten der modernen westlichen Verfassungsstaaten. Jenseits aller Kontroversen verschaffte dies dem Evening Standard zufolge Palmerston den Status der vimpersonation of national feeling, which Liberal statesmanship must once more embody if it is to have the guidance and confidence of the people ${ }^{152}$.

Außer der geringen Anteilnahme der Presse an der öffentlichen Denkmalaufstellung deutete auch ein im zeitlichen Umfeld der Denkmalinitiative entstandenes Pamphlet eines dänischen Autors auf das äußerst umstrittene Prestige Palmerstons, das den Versuch seiner Stilisierung zur nationalen Konsensfigur beeinträchtigen mußte. Vorrangig stand dort Palmerstons Haltung zur

${ }^{151}$ Vgl. The Evening Standard, 3. Februar 1876, S. 8. Bereits im Juni 1869 hatte eine erste Probeaufstellung der Palmerston-Statue am Standort stattgefunden; vgl. Lloyd's Weekly Newspaper, 20. Juni 1869, S. 7. Daß fast 10 Jahre bis zur definitiven Errichtung vergingen, deutet auf Mißhelligkeiten hin, die auch die liberale Gladstone-Regierung nicht zu beseitigen vermochte.

${ }^{152} \mathrm{Vgl}$. The Evening Standard, 3. Februar 1876, S. 8. 
Schleswig-Holstein-Frage in der Kritik. Daß er sich in seiner Eigenschaft als Premierminister im dänisch-deutschen Krieg 1864 neutral verhielt, obgleich Großbritannien im Londoner Protokoll von 1852 als Garantiemacht für die dänische Gesamtmonarchie aufgetreten war, und daß er nach der dänischen Inkorporation der beiden Herzogtümer 1863 ein Jahr später deren Annexion durch Preußen in Kauf nahm, wurde als politischer Verrat, diplomatisches "mismanagement« und fatale Prinzipienlosigkeit auswärtiger Politik gebrandmarkt ${ }^{153}$. Mit der Pointe des Arguments - „The Palmerston Monument erected from the ruins of the destroyed Danish Monarchy« hatte der Autor sein Pamphlet folgerichtig betitelt ${ }^{154}$.

Indem Palmerstons Rolle als Außenminister während der 1830er Jahre völlig übergangen und so etwa auch seine aktive Unterstützungspolitik für Belgien und zugunsten der südeuropäischen Verfassungsstaaten unbeachtet blieb, war der Autor nicht bereit, diesen frühen Interventionismus als Indiz für ein am Ideal des liberalen Verfassungsstaates orientiertes Nationskonzept anzuerkennen. Sofern sich neben dem kritischen auswärtigen Votum die britische Presse nicht eigens zum Denkmal vernehmen ließ und der Inszenierungsverzicht den Stiftern jede Chance auf programmatische Erklärungen nahm; erschien die Palmerston-Figur mehr denn je von einem Kultstatus entfernt.

Zeremoniell aufwendiger und erstmals konzeptionell konkreter nahm sich erst ein Anfang November 1905, zwei Jahre nach der Ehrung in Westminster Abbey ${ }^{155}$, entstandenes Denkmal für den mehrfachen und langjährigen liberalen Premier William E. Gladstone aus, das am östlichen Ende von The Strand nahe den Royal Courts of Justice an prominenter Stelle plaziert wurde ${ }^{156}$. Zur vor allem von namhaften Liberalen geprägten Festgesellschaft, die unter einer etwa 600 bis 700 Personen überwölbenden Überdachung Platz genommen hatte, während das "less privileged folk ${ }^{157}$ in Reihen vor den Barrieren ausharrte, mit denen die Ordnungskräfte den Denkmalplatz abgesperrt hatten, zählte auch eine Gruppe von innerparteilichen Home Rule-Gegnern, die sich über der Irlandfrage mit Gladstone überworfen hatten ${ }^{158}$. Während sich offizi-

${ }^{153}$ Vgl. Constant DIRCKnNCK-HOLMFELD, The Palmerston Monument erected from the ruins of the destroyed Danish Monarchy, Hamburg 1864, S. IV-VI, VII und S. 10.

${ }^{154} \mathrm{Vgl}$. ibid. S. 1

iss Vgl. READ, Victorian Sculpture, S. 466. Weitere Statuen oder Büsten entstanden u.a. in Manchester, Glasgow, Liverpool, Oxford und Edinburgh; vgl. ibid. S. 172, 369, 439, 455, 467f.

${ }^{156} \mathrm{Vgl}$. The Manchester Guardian, 6. November 1905, S. 7-8, hier S. 7; Lloyd's Weekly Newpspaper, 5. November 1905, S. 1; The Standard, 6. November 1905, S. 9; Evening Standard and St. James's Gazette, 4. November 1905, S. 9.

157 Vgl. Lloyd's Weekly Newspaper, 5. November 1905, S. 1.

${ }^{158}$ Dazu zählten Duke of Devonshire (i.e. Spencer Compton Cavendish, Marquess of Hartington) und der Liberale Leonard Courtney. Anwesend waren auch die ehemaligen Gladstone-Kabinettsmitglieder W. Forster, Shaw-Lefevre, der Liberal Imperialist Lord Rosebery und der Radical Sir C. Dilke, der Lord Mayor von London, der Vorsitzende des LCC 
elle Vertreter der konservativen Regierung Balfour nicht einfanden, waren durchaus einzelne konservative Parlamentarier, daneben Repräsentanten der Kirche und der metropolitanen Gesellschaft erschienen.

Der Unionist und Enkel Sir Robert Peels, William Robert W. Peel, definierte Gladstone als parteiübergreifende "national possession « und sein Denkmal folglich als "national monument ${ }^{159}$. In ähnlicher Absicht gewann der ehemalige liberale Irlandminister John Morley dem Standort die neue Qualität ab, nun nicht nur an exklusiven politischen oder sakrosankten Stätten, sondern mitten in der City, win one of the greatest centres of commerce, the centre of the financial world« Gladstones Verdienst um die politisch-soziale und ökonomisch-materielle Verankerung der nationalen Ordnung zu manifestieren ${ }^{160}$. Indem er ihm neben Effizienz und rhetorischem Talent vor allem die Fähigkeit bescheinigte, "great multitudes of men« zu erreichen, hob Morley auf Gladstones legendäre öffentliche Redekampagnen und Appelle an die außerparlamentarische Öffentlichkeit ab, mit denen neuen Kommunikationsformen der allmählich verankerten Massendemokratie Rechnung getragen worden war. Morley deutete sie als eine Art diskursives Inklusionsangebot, das Gladstone der nationalen Öffentlichkeit zu unterbreiten schien, betonte dann aber umso mehr, daß der Premier nicht zum Spielball der "public opinion« geworden sei, sondern sich umgekehrt immer auf ihre mindestens rhetorische Domestizierung verstanden habe.

Neben der ökonomisch fortschrittlichen und gemäßigt-demokratischen Nation stand Gladstone Morleys Ausführungen zufolge drittens auch für eine pazifistische, den konstitutionellen Liberalismus befördernde Weltordnung ein, indem er einen "splendid fight and struggle for freedom « fuihrte, der ihn etwa Mitte der 1870 er Jahre für die von der Türkei unterdrückten Bulgaren eintreten lie $B^{161}$. Daß Gladstone diese moralisch anspruchsvolle liberale Prinzipienpolitik die massive Gegnerschaft nicht nur des Disraelischen Konservativismus, sondern auch Anfeindungen innerhalb der eigenen Partei eintrug, ließ Morley unberücksichtigt. Schließlich firmierte Gladstone als Exempel des "great Christian man $\aleph^{162}$ und bezeugte damit die moralisch-religiöse Konnotation und wertkonservative Grundorientierung, die sich in seiner Gestalt mit der Nation verband. $\mathrm{Da} \beta$ er darüber hinaus für eine besondere Affinität zur anglikanischen Church of England stand, wollte Morley so klar nicht ausführen, um hier Exklusionen schon allein in den eigenen - auch nonkonformistischen - Reihen der Liberalen Partei zu vermeiden.

Sir Edwin Comwall, der Schriftsteller Frederic Harrison sowie zwei Geistliche. Die Enthüllung fand unter Glockengeläut der naheliegenden St. Clement Dane's Church statt.

159 The Manchester Guardian, 6. November 1905, S. 7.

160 Vgl. ibid. S. 8.

${ }^{161}$ Vgl. ibid.

${ }^{162}$ Vgl. ibid. 
Wie zur Beschwörung eines besonderen Konsensbedarfs der Nation, die hier ungeachtet parteipolitischer Fronten einem ihrer Repräsentanten huldigen sollte, trat am Ende auch der Duke of Devonshire an, der nicht anders als Lord Peel zu den erbitterten, um Joseph Chamberlain gescharten Gegnern von Gladstones Home Rule Politik in der eigenen Partei gestanden und sich daher Salisbury für eine Allianz von Konservativen und Liberal Unionists angedient hatte ${ }^{163}$. Nicht daß diese irlandpolitische mehr noch als die außenpolitische Konfliktlinie den Liberalismus vor Zerreißproben stellte, sondern die formelhafte Versicherung konfliktresistenter Einmütigkeit im Interesse der "nation « stand im Mittelpunkt von Devonshires Ausführungen ${ }^{164}$.

Selbst außerhalb der liberalen Presse begegnete man der neuen Kultfigur ohne Polemik. Der Manchester Guardian durchschaute zwar, daß die Konsensrhetorik eklektischer Erinnerungsarbeit geschuldet war $^{165}$. Die Umstrittenheit der Figur deutete er aber zum Nachweis dafür um, daß Gladstone die Kernfragen nationaler Politik beim Namen zu nennen und konstruktiven Streit zu provozieren wußte. Den Status des "national hero« erkannte die linke Gazette Gladstone unter diesen Umständen $\mathrm{zu}^{166}$. Eine ähnliche argumentative Balance hielt der konservative Standard, indem er die Apostrophierung des Denkmals als "national monument" mitvollzog, ohne sich den Elogen voll anzuschließen ${ }^{167}$. Honoriert wurde neben Gladstones manipulativem Gespür für den Umgang mit einem Massenpublikum jetzt allerdings auch seine Nähe zur anglikanischen Staatskirche ${ }^{168}$. Eine allzu pazifistische und antiimperialistische Außenpolitik Gladstones ließen den Standard aber rasch auch wieder auf Distanz gehen. Gladstone mochte für eine partizipatorisch-moderne Ordnung der nationalen Gesellschaft stehen, außenpolitisch aber büßte die Nation dem konservativen Votum zufolge unter seiner langjährigen Ägide Effizienz und Machtressourcen in unentschuldbar drastischem Ausmaß ein ${ }^{169}$.

Mit der nachholenden Kultgeste, zu der sich der politische Liberalismus im Rahmen der Denkmalerrichtung für Gladstone verstanden hatte, wurde gleichsam symbolpolitischer Rückstand zu den bis dahin bereits zustandegekommenen konkurrierenden konservativen Inszenienungen ausgeglichen ${ }^{170}$. Die liberalen Denkmalinterpreten freilich hatten Mühe, über parteiinternem Dissens zu einem verbindlichen Nationskonzept zu gelangen. Affinitätsbekenntnisse zu Volk und Religion blieben vordergründig vage, während Freihandels- und Pa-

${ }^{163} \mathrm{Vgl}$. HOPPEN, The Mid-victorian generation, S. 669-670, 681-682.

${ }^{164} \mathrm{Vgl}$. The Manchester Guardian, 6. November 1905, S. 7.

${ }^{165}$ Vgl. ibid. 4. November 1905, S. 7; ibid. 6. November 1905, S. 6.

${ }^{166}$ Vgl. ibid.

${ }^{167}$ Vgl. The Standard, 6. November 1905, S. 6.

${ }^{168}$ Vgl. ibid.

${ }^{169}$ Näher an der inklusiven Rhetorik blieb demgegenüber die Pall Mall Gazette, 6. November 1905, S. 2.

${ }^{170} \mathrm{Vgl}$. dazu das folgende Kapitel IV.3.3. 
zifismusbeschwörungen eine traditionelle Legitimation eines regelrecht urliberalen Nationsbildes betonten. $\mathrm{Da} B$ weder die Irland- noch die imperiale Politik zu Definitionskriterien avancierten, entsprach einer kompensatorischen Argumentationsstrategie, mit der von den tiefen meinungspolitischen Rissen zwischen Home Rulers und Liberal Unionists zum einen, "Pro-Boers" und Liberal Imperialists zum anderen, abgelenkt werden sollte ${ }^{171}$.

Konsensformeln prägten schließlich auch das Prozedere, als Mitte Februar 1911 an prominenter Stelle an der Kreuzung von Whitehall und der Horseguards Avenue nahe dem Kriegsministerium eine Statue für Spencer Compton Cavendish, Marquess of Hartington und Duke of Devonshire errichtet wurde, den zwischenzeitlichen Kriegsminister und Führer der Liberal Unionists und um die Jahrhundertwende Mitglied des konservativen Salisbury-Kabinetts ${ }^{172}$. Zum Festakt hatten sich zahlreiche Zuschauer in Whitehall eingefunden, darunter Politiker der liberalen wie der konservativen Parteien, die meisten von ihnen zugleich auch Subskribenten ${ }^{173}$.

Die kurze Zeremonie bestand letztlich nur aus der Ansprache des irischen Landlords, Kolonialpolitikers und Führers der Konservativen im Oberhaus, Lord Lansdowne. Indem der Duke das ihm angetragene Amt des Premiers mehrfach ablehnte, verkörperte er für Lansdowne ein moralisch aufrichtiges, nicht an Machtpragmatismus, sondern am "public interest« orientiertes Politikverständnis ${ }^{174}$. "A sense of duty to his party « und vor allem "to his country" zum einen, eine "absolute independence of his nature«, die ihn von Zeit zu Zeit auch in Gegensatz zur eigenen Partei gebracht hatte und schließlich "transparent sincerity" statt Taktik-orientierten Handelns, bildeten die Eckpfeiler einer politischen Kultur, für die der Duke of Devonshire den Worten Lansdownes zufolge stand ${ }^{175}$. Der rhetorische Konsens lebte erneut von der Auslassung, und so mühte sich Lansdowne, die Figur so wenig wie möglich mit konkreten Politikinhalten in Verbindung zu bringen. Immerhin hatte der Duke of Devonshire weder Gladstones antitürkische Kampagne während der "Oriental Question « Ende der 1870er Jahre noch die Home Rule-Politik in den folgenden Dekaden mitgetragen und statt dessen die politische Nähe zu den Konservativen gesucht ${ }^{176}$. Daß er dafur durchaus Lansdownes politische Sympathie hatte, wurde nicht offen bekannt.

${ }^{171}$ Vgl. FEUCHTWANGER, Democracy and Empire, S. 231-246.

${ }^{17}$ Vgl. The Daily Telegraph, 15. Februar 1911, S. 13; The Standard, 15. Februar 1911, S. 7; The Manchester Guardian, 15. Februar 1911, S. 10.

${ }^{173}$ Anwesend waren u.a. der spätere Kolonialminister Lewis Harcourt, Salisburys Schwiegersohn, der emphatische Milner-Anhänger, Earl of Selbome, der toryistische Marquis of Londonderry sowie der Gouverneur Ägyptens bis 1907, Viscount Cromer.

174 Vgl. ibid.

${ }^{175}$ Vgl. ibid.

${ }^{176}$ Vgl. FEUCHTWANGER, Democracy and Empire, S. 103, 105, 188. 
Schließlich gelangte auch der politische »Radicalism«, der bereits mit Cobden zu einem monumentalen Vertreter gekommen war, nun noch einmal zu einem Repräsentanten, als Ende Januar 1878 der Philosoph und Parlamentsabgeordnete für Westminster, John Stuart Mill, ein Denkmal am östlichen Ende des Victoria Embankment erhielt ${ }^{177}$. An der mittäglichen Einweihungsfeier nahmen kein einziger Vertreter der konservativen Disraeli-Administration und nur wenige liberale Politiker neben Mitgliedern des Denkmalkomitees sowie Vertretern des MBW teil. In der seltenen, zusätzlichen Teilnahme von Frauen nicht nur an der Initiative, sondern auch am Ritual selbst, spiegelte sich unmittelbar symbolisch wider, daß Mill zwar weniger als Prophet der klassenlosen Bürgergesellschaft denn einer soziokulturellen und moralischen Hegemonie der Mittelklassen aufgetreten war, zugleich aber Emanzipationspostulate zugunsten der Frauen vertreten hatte ${ }^{178}$. Ein Vertreter der Subskribenten nutzte dann auch diesen Umstand, um die im Hinblick auf die Geschlechter inklusive Konzeption der nationalen Gesellschaft zu deuten, die Mill hier repräsentierte ${ }^{179}$. Damit verband sich ein knapper Rekurs auf Mills Schriften zur politischen Ökonomie und Philosophie, die, inzwischen zum festen Kanon akademischer Lehre an den Universitäten Oxford und Cambridge gehörten ${ }^{180}$.

Der linksliberale Abgeordnete Henry Fawcett, der sich zusammen mit Mill im Rahmen der 1865 gegründeten Commons Preservation Society für verbesserte politische Partizipationschancen der Arbeiter engagiert hatte ${ }^{181}$ und Anfang der 1890er Jahre selbst ein Denkmal erhalten sollte, bündelte das Motiv für die Denkmalerrichtung in der Formel, da $B$ wthe people of England had never had a more enlightened advocate, or one who had worked with more disinterested zeal in promoting the true happiness and welfare ${ }^{182}$. Damit redete Fawcett im Namen Mills der demokratisierten Nation das Wort, ohne freilich zu thematisieren, daß Mill wie andere prominente Liberale durchaus an Proporzbarrieren dachte, die eine durch Besitz und Bildung zur politischen Führung der Nation privilegierte Elite weiterhin abschirmen sollte. Im Mittelpunkt stand bei Fawcett vielmehr die Überzeugung von der Notwendigkeit

in Vgl. The Daily Telegraph, 28. Januar 1878, S. 3; The Evening Standard, 26. Januar 1878, S. 5; The Morning Post, 28. Januar 1878, S. 3; The Guardian, 28. Januar 1878, S. 6 :

${ }^{178}$ Unter den Gästen befand sich neben mehreren Liberalen die bereits im Komitee beteiligte Philanthropin und Schrifststellerin Frances Cobbe. Vgl. auch Meeting of the MBW, 26. Oktober 1877, in: Minutes of Proceeding of the MBW Juli-Dezember 1877, 461/33. Der zeremonielle Rahmen blieb äußerst bescheiden. Vgl. u.a. The Daily Telegraph, 28. Januar 1878, S. 3.

179 Vgl. The Morning Post, 28. Januar 1878, S. 3; The Guardian, 28. Januar 1878, S. 6.

${ }^{180}$ Vgl. The Evening Standard, 26. Januar 1878, S. 5; The Moming Post, 28. Januar 1878, S. 3; The Times, 28 . Januar 1878, S. 6.

${ }^{181} \mathrm{Vgl}$. Jonathan PARRY, The rise and fall of liberal government in Victorian Britain, New Haven, London 1993, S. 235.

182 The Evening Standard, 26. Januar 1878, S. 5. 
eines umfassenden sozialen und politischen Friedens innerhalb der nationalen Gesellschaft, der gesichert schien, wenn der legitime Verfolg individueller Glücks- und Wohlstandsbestrebungen (»happiness and welfare«) gesamtgesellschaftlich verträglich organisiert war. $\mathrm{Da} B$ der politische Liberalismus nach Ansicht Mills berufen war, der politisch reformierten, partizipatorischen, wenngleich nicht gänzlich egalitären Nation vorzustehen, klang in Fawcetts Ausfiuhrungen schließlich vage an ${ }^{183}$.

\subsection{Plädoyers für die sozialmoralische Reform}

Mit den verstreut während der beiden Dekaden um die Jahrhundertwende entstandenen Denkmälern für liberale Philanthropen und städtische Reformer fanden monumentale Zeichensetzungen statt, die sich an der Schnittstelle von "national" und "civic culture" befanden, sofern sie Personen betrafen, die entweder - wie im Falle der Denkmäler für Fawcett und Waterlow - für den Zugang der working class zum öffentlichen Raum in Form von öffentlichen Parks und Grünflächen eintraten, oder - so bei den Denkmälern für Lawson und Lord Shaftesbury - auf die moralische Besserung der Unterschichten zielten. Daß dem Reformimpetus nicht nur die Gewährung von Partizipationsrechten, sondern auch das Bestreben zugrundelag, die Inklusionsbedingungen mitzudefinieren, war die weit über die Kapitale hinaus grundlegende Thematik, die die Monumente untereinander verband.

Von nachrangiger öffentlicher Bedeutung blieb dabei zunächst weniger seiner Inszenierung, wohl aber des Standorts wegen das Anfang Juni 1893 nahe seinem ehemaligem Wohnsitz eingeweihte Denkmal für den Linksliberalen und OKkonomen Henry Fawcett in Vauxhall Park, südlich der Themse am Westrand des Stadtteils Lambeth und damit deutlich entfernt von Westminster gelegen ${ }^{184}$. Die Einweihungsfeier begleiteten neben dem Erzbischof von Canterbury und dem Stifter des Denkmals, dem Keramik-Fabrikanten und späteren Präsidenten der Society of Arts, Sir Henry Doulton erneut mehrere Frauen. Dies erklärt sich zum einen mit Fawcetts Engagement für die Berufstätigkeit von Frauen während seiner Zeit als Minister in den 1880er Jahren, zum andern mit dem Erscheinen der Anhängerinnen von Fawcetts Frau Millicent Garrett, die sich in der für Wahlrecht und Bildung kämpfenden Frauenbewegung einen Namen gemacht hatte ${ }^{185}$.

Doulton trat im Zeremoniell gleichermaßen als privater Stifter und Deuter des Denkmals auf und hob auf das Engagement Fawcetts zugunsten des Er-

\footnotetext{
${ }^{183}$ Vgl. The Spectator, 2. Februar 1878, S. 3.

${ }^{184} \mathrm{Vgl}$. The Standard, 8. Juni 1893, S. 5; The Times, 8. Juni 1893, S. 5.

${ }^{185}$ Vgl. FeUCHTWANGER, Democracy and Empire, S. 335.
} 
halts und Ausbaus von öffentlich zugänglichen Rekreationsflächen im Londoner Stadtbereich ab. Damit bezog er sich auf jene Initiative liberaler Backbencher seit Mitte der 1860er Jahre, in deren Zuge sich Fawcett einer Commons Preservation Society ${ }^{186}$ angeschlossen hatte, die sich Arbeiterinteressen zu eigen machte, indem sie aus gesundheits- und gleichsam freizeitpolitischen Gründen gegen die Beseitigung von öffentlichen Parkflächen in London agitierte und zahlreiche Gerichtsverfahren zugunsten von deren Erhalt erfolgreich bestritt, später durch ihre namhaften Vertreter auch eine entsprechende Gesetzgebung zum Schutz städtischer Grünanlagen hatte lancieren können ${ }^{187}$.

Der Erzbischof von Canterbury belobigte daneben Fawcetts Einsatz zugunsten der Einfuihrung allgemeiner Schulpflicht, unterließ allerdings um einer versöhnlichen Laudatio willen den Hinweis darauf, daß sich Fawcett in der Tat immer an einem nicht-klerikalen Unterrichtswesen interessiert gezeigt hatte, und deutete sein Engagement statt dessen als Partizipationsprogramm zugunsten der »working classes ${ }^{188}$. Während das Presseecho bescheiden blieb, war sich die Times sicher, daß hier ein Monument entstanden war, daß nicht nur für den Stadtteil Lambeth, sondern auch "for the country at large« bedeutsam war ${ }^{189}$. Zwar ordnete sie Fawcett als Liberal Unionist weniger der Gesamtnation als einer ihrer parteipolitischen Fraktionen zu. Den Stoff für eine national und partizipatorisch konnotierte »Fawcett legend" gab das Denkmal gleichwohl her, indem es daran erinnerte, daß deren Protagonist auf der Seite der "people« gestanden und in ihrem Namen politisch gehandelt hatte ${ }^{190}$.

Im Sommer 1900 folgte noch zu Lebzeiten des Geehrten ein Denkmal für den ehemaligen Bürgermeister der Stadt und engagierten liberalen Abgeordneten Sidney Waterlow im von ihm gegründeten gleichnamigen Park im nordwestlich gelegenen Londoner Stadtteil Highgate ${ }^{191}$. Die im Beisein von Prinzessin Luise vollzogene Einweihungsfeier stellte auf die Schenkung des Parks

${ }^{186}$ Vgl. ALLEN, The battle for the common, S. 61-65; Neil MACMASTER, The battle for Mousehold Heath 1857-1884: >Popular politics and the Victorian Public Park, in: P\&P 127 (1990) S. 117-154, hier S. 117-120.

${ }^{187}$ Vgl. PARRY, The rise and fall of liberal government, S. 235, 374.

${ }^{188}$ Vgl. The Standard, 8. Juni 1893, S. 5; The Times, 8. Juni 1893, S. 5; Lloyd's Weekly Newspaper, 11. Juni 1893, S. 8. Im August 1890 war die nationale Bildungspolitik bereits mit einem Denkmal für den langjährigen Bildungsminister unter Gladstone, William E. Forster, in den Victoria Embankment Gardens gefeiert worden. Forsters Bildungssystemreform galt als konstitutiver Beitrag zur Binnenausstattung der Empire-Nation. Vgl. The Times, 2. August 1890, S. 5; The Standard, 2. August 1890, S. 3. Bildungspolitischer Fortschritt bereicherte dem Topos zufolge die intellektuelle wie moralische Qualifikation eines Volkes, das zu imperialer Macht berufen schien.

${ }^{189} \mathrm{Vgl}$. The Times, 8. Juni 1893, S. 9.

${ }^{190}$ Vgl. ibid.

${ }^{191}$ Vgl. Waterlow Park. Ceremony of Unveiling of the statue subscribed for by Inhabitants of London to Sir Sidney Hedley Waterlow, Bart., in recognition of his gift to them of the Park, London 1900 (LCC), passim. 
durch Waterlow an den LCC im Oktober $1891 \mathrm{ab}$, durch die sich Waterlow als Philanthrop erwiesen hatte, der sich mit der "weekly-wage class» und den "poorer people of London« solidarisierte und als Inkarnation der mimprovement《- und »open spaces«-Bewegung firmierte, indem die Stiftung als »one of the best methods for improving and elevating the social and physical condition of the working classes (...), to secure for them an increased number of public parks, recreation grounds, and open spaces « galt $^{192}$.

So wenig die Programmatik der Denkmalstifter in beiden Fällen ein spezifisches Nationsbild ausdrücklich thematisierte, illustrierte sie doch einen über die Belange der Stadt weit hinausgehenden Impetus der Mittelklasse und besonders einzelner finanzkräftiger und patronagewilliger Personen an der Spitze der »open spaces«-Bewegung, die nicht nur den Lebens- und Freizeitstandard der verarmten Unterschichten aufwerten wollte, sondern auch dem Ideal einer egalitär zum öffentlichen Raum zugelassenen Gesamtgesellschaft verpflichtet war. Während in der spärlichen Festrhetorik zwar von der räumlichen Inklusionsidee die Rede war, fehlten Hinweise der Denkmalstifter auf die handfeste Regulierungs- und Domestizierungambition, die sich mit ihr untrennbar verband, hingegen völlig. Unbeachtet blieb daher, daß die "public parks" und "open spaces« nicht zuletzt als Domänen polizeilicher Aufsicht eingerichtet wurden und in London ganz besonders jene Konkurrenzarenen abdrängen oder neubesetzen sollten, die der politische Radikalismus und verschiedene Reformbewegungen zur Propagierung ihrer in der Regel regierungskritischen Politikziele genutzt hatten ${ }^{193}$. Zugleich spiegelten beide Monumente die Reformambition der besitzenden Mittelklasse wider, die seit der Jahrhundertmitte evangelikal oder utilitaristisch motiviert, missionarische, gesundheits- oder wohnungsbaupolitische Anstrengungen unternahm, um der eklatanten Unterversorgung und - wie man anzunehmen geneigt war - moralischen Depravierung der »London poor « entgegenzutreten ${ }^{194}$. Geehrt wurde mithin Personal, das Defensivstrategien verkörperte, mit denen die Unterschichten, die über die gängigen Institutionen der Sozialdisziplinierung wie Kirche oder Bildungseinrichtungen nicht erreichbar waren, nun auf dem Wege einer gezielten Raumpolitik beschwichtigt werden sollten.

Nationale Belange wurden mit den Denkmälern für die sozialreformerischen Liberalen von den Stiftern selbst nur sehr vage assoziiert, während sie gele-

192 Ibid. S. 3-5.

${ }^{193}$ Vgl. TAYLOR, "Common Stealers«, hier S. 385-387. Vgl. zu Frankreich Philip NORD, Social defence and conservative regeneration: the national revival, 1900-1914, in: TOMBS, Nationhood, S. 210-228, hier S. 217.

$194 \mathrm{Vgl}$. Gareth Stedman JONES, Working-class culture and working-class politics in London 1870-1900: Notes on the remaking of a working class, in: DERS., Languages of class. Studies in English working class history, 1832-1982, Cambridge 1982, S. 179-238, hier S. 189-192; Deborah E.B. WIENER, Architecture and social reform in late-Victorian London, Manchester 1994, S. 1-18. 
gentlich auf dem seltenen Wege des Protests auch von außen als Sinnbezug gleichsam erzwungen wurden: Als im Juli 1909 der Liberale Wilfrid Lawson ein Denkmal nahe The Strand, hinter der St. Clement Dane's Church erhielt, zu der vor allem Mitglieder der dem Dissent nahestehenden, radikalliberalen United Kingdom Alliance und andere Abstinenz-Reformer erschienen waren, versuchte eine Gruppe von Suffragetten, mit ihren "Shame on you, Mr. Asquith $\ll-R u f e n$ das vom Premier Herbert $H$. Asquith geleitete Zeremoniell zu kippen ${ }^{195}$. Polizeiinspektoren griffen sofort ein und entfernten die Frauen gewaltsam vom Festort, mußten aber bald darauf erneut gegen eine weitere Demonstrantengruppe einschreiten, die sich zwar außerhalb der Gardens hielt, aber unter fortgesetzten Rufen ein Banner mit der Aufschrift "Votes for women« entrollte. Sogar einen mit der Parole »Demand the Vote« beschrifteten Ballon ließ man langsam am Denkmal vorbeisegeln, so daß das Wahlrechtspostulat zum Mißfallen der Denkmalinitiatoren in den Mittelpunkt der Veranstaltung vordringen konnte ${ }^{196}$.

Asquith indessen, der sich den Zorn der Demonstrantinnen zuzog, weil er sich wie einige seiner Kabinettskollegen seit Jahren intransigent gegenüber der Wahlrechtsforderung verhielt und deshalb schon weit im Vorfeld des Wahlkampfs für die Parlamentswahlen Anfang 1910 zur bevorzugten Zielschreibe des Suffragettenprotests avanciert war, versuchte die Störung zu übergehen und fuhr mit der Denkmalenthüllung fort. Indessen verdankte sich die Intervention nicht der politischen Position Lawsons, sondern einer gegen die Zelebranten und Regierungsmitglieder gerichteten Anfeindung. Asquith dagegen hatte die eigentliche Festrede schon im Rahmen einer Vorversammlung gehalten, bei der er Lawsons Engagement würdigte, der unmäßigen Alkoholkonsum als kurienungsbedürftigen Sekundäreffekt sozialer Probleme auffaßte und mit seiner Reformambition dem liberalen Reform- und evangelikalen selfimprovement-Erbe Englands wie einer umfassenden, parteipolitisch nicht festgelegten Reformidee zuzuordnen war.

Die Resonanz der Presse auf die Feier blieb allerdings äußerst begrenzt ${ }^{197}$. Selbst die Symboldynamik, die die Demonstranten zu entwickeln versucht hatten, blieb ohne besonderen Widerhall. Die Denkmalerrichtungen für die Philanthropen und liberalen Reformer mochten somit am Ende vergleichsweise unscheinbare Zeichensetzungen in der Metropole geblieben sein, sie dokumentierten dessenungeachtet aber den Versuch, Kultexempel und Deutungsmuster zu etablieren, die symbolische Inklusion und sozialdefensive Kontrolle als allgemeines Reformkonzept für eine keineswegs auf London begrenzte Gesellschaft spezifisch miteinander verbanden.

${ }^{195} \mathrm{Vgl}$. ibid

${ }^{196} \mathrm{Vgl}$. ibid.

${ }^{197}$ Vgl. sehr knapp The Standard, 21. Juli 1909, S. 8; The Daily Telegraph, 21. Juli 1909, S. 5 . 
Monumental verhandelt wurde die Binnenkonstitution der nationalen Ordnung schließlich auch $\mathrm{da}$, wo religiös motivierte soziale Interventionen thematisiert wurden, mit denen utilitaristische Laissez-faire-Mechanismen und Individualismus zugunsten der vom allgemeinen Wohlstand Ausgeschlossenen durchbrochen werden sollten. Unter diesen Umständen widmeten seine Anhänger Ende Juni 1893 dem Philanthropen Anthony Ashley Cooper, Lord Shaftesbury, eine von einer Eros-Allegorie überragte Brunnenkonstruktion am Picadilly Circus ${ }^{198}$. Bereits bei ihrem Antrag gegenüber dem MBW, das um Überlassung eines Standorts für das Denkmal ersucht wurde, hatten die Initiatoren 1885 unter dem Vorsitz des Lord Mayor von London und des Liberalen Earl Granville die Programmatik des »national Memorial« entfaltet, das sie zu errichten gedachten:

The long-continued and self-denying efforts of the late Earl of Shaftesbury to promote the material, moral and religious well-being of the neglected, the outcast and the degraded poor of our great cities and the mining and the other centres of industry, entitle him to the grateful recognition of all classes of his countrymen and to a foremost place amongst the honoured and distinguished men, who by their persistent and disinterested labours, have rendered the highest services to their country and to mankind ${ }^{199}$.

In der Begründung klang an, daß der Tory Shaftesbury vor allem während der 1880er Jahre die steigende soziale Ungleichheit der britischen Gesellschaft, Massenarmut und materiell bedingte Segregation in der Hauptstadt wie in der Provinz ins Visier genommen hatte und sich schließlich unter anderem aktiv an einer parteiübergreifend konstituierten Royal Commission beteiligte, die sich Mitte der 1880er Jahre mit dem Wohnungsproblem der Arbeiterklasse beschäftigte $^{200}$. Freilich ließ der moderate Ton der Denkmalstifter erkennen, daß Shaftesbury keinesfalls als Exponent sozialrevolutionärer Politik gehandelt hatte, die ihm in der Tat gänzlich fremd war, sofern er - dem sozialkonservativen Paternalismus seiner Zeit verpflichtet und als Protagonist der evangelikalen Bewegung - Egalitätsdefizite weniger ökonomischen oder sozialen Prozessen als vor allem moralisch-religiöser Depravation geschuldet sah und schon deshalb lediglich fuir ein moderates $\mathrm{MaB}$ an staatlicher Interventionspolitik eintrat ${ }^{201}$.

Anläßlich der Einweihung 1893 knüpften die knappen Ansprachen an den Tenor dieser ersten Verlautbarung von $1885 \mathrm{an}^{202}$. Darüber hinaus folgten Wortbeiträge, die eher gegenseitiger Selbstbestätigung und moralischer Be-

${ }^{198}$ Vgl. zum Folgenden The Daily Telegraph, 30. Juni 1893, S. 6; The Morning Post, 30. Juni 1893, S. 5; The Evening Standard, 29. Juni 1893, S. 1.

199 Resolution passed at a Public Meeting held at Mansion House, on the $16^{\text {th }}$ october 1885 , MBW 584 Presented Papers, Bd. 368, Nr. 40.

${ }^{200} \mathrm{Vgl}$. FEUCHTWANGER, Democracy and Empire, S. 126-128.

${ }^{201}$ Vgl. HII TON, The Age of Atonement, S. 7-35, 95, 212. Vgl. auch [An.,] Lord Shaftesbury and George Peabody. The story of two great public benefactors. London, Edinburgh 1896.

${ }^{202}$ Vgl. FeuchtwaNGER, Democracy and Empire, S. 127. 
stärkung der Initiatoren untereinander galten, indem die Komiteemitglieder Dankesadressen vortrugen, mit denen sie das gemeinsame Engagement belobigten $^{203}$. Identitätsstiftung war hier nicht nur eine propagandistische Zielvorgabe nach außen, sondern auch Teil einer nach innen, auf die Initiatoren selbst gerichteten Deutung, indem soziale Kooperation und Vernetzung auch als Kohäsionszugewinn zugunsten der eigenen Gruppe verbucht wurden ${ }^{204}$. Hier errichtete sich nicht zuletzt die viktorianische "middle class" ein Denkmal, zu deren eigener Statusdefinition innerhalb der nationalen Gesellschaft eine evangelikal motivierte Philanthropie gehörte, die nicht nur auf soziale Distinktion gegenüber den sozial Deklassierten, sondern durchaus auch auf einen genuin eigenen Beitrag zur moralisch-religiösen Verfaßtheit der Nation abhob ${ }^{205}$. Als Kronzeuge für ein sozialrevolutionäres Nationskonzept hingegen wurde Shaftesbury keineswegs zitiert, mithin soziale Ungleichheit als kurierungsbedürftig, nicht aber als Spätfolge der Industrialisierung identifiziert, und der Staat für eine interventionistische Ausgleichspolitik in die Pflicht genommen. Soziale Ungleichheit firmierte schließlich nicht nur als Defizit der nationalen Ordnung, sondern zugleich als das eigentliche Bewährungsfeld des philanthropischen Bürgertums, das auf diese Weise seine moralische Respektabilität unter Beweis stellte.

\subsection{Zur konservativen Aneignung des Nations-Begriffs}

Seit Mitte der 1870er Jahre verfuhr der politische Konservativismus gemessen an den bescheidenen Anfängen zusehends erfolgreicher bei öffentlichen Inszenierungen von national konnotiertem Kultpersonal in London. Programmatisch und diskursiv entsprach diesem Trend eine rasche Okkupation des Nationsbegriffs von dieser Seite her, die sich symbolpolitisch ungleich deutlicher niedergeschlagen hat als in Paris.

Am 11. Juli 1874 wurde eine Statue für den insgesamt drei Mal und zuletzt bis 1868 amtierenden konservativen Premier Lord Edward Stanley und Earl of Derby auf dem Parliament Square errichtet ${ }^{206}$. Zur Feier erschienen neben dem

${ }^{203}$ Vgl. The Daily Telegraph, 30. Juni 1893, S. 6.

${ }^{204}$ Vgl. zum Prozedere zwischen den Komiteemitgliedern etwa The Evening Standard, 29. Juni 1893 , S. 1.

${ }^{205}$ Vgl. Bernd WEISBROD, Philanthropie und bürgerliche Kultur. Zur Sozialgeschichte des viktorianischen Bürgertums, in: Hartmut BERGHOFF, Dieter ZIEGLER (Hg.), Pionier oder Nachzügler? Vergleichende Studien zur Geschichte Großbritanniens und Deutschlands im Zeitalter der Industrialisierung, FS für Sidney Pollard, Bochum 1995, S. 205-220, hier S. 205.

${ }^{206}$ Vgl. zum Folgenden The Standard, 13. Juli 1874, S. 2; The Times, 13. Juli 1874, S. 10; The Daily Telegraph, 13. Juli 1874, S. 3. Eine im Winter 1871 an der Südseite von Holland Park in Kensington aufgestellte Statue für Henry Richard Fox, Baron of Holland 
amtierenden konservativen Premier Benjamin Disraeli zahlreiche Mitglieder aus dessen Kabinett und Unterhausabgeordnete, darüber hinaus u.a. der persische Botschafter sowie ein italienischer und ein türkischer Minister ${ }^{207}$. Damit zeugte bereits die Festversammlung zum einen von einer klaren Dominanz des politischen Konservativismus, zum anderen von dem Versuch, durch die Ladung ausländischer Repräsentanten den Anschein von Internationalität zu erwecken. Bereits hier wirkte eine manipulative Regie der seit Februar des Jahres amtierenden Administration, deren politischer Führer Disraeli sich seit Beginn der 1870er Jahre in Attacken gegen den pazifistischen Liberalismus ergangen und statt dessen ganz auf eine vehemente Empire-Rhetorik gesetzt hatte ${ }^{208}$. Disraeli nahm eine dominante Rolle im Ritus ein, indem ihn ein Empfangskomitee begrüßte, er die Enthüllung des Denkmals selbst vornahm und als prominenter Festredner ein hohes $\mathrm{MaB}$ an Sinnstiftungsautorität ausstrahl$\mathrm{te}^{209}$.

Während die Festszene zunächst auf den Entwurf eines außenpolitischen Nationsprofils hinzudeuten schien, kaprizierten sich die Festrhetorik und weite Teile der öffentlichen Kommentare auf die Gewichtung politisch-sozialer Reformen im Nationskonzept, für das Derby einstand, und ließen zwischenparteiliche Konkurrenz um die Anwartschaft auf einen Reform-zentrierten Nationsbegriff erkennen. Disraeli verknüpfte in seiner Rede Derbys politisches Schicksal eng mit der Geschichte des Landes und der Institution des Parlaments, wo Derby zunächst seit den 1820er Jahren auf Seiten der Whigs gewirkt hatte, bevor er über seinem Dissens mit deren konzessionsbereitdurchlässiger Irlandpolitik in das Lager der Tories übergewechselt war. Disraeli unterstrich die politischen Inhalte, für die der Führer vergleichsweise kurzlebiger konservativer Regierungen gestanden hatte und identifizierte Lord Derby dann zuallererst als großen Wegbereiter der zweiten Wahlrechtsreform von 1867. Indem Disraeli nun zu deren Ziel erklärte, den »working classes of this country ${ }^{210} \mathrm{zu}$ mehr politischer Partizipation verholfen zu haben, suggerierte er, daß dem Konservativen ein erheblicher partizipatorischer Zugewinn zu danken sei.

Zwar spielte Disraeli zu Recht auf das innovative Potential der Reform an, die durch Uniformierung des Parlamentswahlrechts, den Ausgleich des übermäßigen Vertretungsanteils des agrarischen Südens zugunsten der industriellen

(1773-1840), fand ohne öffentliche Inszenierung statt. Vgl. nicht identifizierter Presseartikel, Kensington and Chelsea Libraries, Holl. [up]; The Times, 1. Dezember 1871, S. 6.

${ }^{207}$ Vgl. The Standard, 13. Juli 1874, S. 2; The Times, 13. Juli 1874, S. 10; The Daily Telegraph, 13. Juli 1874, S. 3. Anwesend waren demnach etwa 400 Gäste.

${ }^{208}$ Vgl. u.a. PEARCE, STEWART, British political History, S. 149.

${ }^{209}$ Vgl. The Standard, 13. Juli 1874, S. 2; The Times, 13. Juli 1874, S. 10; The Daily Telegraph, 13. Juli 1874, S. 3.

210 Ibid. 
Städte im Norden und durch die Neugliederung der Wahlkreisstruktur eklatante Mißstände und korruptive Praktiken dauerhaft einzudämmen begann und 1867 in der Tat eine erneute Erhöhung der Zahl der Wahlberechtigten garantierte $^{211}$. Indessen unterließ er es, auf die nach wie vor gültigen Restriktionen hinzuweisen, denen zufolge das Wahlrecht an Grundeigentum oder Kapital gebunden blieb, Partizipationserwartungen also einseitig zugunsten der aufsteigenden industriellen Mittelklasse, aber nur sehr zögerlich zugunsten jener "working classes" erfüllt wurden, von denen propagandistisch die Rede gewesen war. Zugleich verfälschte er die politische Ambition der Reformer, die weniger auf die vollständige Partizipation der nationalen Gesellschaft am politischen System, als auf effiziente Revolutionsprophylaxe durch einen an der ökonomischen Modernisierung orientierten Wandel zielten. Auch blieb außer Acht, daß den konservativen Reformem 1867 nicht zuletzt an der Abdrängung des liberalen Gegners und an der Einwerbung populärer Zustimmung für die Beseitigung des Reformstaus gelegen war $^{212}$.

Disraelis Rede vor dem Lord Derby-Monument war mithin dazu angetan, politischen Reformgeist und ein scheinbar schrankenlos inklusives Nationskonzept als politische Ideale nicht nur Lord Derbys, sondern des Konservativismus im allgemeinen zu dokumentieren. Damit sollte der traditionelle Anspruch des Liberalismus auf eine Art politischen Reformmonopols in Staat und Gesellschaft unterlaufen werden. Andere Redner stellten statt einer programmatischen Deutung Lord Derbys »private virtues« gerade nicht als »common man«, sondern als »landlord« und Intellektueller in den Vordergnund ${ }^{213}$. Insofern wurde der Idee von der inklusiven Nation durchaus das Bild einer Gesellschaft gegenübergestellt, die sich zumindest in Regierungsfunktionen eine sozialmoralisch distinkte Elite leistete.

Die konservative Morning Post feierte zwar den Promotoren des

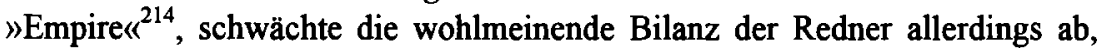
indem er eingestand, daß Lord Derby an der Parlamentsreform wohl im Rahmen einer nachdrücklichen »advocacy«, nicht aber mit der suggerierten Initialfunktion beteiligt war $^{215}$. Dennoch standen er und Disraeli der Überzeugung der Morning Post zufolge für einen modernisierten, flexibilisierten politischen Konservativismus, der zu einer Führungsrolle an der Spitze der Nation ausersehen war, weil er es verstanden habe, wthe desire of the people for steady

211 Vgl. zur Reform Bill von 1832 PARRY, The rise and fall of liberal government, S. 72-94; zum Representation of the People Act von 1867 v.a. Catherine HALL, Keith MCClelland, Jane RENDALl (Hg.), Defining the Victorian nation. Class, race, gender and the British Reform Act of 1867, Cambridge 2000.

${ }^{212} \mathrm{Vgl}$. S. DRESCHER, Whose abolition? Popular pressure and the ending of the British slave trade, in: P\&P 143 (1994) S. 136-166.

${ }^{213} \mathrm{Vgl}$. The Times, 13. Juli 1874, S. 10.

${ }^{214} \mathrm{Vgl}$. The Morning Post, 13. Juli 1874, S. 4.

${ }^{215}$ Vgl. ibid. 
health and progress « und also die Stimme zumindest des wahlberechtigten Volks zum Maßstab politischen Handelns zu machen ${ }^{216}$. Daß der Konservativismus sich hier nicht nur im Sinne der demokratischen Nation öffnete, sondern längst auch dem Druck der mit dem Wahlrecht verbundenen Abstrafmechanismen unterlag und also Flexibilität zumindest auch um der Machterringung und des Machterhalts wegen entwickelt hatte, mochte die Morning Post so nicht herausstellen. Eher umständlich entfaltete das Blatt statt dessen die Vorstellung einer partizipatorisch-inklusiven Nation, indem es zunächst im politischen Engagement des Aristokraten Lord Derby das Symptom für von Aufstiegsambitionen freien politischen Enthusiasmus, in der Karriere des nicht-adligen Disraeli aber den Nachweis kompletter Durchlässigkeit des politischen Systems bis in die elitären Spitzenpositionen zu erkennen glaubte ${ }^{217}$.

Vollmundiger unterstützte der Standard die Disraeli-Rede. Mit der Deutung Lord Derbys als nationaler Figur verband sich dabei anders als in der Morning Post weniger der politische Beifall zur geglückten Flexibilisierung des Konservativismus als die rückwärtsgewandte Beschwörung von Traditionen glorreicher Staatsführung und vor allem die betonte definitorische Inbesitznahme von "patriotic principles« und "England« durch die Konservativen ${ }^{218}$. Auch der liberale Daily Telegraph erachtete die unterschiedliche soziale Abkunft Derbys und Disraelis als Symptom des "free, inter-penetrating political life« und einer politischen Kultur, in der politische Visionen Klassenschranken nivellieren konnten und die mit dieser Qualität ohne wrival among civilised nations« blieb ${ }^{219}$. Das politische Vermächtnis des Lord Derby veranschlagte der Daily Telegraph demgegenüber in weitaus bescheidenerem Rahmen als die konservativen Blätter und attestierte ihm mehr rhetorisches Talent als politische Verdienste ${ }^{220}$. Das genuin liberale Reform-Monopol wollte der Daily Telegraph insofern auch angesichts des Triumphs einer konservativen Regierung wenige Monate zuvor keinesfalls gebrochen sehen.

Die linke Lloyd's Weekly Newspaper schließlich vereinseitigte den in der gesamten Presse angestellten Vergleich zwischen Derby und Disraeli so stark, $\mathrm{da} B$ als Inbegriff der Nation, auf die sich das Blatt positiv zu beziehen versuchte, nicht die Denkmalfigur, sondern der amtierende Premier Disraeli erschien, in dessen Amtsinhaberschaft eine Partizipationsverheißung zu liegen schien $^{221}$. Ansonsten war eher kritische Distanz zu erkennen ${ }^{22}$. Das Derby-

${ }^{216} \mathrm{Vgl}$. ibid.

$217 \mathrm{Vgl}$. ibid.

${ }^{218}$ The Standard, 13. Juli 1874, S. 4.

${ }^{219}$ Vgl. The Daily Telegraph, 11. Juli 1874, S. 4.

${ }^{220} \mathrm{Vgl}$. ibid.

221 Ibid.

${ }^{222}$ Vandalismus gegen eine in Preston aufgestellte Statue sah The Times, 20. Dezember 1876, S. 5, allerdings nicht politisch motiviert. 
Denkmal bildete damit - mehr noch in der publizierten öffentlichen Meinung, als in der Festrhetorik - den Auftakt zu einem bis dahin ungekannten $\mathrm{MaB}$ an monumentaler Selbstinszenierung des Konservativismus und einer spezifisch nationalen Diktion, die überwiegend an Fragen der Binnenkonstituierung Großbritanniens orientiert blieb, während sich auf dem Wege zeremonieller Gesten eine Anwartschaft auch und gerade auf die Außenprojektion der Nation subtil andeutete.

Knapp zehn Jahre später wirkten im Rahmen der Einweihung eines Denkmals für den konservativen Premierminister Benjamin Disraeli am 19. April 1883 auf dem Parliament Square anläßlich der zweiten Wiederkehr seines Todestages Zeremoniell und Festrhetorik noch kongruenter und intensivierten den symbolpolitischen und definitorischen Zugriff des politischen Konservativismus auf den Nationsbegriff ${ }^{223}$. Die große Zuschauermenge, die sich am Platz zusammengefunden hatte, trat in zuvor nicht dagewesener Form symbolisch als Gesinnungsgemeinschaft in Erscheinung, indem sie demonstrativ jene „Primrose« trug, die seit dem Vorjahr als Ausweis besonderer Loyalität zu Disraeli galt ${ }^{224}$. Auch über die Festgemeinde hinaus war die Primrose das Erkennungszeichen des Tages, beherrschte das Straßenbild im gesamten Zentrum der Metropole ${ }^{225}$. Es entsprach dem im Vergleich zu den meisten in London vorausgegangenen Denkmalfeiern erhöhten symbolischen und programmatischen Inszenierungsaufwand, daß die enthusiasmierte Menge der Festbesucher, die die Reden bisweilen mit lauten Zurufen bekräftigt hatte, sich dem offiziellen Ende der Feier verbal zu widersetzen versuchte und in Eigenregie nach einer Fortsetzung der Rede des prominenten Konservativen Lord Salisburys rief. Die Apologie der nationalen Affektgemeinschaft, die in den zahlreichen Reden entfaltet wurde, trug freilich keinesfalls so weit, eine spontane Programmänderung zuzulassen, so daß dem Begehren nach auch nur minimaler Partizipation am offiziellen Ritus nicht Folge geleistet wurde ${ }^{226}$.

Sir Stafford Northcote, der sich seit der Abdrängung der Konservativen 1880 in die Opposition als einer der neuen Köpfe der Tories profiliert hatte, beschwor eindringlich, wie dies bis zu diesem Zeitpunkt am ehesten im Anschluß

${ }^{223}$ Vgl. zum Folgenden The Morning Post, 20. April 1883, S. 6-7, hier S. 6; The Standard, 20. April 1883, S. 5; The Daily Telegraph, 19. April 1883, S. 5; ibid. 20. April 1883, S. 5; The Manchester Guardian, 20. April 1883, S. 5; knapp Reynold's Newspaper, 22. April 1883, S. 4

${ }^{224}$ Auch außerhalb Londons wurden am 19. April 1883 „Primroses « getragen und dekoriert, vgl. v.a. The Standard, ibid. Zur Herkunft der Symbolik PUGH, The Tories, S. 18-19; George Earle BuCKLE ( $\mathrm{Hg}$.), The Life of Benjamin Disraeli, Earl of Beaconsfield, Bd. 6 (1876-1881), London 1920, S. 628-631.

${ }^{225}$ Geladen waren außer Innenminister Sir William Harcourt weniger offizielle Vertreter der liberalen Gladstone-Regierung als namhafte Konservative, darunter ehemalige Minister. Vgl. The Moming Post, 20. April 1883, S. 6-7 und die genannten Artikel.

${ }^{226}$ Vgl. ibid. S. 7. 
an das Ableben des Prince Consort geschehen war, das Verschmelzen des gesamten Landes zur erschütterten Trauergemeinde nach Disraelis Tod, unter dessen Eindruck parteipolitischer Dissens nivelliert erschien und die Briten sich über der gemeinsamen Trauererfahrung als nahezu radikal-egalitäre Volks-Nation konstituierten:

And it was not a little remarkable to think that one who passed so large a portion of his life in sharp political controversy (...), should, nevertheless, (..) have rooted himself so in the affections (..) of the British people ${ }^{227}$.

Der Traueraffekt erwies sich in Northcotes Rede einmal mehr als regelrechte Gesinnungsprobe für eine Nation, die sich dem Topos zufolge jenseits tagespolitischer Bekenntnisse und nationalhistorischer Mythen als Affekt- und Erfahrungsgemeinschaft zusammenfand, während Disraeli mehr als je zuvor während seiner politischen Karriere deren Befindlichkeit bestimmte ${ }^{228}$. Ebenso maß Northcote der geglückten Einigung der Nation auf konsensuale Symbole wie auf ein Arsenal renommierter und öffentlich exponierter Kultfiguren, wie sie unter anderem im Disraeli-Denkmal Gestalt angenommen hatten, spezifische Nationsbildungspotentiale bei, indem im Zuge der Erinnerung an ihr Handeln und Reden die überschaubare, rational-intelligible und emotionalnachempfindbare Quintessenz dessen zutage trat, was die Nation jenseits materiellen Gewinnstrebens und effizienter Wehrhaftigkeit nach außen ausmach$\mathrm{te}^{229}$. Damit unterstrich Northcote neben dem Illustrations- auch einen für unersetzlich erachteten Anthropomorphisierungseffekt, den die Denkmalfiguren im Blick auf die Nation zumindest der Erwartung ihrer Stifter gemäß zu zeitigen vermochten.

Entsprechend titulierte der zweite Mann an der Spitze der Konservativen nach Disraeli, Robert Gascoigne-Cecil, Marquess of Salisbury, das DisraeliDenkmal als membodiment [ [of] some one idea that was grateful to the English people« und Disraeli als Inbegriff und Einer der Nation, der die »idea of nationality, of national greatness, and of the unity of the country « in Zeiten ihrer Bedrohung vor Dissoziierung bewahrt habe ${ }^{230}$. Mit der Zuordnung Dis-

${ }^{227}$ Ibid. und Evening Standard, 20. April 1883, S. 8.

${ }^{228}$ Northcote wies darauf hin, daß ein offizielles Staatsbegräbnis nur ausgeblieben war, weil Disraeli seine Beisetzung anders verfügt hatte, während in Westminster Abbey ein Monument zu seinen Ehren entstanden war. Das Londoner Monument bezeichnete Northcote als Apotheose aller bislang vorgenommenen Ehrungen, sofern es sich am authentischen Ort des politischen Wirkens Disraelis befand. Vgl. The Morning Post, 20. April 1883, S. 7

${ }^{229} \mathrm{Vgl}$. ibid.: »I do not think I misjudge the people of this country when I say that the time is far distant when they will fail to see in the honour bestowed upon their great men, and in the inspirations drawn from the records of their prudence, their courage, their statesmanship, their devotion, their eloquence and their magnanimity a treasure greater, a force more important to this kingdom than the amplest wealth, or the most extended commerce, or the most powerful army and navy.«

${ }^{230} \mathrm{Vgl}$. ibid. und Evening Standard, 20. April 1883, S. 8. 
raelis zur Queen als ihr »most devoted and most beloved servant« wurde zudem noch einmal die dezidiert monarchische Prägung der Nation unterstrichen, für die Disraeli stand.

Verwendeten Northcote und Salisbury alle rhetorischen Anstrengungen darauf, jene identifikatorische Kopplung von monumentalisierter Figur und Nation plausibel zu machen, von deren Nachweis sie sich einen Sinnstiftungseffekt erhofften, der über den Moment der aktuellen Feier hinausreichen sollte, war es erstmals der Konservative Lord John Manners, der sich näher zum Gehalt eines Nationskonzepts äußerte: »The safety, the increased stability of the empire, and the promotion of the social, the physical and the moral well-being of its toiling population were the objects which he [i.e. Disraeli, H.R.] ever placed before his practical view ${ }^{231}$. Manners griff hier auf, daß Disraeli sich seiner Wählerschaft in der Tat vor allem als Förderer des Empire und schließlich auch Vorkämpfer sozialer Reformen empfohlen hatte, verharrte indessen auf einem eher propagandistischen Niveau, indem er den in der Tat zahlreichen innenpolitischen Reformmaßnahmen eine konzise Strategie zum Wohle der Nation unterstellte, mit denen die Disraeli-Regierung faktisch allerdings kein stimmiges Politikprogramm umgesetzt, sondern vor allem situativ, bisweilen defensiv auf außerparlamentarischen Druck reagiert oder politische Richtlinien weiterverfolgt hatte, die bereits von den liberalen Vorgängern stammten ${ }^{232}$.

Im Spiegel der Festreden begann der politische Konservativismus mit dem Disraeli-Kult, das Definitionsmonopol über den Nationsbegriff zu reklamieren und den Konnex zum Empire programmatisch in den Mittelpunkt seiner Programmatik zu rücken. Die Anwartschaft des Liberalismus auf das Konzept der Reformnation wurde konsequent ignoriert, wie überhaupt die Aufmerksamkeit von der Binnenkonstitution weg auf die außenpolitische Dimension und eine spezifische Nähe der Empire-Nation zur Monarchie verlagert wurde. Die demonstrative Aneignung des Empress of India-Titels durch Queen Victoria, der 1876 in den parteipolitischen Lagern jedweder Couleur ${ }^{233}$ nicht anders als in der politischen Presse ${ }^{234}$ zu gedämpfter Emphase Anlaß gegeben hatte, wurde zwar auch hier lediglich indirekt thematisiert, blieb aber gleichwohl als triumphale Assoziation von Monarchie und Empire und als Synonym für einen diffusen Garantiemachtstatus der Konservativen für diese Werteallianz im Zentrum der vor dem Disraeli-Monument propagierten Nationsidee virulent.

231 Ibid.

${ }^{232}$ Vgl. dazu hier nur PEARCE, STEWART, British political History, S. 74-83.

${ }^{233} \mathrm{Vgl}$. TAYLOR, The British Empire, S. 119; PUGH, The Tories and the people, S. 75.

${ }^{234}$ Vgl.The Times, 13. März 1876, S. 8; The Guardian, 20. März 1876, S. 8; Lloyd's Weekly Newspaper, 19. März 1876, S. 6. 
Der Standard übernahm die Rhetorik der Zelebranten ${ }^{235}$ und honorierte als "genuinely national and popular«, daß die Festgesellschaft auch außerhalb der Absperrungen als vorbildlich disziplinierte "compact and most orderly mass of humanity ${ }^{236}$ in Erscheinung getreten sei. Nicht als plurale Gesellschaft, sondern als ebenso uniforme wie pittoresk aufgemachte Menge war die Teilhabe der Nation am Fest gelitten. Nicht allein, daß sich Handwerker eigens aus dem Londoner East-End zum feierlichen AnlaB in der Menge einfanden, sondern vor allem, daß sie dank der Schlüsselblumen, die auch sie symbolisch trugen, in der vom »genuine patriotism《 ergriffenen Masse untergingen, wurde beifällig erwähnt ${ }^{237}$. Damit wurde an der Symbolik mehr der Uniformierungseffekt als die partizipatorische Geste begrüßt.

Disraelis nationaler Exempelcharakter ergab sich unterdessen nicht nur aus seinem konsequenten »battle for the just influence of the Crown«, sondern auch aus seiner spezifischen Auffassung von »English history« und »English traditions«, wonach mit der Nation zuallererst »the England of the English people, the English nobles, the English Church and the English Crown ${ }^{238}$ gemeint war und also eine im von Staatskirche und Krone markierten Ordnungsrahmen sozial klar hierarchisierte Gesellschaft. Indem zu dieser Nationsauffassung Disraelis " unwavering faith for the Conservative instincts of the working classes « gerechnet wurde, suchte der Standard zu suggerieren, daß das sozialkonservative Ordnungsmodell durchaus auch für die nicht-privilegierten Schichten attraktiv erscheinen mußte, die von einer Disraelischen Sozialreformpolitik zumindest eine graduelle Konsolidierung ihrer Lebensverhältnisse zu erwarten hatten.

Um parteipolitische Ausgrenzungen kam der Standard trotz der im Einklang mit den Reden selbst auferlegten Konsensrhetorik schließlich nicht herum und nahm sie gleich in dreifacher Weise vor. Zum ersten distanzierte er sich vom englischen Nonkonformisten und radikalen Mitinitiator der Anti-Corn-LawLeague Bright ${ }^{239}$, um den konservativen Nationsbegriff von für radikal erachteten Partizipationserwartungen oder gar Aspirationen auf eine barrierelose Massendemokratie ausdrücklich frei zu halten. Der Distanzierung vom liberalen Radikalismus folgte zweitens jene vom traditionalen Whig-Liberalismus und seiner antimonarchischen Version der englischen Nationalgeschichte, wonach die Protagonisten der Revolution von 1688 eine Tradition des Freiheitskampfes begründeten, dem sich Parlamentssouveränität und konstitutionell garantierte Freiheitsrechte als legitimatorische Bezugspunkte auch des moder-

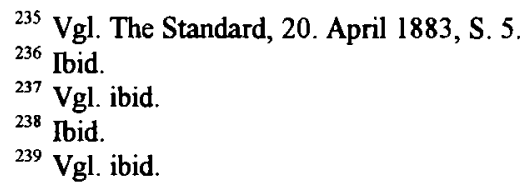


nen Liberalismus verdankten ${ }^{240}$. Demgegenüber machte sich der Standard implizit das konservative historiographische Gegenmodell zu eigen, wonach das anarchistische, die gewachsene Staatsordnung bedrohende Potential der Revolutionäre im 17. Jahrhundert der Krone unerwünschte Autoritätseinbußen gebracht habe ${ }^{241}$. Eine dritte Distanzierung erfolgte vom während der frühen 1880er Jahre noch weithin marginalen und Mittelklasse-zentrierten politischen Sozialismus, dem nicht nur anarchisches Sektierertum und Aufkündigung der organischen Gesellschaftshierarchie, sondern auch erhebliche Loyalitätsdefizite gegenüber der Nation zugunsten transnationaler Zukunftserwartungen zur Last gelegt wurden ${ }^{242}$. Die Panegyrik der Festredner hatte der Standard damit unterlaufen und die Assoziation von Deutungskämpfen um ein Nationskonzept zugelassen, die unter der Oberfläche der Konsensrhetorik weiter anhielten.

Im liberalen Meinungslager kam kein stimmiges Echo auf die Monumentalisierung Disraelis und die demonstrative Programmatik der »konservativen Nation « zustande. Der Daily Telegraph gestand nicht nur Disraeli die Aufnahme in das »open-air Pantheon« auf dem Parliament-Square $\mathrm{zu}^{243}$. Er bekannte sich auch zu der Form, in der Disraeli die Nation an prominenter Stelle als "Empire" begriffen hatte, "that has interests and dangers, neighbours and enemies in every sea, and almost on every coast«, und bedauerte schließlich, daß diese Prämisse nationalen Denkens nicht einhellig akzeptiert $\operatorname{sei}^{244}$. Die Pointe enthielt einen Seitenhieb auf die amtierende liberale GladstoneRegierung, die ihren Wahlkampf wesentlich auf die Kritik der militant imperialen Politik Disraelis abgestellt hatte, während ihre eigene, eher pazifistische Außenpolitik spätestens seit dem Burenaufstand in Transvaal noch im Jahr der Regierungsübernahme ins Kreuzfeuer der Kritik durchaus auch aus den Reihen Liberaler geraten war $^{245}$. Insofern näherte sich das liberale Organ hier in der Tat dem konservativen, imperialistisch geprägten Nationsbegriff an.

Daneben waren aber gelegentlich kritischere Töne zu hören. Gladstones ehemaliger Privatsekretär Edward Hamilton etwa nahm im Rahmen seiner Tagebuchaufzeichnungen nur knapp und spöttisch die Begründung des Disraeli-

${ }^{240}$ Vgl. ibid.

${ }^{241}$ Es war der Widerspruch zu konservativen Deutungsmustern der britischen Nationalgeschichte, der den Standard die rhetorische Contenance verlieren und polemisch werden ließ. In bemerkenswerter Übereinstimmung mit der angefeindeten Whig-Historiographie galten dabei die Revolutionen des 17 . Jhs. als zentrale Krisen- und Umbruchserfahrungen und nicht hintergehbare Zäsurdaten der Nationalhistorie. Zugleich wurde erkannt, daß mit einer royalistischen oder parlamentarischen Revolutionsdeutung Vorentscheidungen über den von hier aus geprägten Nationsbegriff fielen

${ }^{242}$ Vgl. ibid.

${ }^{243}$ Vgl. The Daily Telegraph, 19. April 1883, S. 6.

${ }^{244} \mathrm{Vgl}$. ibid.

${ }^{245}$ Vgl. aber auch die Polemik im Pamphlet This is the tree that Ben has raised. A political satire. Dedicated without permission on the G.M.O., London o. J. [up]. 
Kults als öffentlich gepflegtes »sentimental hobby« zur Kenntnis und karikierte die Primrose-Symbolik als mmarvellously inappropriate and unEnglish ${ }^{246}$. Mit der politisch linken Tendenz der Presse wuchs die Bereitschaft, der Idee von Disraelis nationaler Repräsentanz von Grund auf zu widersprechen. So wurden im Spectator Zweifel an der litaneiartig vorgetragenen Beteuerung angemeldet, daß Disraeli zum affektiven Bezugspunkt der Nation habe geraten können, und statt dessen geargwöhnt, Disraeli habe das englische Volk niemals ganz verstanden und sei seinerseits eher befremdet und durchaus mißtrauisch wahrgenommen worden ${ }^{247}$. Skeptisch behauptete auch der linke Nonconformist and Independent, daß Disraeli selbst in den eigenen Reihen den Status des Außenseiters nicht nur nie losgeworden sei, sondern seiner jüdischen Abkunft wegen - ungeachtet seiner Zugehörigkeit zur anglikanischen Kirche - auch selbst kultiviert habe ${ }^{248}$. Eine in der Verschiedenartigkeit der wrace " bestehende Differenz hatte dem Nonconformist zufolge Disraeli selbst auf höchst un-englische Weise zwischen sich und das Land gesetzt und verdankte seinen politischen Aufstieg eher seinem Machtinstinkt denn irgendeiner nationalen Repräsentanz. Hinter den konservativen Demokratisierungsabsichten wähnte der Nonconformist ohnedies Manipulationsambitionen, hinter dem imperialen Außenpolitikprogramm eine Vertröstungsstrategie gegenüber den politisch und sozial Marginalisierten ${ }^{249}$. Ähnlich wie der Spectator umriß der Nonconformist von hier aus ein anders gelagertes Nationskonzept, indem er die Nivellierung sozialer »inequalities« forderte ${ }^{250}$.

Die populäre linke Presse schloß sich den Voten der distinguierteren, von einem mit Abstand elitäreren Mittelklassepublikum rezipierten linksliberalen Blättern indessen nicht an. Lloyd's Weekly Newspaper gestand zwar ein, daß "good Liberals« mit Disraelis Politik im allgemeinen und seiner fast schon reaktionären Demokratiefeindlichkeit im besonderen schlechterdings nicht konform gehen konnten, und apostrophierte ähnlich wie die kritischen Zeitungen Disraeli seiner jüdischen Abkunft wegen als »alien in race ${ }^{251}$. Derglei-

${ }^{246}$ Vgl. Dudley W.B. BaHLMAN (Hg.), The Diary of Sir Edward Walter HAMILTON 18801885, Bd. 1 (1883-1885), Oxford 1972, S. 425.

${ }^{247} \mathrm{Vgl}$. The Spectator, 21. April 1883, S. 4: Wust as he was a student of England (...), so England in her turn was to the end rather absorbed in studying Lord Beaconsfield than in either obeying him or trusting him. He was a pleasant enigma to us, which was never solved, though we believed (...) that his power was too much limited by the character of the medium in which it moved, to endanger greatly our safety and our welfare."

${ }^{248} \mathrm{Vgl}$. The Nonconformist and Independent, 26. April 1883, S. 373: sted on the differences which nature and history have placed between his race and ours. (...) He led them [i.e. the parties, H.R.] by a way and to an end which he knew but did not disclose. A more un-English proceeding cannot be conceived, for among us the essence of public life is frankness. "

${ }^{249} \mathrm{Vgl}$. ibid.

${ }^{250} \mathrm{Vgl}$. ibid. und ähnlich The Manchester Guardian, 20. April 1883, S. 5.

${ }^{251}$ Vgl. Lloyd's Weekly Newspaper, 29. April 1883, S. 6. 
chen Relativierungen hinderten das Blatt aber keineswegs daran, in der Primrose in der Tat das Symbol dafür zu sehen, daß sich um Disraeli ein von parteipolitischen Ränken absehender »English people« als Nation konstituierte. Dergleichen Deutungsmuster funktionierten allerdings nur unter der Voraussetzung, daß die Programmatik der Denkmalstiftung im Detail ausgeblendet und ein politisch komplett neutralisierbarer Nationsbegriff unterstellt wurde, der offenbar jene Gemeinschaft charakterisieren sollte, deren Gemeinsamkeit sich in einer diffusen Vaterlandsliebe (llove of the country ) erschöpfte ${ }^{252}$. Der Preis, den Lloyds's Weekly für die Inklusionsrhetorik hier argumentativ zahlte, erwies sich als beträchtlich, denn sie schien nur auf Kosten eines programmatisch halbwegs entleerten Nationsbegriffs durchgehalten werden zu können ${ }^{253}$. Der gemeinhin geäußerte Vorbehalt gegenüber Disraelis jüdischer Herkunft deutete ethnisch-religiöse Exklusionsmechanismen deutlich an.

Jenseits des publizistischen Diskurses in der politischen Tagespresse zeugte das Überleben des »Primrose Day« am 19. April davon, daß der öffentliche Zuspruch zu einem national motivierten Disraeli-Kult sich verstetigte. Bereits anläßlich des ersten Jahrestages von Disraelis Tod hatten Anhänger landesweit mit den zumindest der Legende nach vom Staatsmann besonders geliebten Schlüsselblumen eine offizielle Kultgeste gleichsam erfunden ${ }^{254}$, die nun in Kombination mit der Denkmalerrichtung wiederaufgegriffen und intensiviert wurde. Bis zu Kriegsbeginn wurde neben dem Tragen der »Primrose« die Niederlegung von Gebinden und Kränzen an der Statue auf dem Parliament Square oder vergleichbaren Monumenten in der Provinz zum festen rituellen Bestandteil des Disraeli-Kults ${ }^{255}$. Seinen institutionellen Rückhalt fand er darüber hinaus in der Ende 1883 gegründeten, auf den Erhalt der traditionalen Institutionen, der Staatskirche und des British Empire eingeschworenen Primrose League, die den Primrose Day im Rahmen eigener Festakte beging, sich aber schließlich auch federführend an den öffentlichen Manifestationen beteiligte und bald die gesamte Denkmaldekoration anläßlich des Festtages vornahm ${ }^{256}$.

Die Einweihung des Disraeli-Denkmals von 1883 dokumentierte damit eine ebenso zeremoniell wie rhetorisch-programmatisch gelungene Inanspruchnahme der Nations-Vokabel durch den politischen Konservativismus und erwies

\footnotetext{
${ }^{252}$ Vgl. ibid.

${ }^{253} \mathrm{Vgl}$. ähnlich Reynold's Newspaper, 22. April 1883, S. 2.

${ }^{254} \mathrm{Vgl}$. The Standard, 20. April 1883, S. 5.

${ }^{255}$ Vgl. hier nur The Times, 20. April 1888, S. 10.
}

${ }^{256}$ Vgl. u.a. The Times ibid.; ibid. 20. April 1911, S. 8; ibid. 20. April 1914, S. 10; ibid. 20. April 1915, S. 6; ibid. 19. April 1917, S. 7. 1917 wurde das Disraeli-Denkmal nur mit einem einfachen Kranz dekoriert. Vgl. knapp zur Primrose League John MACKENZIE, Imperial propaganda societies and imperial studies, in: DERS., Propaganda and Empire. The manipulation of British Public Opinion, 1880-1960, Manchester 1984, repr. 1988, S. 147-172, hier S. 149f.; PUGH, The Tories, S. 12-22; HoC, Sitzung vom 20. April 1894 , in: Hansard $4^{\text {th }}$ s. 23 (1894) Sp. 980-981. 
sich insofern als Bestandteil jener substantiellen Trendwende seit Ende der 1870er Jahre, in deren Folge die politische Rechtsorientierung des Begriffskonzepts wuchs ${ }^{257}$. Das historische Initialmoment, das dem neuen Anspruch zugrundelag, wurde an zentraler Stelle im symbolischen Arrangement am Denkmal bezeichnet, indem an den Denkmalsockel ein massiver Kranz mit den obligatorischen Schlüsselblumen angelehnt stand, der eine Schleife mit der Aufschrift "Peace with Honour» trug und damit die Parole aufgriff, mit der Disraeli auf dem Berliner Kongreß 1878 zur Beilegung der internationalen Krise die Position Großbritanniens an der Seite der Türkei und gegen Rußland charakterisiert hatte ${ }^{258}$. Daß Gladstones Einwände gegen eine militärische Unterstützung der Türkei aufgrund von Massakervorwürfen bulgarischer Christen nicht nur in der eigenen liberalen Partei verhallten, sondern auch die russophobe und jingoistische Kampagne der Konservativen deutlich höheren öffentlichen Zuspruch erhielt, hatte diesen den Weg zur populären Propagierung eines aggressiv-militärischen, imperialistischen Nationskonzepts geebnet $^{259}$.

Die Denkmalerrichtung illustrierte nun, daß die Anwartschaft des Konservativismus auf die verbindliche Konnotierung des Nationsbegriffs nicht bei dessen Außenkonturen verharren konnte, sondern sich vor allem mit jener dem Liberalismus zugeschriebenen Traditionsbildung zugunsten der Verbindung von Nation und Reform auseinanderzusetzen hatte. Im Spiegel des Presseechos jedenfalls wurde deutlich, daß - gemessen an den Kommentaren der linken Sunday Papers - die Attraktivität der konservativen Programmatik stieg, während die Liberalen in Sympathisanten und Kritiker gespalten blieben. Daß dennoch die offiziellen Reden nicht der Jingoismus beherrschte, dokumentierte zugleich, daß die Konservativen nicht uneingeschränkt als dessen Apologeten auftuaten, sondern eine entsprechende Propaganda eher den politischen Formationen am rechten Rand des politischen Spektrums überließen ${ }^{260}$.

${ }^{257}$ WILliaMS, The contentious crown, S. 170; CUNNINGHAM, The language of patriotism, S. 75

${ }^{258}$ Vgl. FeUCHTWANGER, Democracy and Empire, S. 102-107.

${ }^{259} \mathrm{Vgl}$. CUNNINGHAM, The language of patriotism, ibid.

${ }^{260} \mathrm{Vgl}$. dazu auch TAYLOR, The British Empire, S. 119. 


\section{Vergleich}

Die Denkmalfeste für dezidiert liberales Denkmalpersonal zählten in keiner der Kapitalen zu den zeremoniell besonders gewichteten Projekten. Daß auch die Berliner Denkmäler für Liberale allesamt deutlich im Inszenierungsschatten der großen Monarchendenkmäler standen, bildete also keine Ausnahme. Immerhin ist hier - anders als etwa anläßlich zahlreicher Londoner Denkmalerrichtungen - zumindest ein rudimentäres Arsenal an rituellen Handlungen wie musikalische Umrahmung, Hymne und Reden beibehalten worden. Neben dem bescheidenen Ritus um die Denkmäler für Waldeck, Schulze-Delitzsch und Virchow seit den 1890er Jahren trugen auch die vergleichsweise marginalen Standorte dazu bei, eine öffentliche Wirkung der Denkmäler zu erschweren. Ausgenommen von diesem Phänomen blieb die Inszenierung des JahnDenkmals 1872, die sich mit einer selbstbewußten Festzugsregie von den monarchisch-machtstaatlichen Symbolorten emanzipierte, allerdings ihrerseits durch das demonstrative Fernbleiben des Kaisers symbolisch abgestraft wurde. Das Festarrangement blieb den nationalen Turnerfesten aus der Zeit vor der Reichsgründung verpflichtet, indem es dem Einzugsbereich der Festteilnehmer zufolge ebenso überpreußisch wie schließlich sogar international geprägt war und neben der regionalen auch Effekte der sozialen Inklusion aufwies, indem sich auch Arbeitervereine am Festzug beteiligten. Festplatzabgrenzungen und die Kanalisierung der Teilnahme durch den Verkauf von Tickets setzten allerdings erneut Partizipationsgrenzen.

Dennoch überwogen in der Festszene die Spuren eines inklusiv-pluralen Nationsverständnisses. Einem spezifischen Arrangement folgte unter anderen Vorzeichen auch die Einweihungsfeier des Stein-Denkmals 1875, die, weil der Kaiser sich das Projekt angeeignet hatte, in sonst unüblichem Ausmaß von hochrangigen Vertretern der Regierung und Militärs neben Repräsentanten von Universität und Stadt geprägt und zugleich als schüchternes Relikt der nationalen Bewegung um eine gesamtdeutsche Symbolik bemüht war. Zumindest der Konstellation der Festgäste nach wiederholte sich diese Prozedur anläßlich der späten Hardenberg-Feier nach der Jahrhundertwende erneut. Das Zeremoniell um die Berliner Denkmäler für Repräsentanten des geeinten Nationalund Reformstaats und dezidiert linksliberales Personal entwickelte sich insofern nach der Logik einer Antiklimax, indem die Jahn-Feier noch aus einem eigenen Traditionsimpetus schöpfte, während die Stein- und HardenbergDenkmalfeste sich bereits offiziös-regierungskonformen Arrangements verdankten und schließlich die Gruppe der linksliberalen Stiftungen auf ein rituelles Minimum reduziert erschien.

Eine durchaus mäßige rituelle Bilanz war auch für die Londoner Denkmäler für Liberale zu ziehen, indem etwa die Palmerston-Statue 1878 annähernd 
formlos plaziert wurde. Demgegenüber wiesen die Londoner Denkmalprojekte für Konservative seit Mitte der 1870er Jahre eine deutliche Aufstockung des Zermoniells auf. So bemühte man sich anläßlich der Einweihung der DerbyStatue 1874 darum, internationale Festgäste hinzuzuziehen und ließ Disraeli eine zentrale Rolle als Zelebrant und Denkmaldeuter im Festablauf übernehmen. Eine rituelle Steigerung stellte schließlich die Feier des DisraeliDenkmals 1883 dar, die ganz auf die vermeintlich sozial und politisch homogenisierende Wirkung der kurz zuvor entstandenen Primrose-Symbolik abstellte. Faktisch arbeitete die Festregie mit der üblichen Aussperrung des Publikums aus dem unmittelbaren Denkmalraum, visuell und rhetorisch fingierte aber das Tragen der Primrose, seinerseits schon zur partizipatorischen Geste überhöht, die Konstituierung einer homogenen Konsensgemeinschaft über soziale und politische Friktionen hinweg und erlaubte die virtuelle Einbeziehung sämtlicher Primrose-Träger im multinationalen Königtum in einen nationalen Disraeli-Kult, den wiederum über die Primrose die Monarchin, von der die Zurechnung der Primrose zu Disraeli maßgeblich stammte, und der Konservativismus gleichermaßen gestiftet hatten. Die Inklusion von Frauen in die Feier des Fawcett-Denkmals 1893 blieb demgegenüber Episode, zumal der seltene Fall öffentlichen Protests und seine Unterdrückung vor dem Lawson-Denkmal 1909 die kompromißlose Eindämmung des Partizipationsanspruchs der Frauenwahlrechtsbewegung illustrierten. Daß schließlich auch die Einweihung der Pariser Trarieux- und Scheurer-Kestner-Denkmäler bescheiden ausfiel, war auf dem Hintergrund erstens einer dennoch geschliffenen Programmatik beider Monumente und zweitens der verbreiteten Monumentalisierung von République-Allegorien und republikanisch-liberalen Ministerdenkmälern deutlich anders zu bewerten, als die zeremonielle Zurückhaltung Berliner Denkmalstifter, für die jeder sonstige Symbolrückhalt in der Kapitale fehlte.

In programmatischer und rhetorischer Hinsicht hat es nun eine vollständige politische Monopolisierung des nationalen Diskurses in keiner der Metropolen gegeben. Spezifische Deutungshoheiten und -konjunkturen haben sich hingegen deutlich abgezeichnet. In Paris dominierten die Sinnstiftungen des republikanischen Liberalismus, ohne sich ausschließlich etablieren zu können. Seine spezifische Flexibilität erlaubte aber Deutungstransitionen und Aneignungen, die zusätzlich zur von Staat wie Stadt betriebenen Kontrolle des Symbolterrains verhindert haben, daß die konservative Opposition Denkmäler gesetzt hat. Ansätze für eine konservative Unterwanderung der liberalen Deutungshoheiten waren gleichwohl unübersehbar. In Berlin erschienen angesichts der dominanten Symbolik und Programmatik der Monarchen- und Militärdenkmäler konservative Zeichensetzungen obsolet, während andererseits die liberalen Kräfte angestrengt versuchten, Symbolmacht zu erringen. In London schließlich erlangten liberale wie konservative Kräfte und Figuren Symbol- 
macht, die konservative Okkupation der Nationsidee erwies sich hier aber als vergleichsweise dominant.

In Paris hatten die République-Statuen und die Denkmäler für die republikanischen Ministerpräsidenten die liberal-republikanische Nation diskursiv vor allem zu konkurrierenden Ordnungsentwürfen der radikalen und sozialistischen Linken oder der reaktionären Konservativen ins Verhältnis gesetzt und je nach tagespolitischer Konfliktlage mit unterschiedlichen Akzenten programmatisch justiert. Das Trarieux- wie das Scheurer-Kestner-Denkmal, die nach der Jahrhundertwende profilierten Handlungsträgern der liberalen Republik gewidmet waren, erschienen demgegenüber in einer vergleichsweise neuen Intensität auf die existenzielle Anfechtung liberaler Deutungshoheiten durch einen intransigent-rechten Nationalismus fixiert. Einem der radikalsten Exklusionsdiskurse, den die politische Rechte mit ihrer antisemitischen Ausrichtung in die politische Debatte des ausgehenden Jahrhunderts getragen hatte, verweigerten sich die liberalen Denkmalstifter nun, indem sie in Trarieux und Scheurer-Kestner die Repräsentanten demonstrativer Inklusion feierten. Einmal firmierte der Vertreter des republikanischen Liberalismus als Repräsentant einer zutiefst zivilisatorisch, moralisch und bürgerlich gefestigten Nationsidee, von der her sich Exklusionsdiskurse als schiere Pervertierung der eigentlichen Emanzipationsverheißung des modernen Nationskonzepts verboten. Zum anderen bot die zweite Denkmalfeier Gelegenheit, ein freiheitlichinklusives Nationsverständnis unmittelbar mit dem an Deutschland verlorenen Elsaß zu verknüpfen, von daher die genuine Zugehörigkeit des Territoriums zur liberalen Nation glaubhaft zu machen und also die auch vom Linksliberalismus nie aufgekündigte Revancheidee unmittelbar an das Inklusionbekenntnis zu koppeln. Die Konzentration auf das Elsaß erwies sich als argumentative Schaltstelle für eine moralische Exkulpierung der Armee, die selbst nach ihrer äußerst zweifelhaften Rolle in den Jahren der Dreyfus-Krise nicht einer mehrheitlich antisemitischen Überformung bezichtigt, sondern über die Assoziation der elsässischen Revolutionsgenerale als nur kurzzeitig fehlgeleiteter Hort patriotisch-freiheitlicher Denkart identifiziert wurde.

Mit beiden Deutungsmustern entzog man sich einer kritischen Erörterung der Frage, in welchem Maße Exklusionsdiskurse immer schon zur öffentlichen Rede von der Nation gehörten. Daß sie, anders als die öffentlichen Deklamationen am Denkmal nahelegten, keinesfalls überwunden waren, dokumentierte die Protestaktion der Rechtspopulisten, die sich dem Inklusionsprimat keinesfalls anschließen wollten. Unter diesen Umständen nahmen die vollmundigen Bekenntnisse liberaler Denkmalstifter äußerst defensive Züge an, schien der republikanische Nationsbegriff nur unter Aufbietung aller rhetorischen Kräfte und mit dem Versuch, eine Art links-republikanische Authentizität der nationalen Idee nachzuweisen, vor rechtsradikaler Uminterpretation geschützt werden zu können. Damit wirkte die Verstärkung der liberal-republikanischen 
Symbolpräsenz in der Kapitale eher angestrengt als souverän und haftete der Toleranz- und Inklusionsrhetorik der Charakter des Rückzugsgefechts an.

Die geringere öffentliche Reichweite der Berliner Denkmäler für Liberale verdankte sich nicht notwendig programmatischer Redundanz, sondern dem Inszenierungsnachteil, der angesichts der bisweilen pompösen Umtriebigkeit im Umfeld der Monarchendenkmäler umso schwerer wiegen mußte. Konstitutiv Neues hatten die Zelebranten der Liberalen zum nationalen Diskurs gleichwohl beizusteuern. Der Versuch der Erben der Turnerbewegung, mit der Jahn-Feier programmatisch im Kaiserreich anzukommen und doch mehr der Einheitsnation als dem monarchischen Machtstaat verpflichtet zu sein, mündete in rhetorische Drahtseilakte. Zunächst zollte man partizipatorischen und demokratischen Idealen der frühen Turnerbewegung im Gefolge Jahns Tribut, der sich freilich nicht als Exponent eines demokratisch-revolutionären Nationsgedankens eignete, weil er eher einem monarchisch-loyalen, antirevolutionären Denken und der Idee eines mystischen Volkstums verpflichtet war. Dann kippte die Rhetorik aber zugunsten einer selbstgewählten Unterordnung unter eine vor allem aus machtpolitischen Gründen goutierte Reichs-Emphase. Der traditionsstiftende Beitrag des Bürgertums zur Nationsbildung seit dem frühen Jahrhundert und die liberal-freiheitlichen Postulate, die ursprünglich nicht sachlich-programmatisch, sondern nur chronologisch nachgeordnet worden waren, blieben Zitat.

Auch im Rahmen der Initiative zum Stein-Denkmal blieben Spuren des ehedem Liberalismus-nahen Projekts erkennbar, obschon sie aus Argwohn vor einer progressiv-partizipatorischen oder gar egalitären Konnotierung der mit Stein verknüpften Nationsidee nachträglich monarchisch überformt worden war. Die individuelle Ermächtigung zu »Freiheit, Selbständigkeit und Eigenthum « wurde durchaus als von den preußischen Reformen anvisierter Teilhabeschub gedeutet, der über die Idee nurmehr machtpolitisch ummünzbarer Ressourcenmobilisierung für eine schlagkräftige Bewährung im Krieg weit hinausging. Symptomatisch für die erhebliche Distanz zwischen Stiftung und Rezeption monumental vermittelter Nationsdeutungen wartete hier nun die sozialdemokratische Presse mit der provokanten Umdeutung der Stein- als Spiegelbild einer Napoleon-Figur auf. So sollte demonstriert werden, daß die Preußischen Reformen eher Wirtschaftssubjekte freigesetzt als die Gesellschaft jenseits der Grenze bürgerlicher Zugehörigkeit egalisiert hatten, und die Gegenutopie der sozial inklusiven Nation verteidigt werden.

Bis mehr als dreißig Jahre später das Hardenberg-Denkmal eingeweiht wurde, war die Bereitschaft zur liberalen Traditionsbildung im Blick auf die Reformer durchaus nicht geschwunden. Zwar galt nun das Eingeständnis, daß Hardenberg am selbstgesetzten Konstitutionalisierungsziel für Preußen gescheitert war, sein partizipatorischer Impetus wurde nun jedoch für eine Nation aktualisiert, die, längst mitten im hochindustriellen Wandel, nicht nur 
machtpolitische und ökomomische Interessen verfolgen konnte, sondern auch soziale Umwälzungen zu koordinieren und nach »sozialer Gerechtigkeit« zu streben hatte.

Die parallel dazu seit den 1890er Jahren verlaufenden Initiativen für die Waldeck-, Schulze-Delitzsch- und Virchow-Denkmäler blieben zunächst programmatisch gedämpft angesichts der Bemühung, den zuerst geehrten Waldeck gegen nie zurückgenommene Inkriminierungen seitens der politischen Reaktion in Schutz zu nehmen. Zu einer souveränen Bestimmung von Position und Tradition des Liberalismus in der Nation war unter der Last der Defensive nicht zu gelangen. Neun Jahre später kamen die Stifter des Schulze-DelitzschDenkmals über diesen Argumentationsstand aber deutlich hinaus, indem sie einem ausgewiesenen Exponenten der Sozialpolitik und des Liberalismus vor der Reichsgründung huldigten. Wieder zeugte die Rhetorik von einem Deutungsspagat, indem »soziale Rechte« und »Selbstbestimmung« zunächst marginal verhandelt wurden, bis man mit selbstbewußteren Deutungen vorpreschte, denen zufolge in Schulze-Delitzschs Namen ein konstitutiver Anteil des Liberalismus an Nationalstaatsgründung und Nationswerdung geltend gemacht wurde. Der neu gewonnene Inszenierungs- und programmatische Eifer liberaler Stifter hielt für das Virchow-Denkmal noch an, ein Denkmalprojekt für Richter indessen scheiterte.

Die Einweihung von Denkmälern für Liberale in Berlin hat damit nicht zu einer fundamentalen Revision des dominanten borussianisch-machtstaatlichen Nations-Konstrukts führen können, wonach die Konstituierung des zentralisierten Nationalstaats nach 1871 die einzige historische Option für die politische Nationswerdung darstellte. Die freiheitlich-liberalen Nationsvorstellungen, die gerade die bürgerliche Nationalbewegung während der ersten Jahrhunderthälfte anvisiert hatte, sind als Traditionsvorrat nationalen Denkens abgedrängt und jedenfalls nicht eigens thematisiert worden. Der Anlauf zu einer dezidiert linksliberalen Gedächtnisbildung und die Reklamierung von Beteiligungsrechten am nationalen Symboldiskurs hat allerdings, wenn auch unter mancher Restriktion, durchaus vernehmlich stattgefunden. Daß der Liberalismus in Deutschland allerdings anders als in Frankreich und England während der zweiten Hälfte des 19. Jahrhunderts nicht dauerhaft als »regierende Partei« (Gall) verankert war, hat den Versuch, symbolisch als konstitutive Kraft der Reichsnation in Erscheinung zu treten, erheblich erschwert ${ }^{261}$.

${ }^{261}$ Zu bestätigen ist hier Nipperdeys These, wonach die "nationaldemokratischen Denkmäler« zwar liberal initiiert worden sind, sich im Zuge des Reichsgründungskompromisses aber längst der neuen reichsnationalen Denkart auf Kosten einer eigenständigen liberalen Tradition untergeordnet haben, so daß sie den liberalen Gedanken nicht mehr erkennbar propagierten und über das Stadium des wmonarchisch-demokratischen Kompromißdenkmals« nicht hinauskamen; vgl. NIPPERDEY, Nationalidee, S. 585. 
In London stand den liberalen Denkmalinitiativen zwar keine übermächtige monarchisch-machtstaatliche Symbolpolitik gegenüber, aber auch dort nahmen sich die Projekte im letzten Jahrhundertdrittel eher verhalten aus. Dies galt zunächst für den kompletten Inszenierungsverzicht im Blick auf das Palmerston-Standbild und eine vereinzelte Pamphletliteratur, die den Minister außenpolitisch diskreditierte. Erst nach der Jahrhundertwende argumentierten die Stifter des Gladstone-Denkmals nachhaltiger und stellten statt der in Berlin vielzitierten Monarchen- nun Ministerfiliationen her, die die Kontinuität der parlamentarischen Nation verbürgen sollten. Ökonomischer Fortschritt und materieller Wohlstand, Tribut an Massendemokratie und "public opinion", Pazifismus und Intervention an der Seite liberaler Verfassungsstaaten sowie eine genuin christliche Orientierung konturierten den mit Gladstone assoziierten Nationsbegriff nach innen und außen, während das später noch folgende Duke of Devonshire-Denkmal wieder eher pauschal auf den $\gg$ British statesman« als Konsensfigur abstellte. Damit wurden Repräsentanten der liberalen Nationsidee als dem öffentlichen Votum gegenüber responsive, christliche, aber konfessionell undogmatische Führungsfiguren illustriert und sowohl gegenüber einem als elitär-aristokratischen und anglikanischen Konservativismus als auch gegenüber jeder Form des demokratischen Radikalismus abgegrenzt. Programmatische Auslassungen wie die Bestimmung des Verhältnisses von Nation und Empire oder der Binnenstruktur des multinationalen Königreichs vor allem im Blick auf Irland ließen dabei Konsensnot der Denkmalstifter als Folgeeffekt einer in die Krise geratenen liberalen Partei erkennen. Darüber hinaus sind die großen Vorreiter der Parlamentsreform der ersten Jahrhunderthälfte nicht monumentalisiert worden. Seinen substantiellen Anteil an der Demokratisierung hat der politische Liberalismus insofern nicht plastisch geltend gemacht.

Parallel zu den genannten Projekten meldete sich auch der Linksliberalismus mit einem Mill-Denkmal in der Öffentlichkeit zu Wort, und plädierte nun dezidiert und neu für das Ende geschlechtsspezifischer Exklusion, während jenseits des Partizipationspostulats nicht anders als von den übrigen liberalen Sinnstiftern vermieden wurde, egalitäre Forderungen zu formulieren. Nur die Denkmäler für die liberalen Sozialreformer stellten die Partizipationsproblematik in den Mittelpunkt, blieben aber programmatisch vage und koppelten ohnedies die Idee von symbolischer Inklusion der Unterschichten in den öffentlichen Raum an das Erfordernis sozialdefensiver Kontrolle. Visionär nahmen sich die Projekte daher nicht aus, mahnten aber reformerischen Handlungsbedarf an. Erst im Rahmen der Stiftung des Shaftesbury-Denkmals klang ein dezidiert national konnotiertes philanthropisches Selbstbewußtsein an, mit dem soziale Ungleichheit ebenso als kurierungsbedürftiges Defizit der Gesellschaft benannt wie zum ureigensten reformerischen Betätigungs- und Bewährungsfeld einer evangelikal und moralisch missionarischen liberalen Elite 
erklärt wurde, während sozialrevolutionäre Korrekturen nicht angemahnt wurden.

Auch erfolgreiche Anläufe zur Übernahme der nationalen Vokabel durch den politischen Konservativismus haben Spuren in den kapitalen Denkmallandschaften gezeitigt. Ausmaß und Intensität des schleichenden Wandels blieben unterschiedlich. In Berlin erwies sich die konservative Nationsdeutung von Beginn an bereits vor und noch einmal verstärkt nach 1871 als dominanter Grundzug öffentlicher Denkmalfeiern, so daß es über diese Art ubiquitärer Unterwanderung der Programmatik, nicht zur Exponierung eines dezidiert konservativen Bürgen der Nation kam; vor allem die Dynasten- und Militärdenkmäler hatten diese Funktion in Ritus und Programmatik längst erfüllt. In Paris hingegen blieb der Vormarsch der monarchisch-reaktionären Rechten, die bis Mitte der 1870er Jahre ein akuter Bedrohungsfaktor für die liberale Republik blieb, zu kurzfristig, um nach der gelungenen Konsolidierung des republikanischen Systems zu Symbolmacht gelangen zu können.

Erst ab Mitte der 1880er Jahre tauchten fast verschämte Initiativen konservativen Zuschnitts auf, die zwar marginal blieben, aber erste Symptome eines wiedererstarkenden autoritären Nationalismus darstellten. Entsprechende Denkmäler kündeten weniger von einer Systemopposition als von der Unterwanderung republikanischer durch konservative Nationskonnotationen. Bevorzugtes Kultpersonal der Umdeuter waren Künstler, deren vordergründig einem kulturellen Konsens zuzuordnendes Profil durch politisch-miliärische Assoziationen modifizierbar schien und eine Traditionsbildung nicht mehr im Anklang an die republikanischen, sondern an Traditionsvorräte des Ersten Empire gestattete.

In einer Art Transitionsstadium des öffentlichen Umwertungsverfahrens befand sich das Béranger-Denkmal von 1885, indem seine Stifter sich vehement um den Nachweis bemühten, daß der Poet mit seinen Elogen nur einem napoleonischen Populismus gefolgt und später gleichsam zur Republik konvertiert war. Als Kultfigur, die um einen beträchtlichen Teil ihrer politischen Vita dezimiert werden mußte, um republikanisch kompatibel zu sein, gehörte Béranger damit nicht mehr zum ureigensten Arsenal republikanischer Sinnreferenten auf die Nation. Politisch einschlägige Aufladungen schritten nur am Rande des öffentlichen Denkmalkults voran. Indiz für Umwertungsversuche, aber im Gesamtbild der kapitalen Denkmaltopographie marginal, blieb in diesem Sinne die Feier des Coppée-Denkmals 1910, dessen Zelebranten den Exponenten eines antiparlamentarisch-rechten und dezidiert katholischen Nationalismus als Gegenbild zum dominanten Republikanismus beschworen. Im Rahmen des Diskurses um die Kopplung von nationaler und religiöser Loyalität sollten weitere Projekte folgen, in denen sich nicht ausschließlich, aber immer wieder auch Okkupationen der Nationsidee durch konservative Deuter abzeichneten. Im markanten Unterschied zu Berlin haben aber die Verfechter eines autoritä- 
ren, Napoleon-zentrierten oder antipartizipatorischen Nationsbilds den nationalen Diskurs zwar subtil mitprägen können, nicht aber systematisch das Symbolareal beherrscht.

Während nun Dominanz in Berlin und partielle Unterwanderung in Paris die symbolische Präsenz konservativer Nationsbilder in den Denkmallandschaften prägten, ist es in London zu einer regelrechten Trendwende in der öffentlichen Symbolpolitik gekommen, indem seit Mitte der 1870er Jahre der politische Konservativismus nach eher kläglichen Unternehmungen in den Jahren zuvor mit Denkmalprojekten Aufmerksamkeit auf sich lenken konnte, die - anders als in Berlin und zum Teil in Paris - weniger ihrer monumentalen Dimensionen, sondern des neuen Impetus wegen, mit dem sie inszeniert und programmatisch aufbereitet wurden, den Konservativismus verstärkt als authentischen Nationsdeuter erscheinen ließen. Weil die liberalen Kultfiguren demgegenüber weniger erfolgreich öffentlich vermittelt worden sind, konnte der Eindruck einer regelrechten Abdrängung der Liberalen von ihrem ehedem beanspruchten Deutungsmonopol über die Nationsidee entstehen.

Während also in Paris definitorische Unterwanderungsversuche seitens konservativer Kräfte am republikanisch-liberalen Deutungsmonopol nicht zu rütteln vermochten, fiel der konservative Deutungsvorsto $B$ in London schon allein deshalb ungleich massiver aus, weil er nicht subkutan blieb, sondern sich im energischen Zugriff auf das öffentliche Symbolterrain niederschlug. Von der Berliner Situation ist man in London dennoch weit entfernt geblieben, weil der konservative Symbolaufschwung in London erstens nicht annähernd so flächendeckend ausgefallen und zweitens programmatisch mit erheblich anderen Orientierungen stattfand.

Anläßlich der Einweihung des Denkmals für Lord Derby 1874 stand noch vor der Rückkopplung der nationalen Ordnung an christliche Werte die Verbindung der Nationsidee mit dem Konzept der wreform《. Damit wurde das mindestens während der ersten Jahrhunderthälfte vorrangig vom politischen Liberalismus beanspruchte Begriffskonzept, zugespitzt auf die Parlamentsreform, gleichsam konservativ okkupiert. Weder das politische Kalkül der Revolutionsvermeidung noch die Partizipationsgrenzen, die zum zeitgenössischen Reformkonzept der Konservativen wie vor ihnen der Whigs bzw. Liberals zählten, wurden namhaft gemacht, sondern eine bis zur Arbeiterschaft reichende Inklusionsutopie als Verheißungsparole ausgegeben. Vor allem sollten Schlagworte wie "patriotism» und »England" konservativ unterlegt werden. Soziale Durchlässigkeit der bürgerlichen Gesellschaft gegenüber der Aristokratie und ein funktionierender Parlamentarismus galten darüber hinaus als Gütezeichen und Stabilitätsgarantien für die nationale Ordnung.

Mit der Einweihung des Disraeli-Denkmals 1883 erreichte der programmatische Zugriff der Konservativen auf die Idee der Nation ihren Höhepunkt. Zu den zentralen Sinnbezügen avancierten nun Monarchie und Empire, die durch 
militärische Sicherung nach außen und Wohlstandswahrung nach innen zu stabilisieren waren, während die rhetorische Nähe zu einem populären, aggressiven und militanten Jingoismus tunlichst gemieden, damit aber die EmpireKonnotation vage belassen wurde. Daß das Reformpostulat, das im Zusammenhang mit der Derby-Feier prominent verhandelt worden war, kaum mehr wiederkehrte, war ein Symptom für die Verlagerung des Blicks weg von der Binnen- auf die Außenkonstitution der nationalen Ordnung. Neu nahm sich darüber hinaus der argumentative Aufwand aus, mit dem der nationale Kultfigurstatus Disraelis über den - sonst nur für Monarchen mobilisierten - Topos der Nation als Trauer- und Affektgemeinschaft zum einen und mit dem Visualisierungs- und Anthropomorphisierungsbedarf der Gesellschaft zum anderen legitimiert wurde. Die liberale wie linke Rezeption des Disraeli-Denkmals blieb uneinheitlich. Einerseits verfing die Empire-Rhetorik, andererseits wurde die konservative Reformpolitik kritisiert und zumindest zu partizipatorischen Nachbesserungen aufgefordert. Besonders die konservative Presse nahm schließlich die an Disraeli entwickelte Nationsidee gegen Egalisierungspostulate und einen sozialistischen Internationalismus in Schutz.

Schließlich blieb der Exklusionsdiskurs in Paris im Umfeld des nie materialisierten »Monument Henry« ein singuläres Zeugnis für einen enthumanisierten Nationsbegriff, den der französische Antisemitismus im Zuge der DreyfusKrise ausbildete, indem er den Juden nicht nur die Zugehörigkeit zur französischen Nation, sondern überhaupt die Existenzberechtigung bestritt. Im Subskriptionsprojekt spiegelte sich keine geringere als die Absicht des rassistischen Radikalismus wider, den Antidreyfusards symbolpolitisch aufzuhelfen. Andererseits war das Projekt dem extrem polemischen Diskurskontext geschuldet und dokumentierte keine Sonderform eines so nur in Frankreich deformierten Nationalismus. Antisemitische Untertöne waren etwa genauso und durchaus in der liberalen Presse im Nachklang auf Disraelis Denkmal in London oder in Berlin im Zusammenhang mit dem Märzgefallenendenkmal und den Verschwörungsneurosen der Konservativen zu beobachten. Singulär blieb im französischen Fall aber die diskursive Dichte der Episode. 
